\title{
Semi-permanent zones of
} radar radial shear within the planetary boundary layer: observations and effects on high intensity precipitation in the wider Auckland region, New Zealand by

Frances Russell

\author{
A thesis \\ submitted to the Victoria University of Wellington \\ in partial fulfilment of the \\ requirements for the degree of \\ Master of Science \\ in Geophysics.
}

Victoria University of Wellington 



\begin{abstract}
This study investigates the role of mechanical forcing within the boundary layer in enhancing low-level precipitation and initiating/intensifying convective precipitation during cases of high intensity precipitation in the wider Auckland region, New Zealand. Eight cases, that occurred between 2001 and 2008 have been investigated. All cases were observed to be strongly dynamically forced, resulting from the passage of mid-latitude cyclones. These features were observed to be centred mainly to the north and west of the study area, with surface winds from the northeast quadrant over the wider Auckland region. Radar imagery is characterised by regions of both convective and stratiform precipitation for all the cases investigated; areas of convection are often observed to be embedded in areas of larger scale precipitation.
\end{abstract}

These cases were subdivided into eleven heavy precipitation events. Nine of these events were subject to further investigation. Environmental conditions during these events were characterised by steady low-level winds from the northeast quadrant, weak to moderate convective instability, with $0-3 \mathrm{~km}$ wind shear indicating a high level of directional shear in the lower atmosphere. To investigate mechanical forcing in the boundary layer, low-level Doppler velocity and reflectivity fields measured by the Mt Tamahunga radar, were examined. These data revealed mesoscale structures of the Doppler velocity field not previously documented in this region. Mechanical forcing was identified by the presence of mesoscale zones of radar radial shear, resulting from horizonal convergence and/or zones of horizontal shear. These features were observed to be semi-permanent on the windward side of Little Barrier and Great Barrier 
islands, the windward side of the Coromandel ranges, and along the west coast of the Auckland region. Further, zones of semi-permanent radar radial shear were observed to extend downstream (lee side) of Mt Moehau and Great Barrier, Little Barrier and Taranga islands in the Hauraki Gulf. These features have not been documented previously for this study area.

The features, observed downstream of each obstacle, were characterised by a long thin low velocity zone present in PPI images of radar radial velocity and were bounded by the above mentioned shear zones. Further, these features were aligned parallel to the surface wind direction, with widths approximately equal to the diameter of the obstacle and extended up to $57 \mathrm{~km}$ downstream of each obstacle. These features are consistent with characteristics of mountain wakes described in the literature.

A partitioning algorithm was calibrated to identify the convective and stratiform components of the radar reflectivity field. This algorithm was applied to reflectivity data for each heavy precipitation event. Local maxima in the frequency of low-level enhanced precipitation were observed in the vicinity of topographic features such as the Coromandel Peninsula and Mt Tamahunga, in addition to the observed location of wakes in the lee of Great Barrier and Little Barrier Island.

Finally, the relationship between mountain wakes observed in the Hauraki Gulf and low-level precipitation enhancement was examined. Investigations showed that when large scale areas of precipitation interacted with these wakes, in some cases convective precipitation was observed to be initiated or intensified. However, the observed areas of enhancement were observed to be short lived and shallow, reaching heights below the radar bright band at $\sim 3.5 \mathrm{~km}$. 


\section{Acknowledgements}

Firstly I must thank my supervisor James McGregor for the help that he has given me throughout this project. A huge thanks also must go to John Crouch, MetService, my 'unofficial supervisor' who was always enthusiastic and willing to share his knowledge of meteorology, in particular his expertise in radar meteorology with me.

Sincere thanks must also go to the Meteorological Service of New Zealand Ltd (MetService) who allowed me to use utilise their computers, to obtain and process radar data. Additionally to all the staff in Meteorological Advice and Training, namely Chris Webster, Ross Marsden, Mark Schwarz, Gabi Thompson and Neal Osborne, who were always willing to answer questions, help find data or help me figure out the mysteries of VMS.

I gratefully acknowledge, MetService who provided radar data, mean sea level analysis maps, data from automatic weather stations and balloon sounding data used in this study. In addition, National Institute of Water and Atmospheric Research (NIWA) who provided additional radar data from their archive and maintain The National Climate Database providing free access to a variety of historical climate information throughout New Zealand. This was the source of much of the automatic weather station data used in this study. 
I would like to thank the staff and students of the geophysics department whom provided help or advise during the course of this study, thanks to Ralph Wahrlich for maintaining the computers and answering computer related questions. A special thanks must go to the people whom I shared an office with, Stacey Dravitzki and Deb Maxwell for always being helpful and supportive. Last but by means least, to my friends and family thanks for all your support. 


\title{
Contents
}

\author{
Abstract
}

Acknowledgements

Table of contents $\quad$ v

List of figures vi v vi

1 Introduction $\quad 1$

1.1 Motivation and Aims . . . . . . . . . . . . . . . . . 1

1.2 Background . . . . . . . . . . . . . . . . 4

1.3 Theory . . . . . . . . . . . . . . . . . . 9

1.3.1 Precipitation Processes . . . . . . . . . . . . 9

1.3.2 Precipitation enhancement and convective initiation . . . 12

2 Data and Methods 23

2.1 Data . . . . . . . . . . . . . . . . . 23

2.1.1 Weather radar . . . . . . . . . . . . . . 24

2.1.2 Mt Tamahunga weather radar . . . . . . . . . . . . . 24

2.1.3 Radar parameters and derived values . . . . . . . . . . 28

2.1.4 Surface observations . . . . . . . . . . . . . . 37

2.1.5 Upper Air data . . . . . . . . . . . . . . . 38

2.1.6 Mean sea level analysis . . . . . . . . . . . . . . 39 
2.2 Case Selection . . . . . . . . . . . . . . . . . . . 39

2.2.1 Case Selection . . . . . . . . . . . . . . . 39

2.3 Data Processing . . . . . . . . . . . . . . . . . . . . . . 42

2.3.1 Gradient in radial velocities . . . . . . . . . . . . . 42

2.3.2 Stability indices and low-level wind shear . . . . . . 45

2.3.3 Radar vertical profiles . . . . . . . . . . . . 48

2.3.4 Convective Stratiform Partitioning . . . . . . . . . . . 49

$\begin{array}{llc}3 & \text { Results } & 53\end{array}$

3.1 Case Overview . . . . . . . . . . . . . . . . . 53

3.2 Boundary layer forcing . . . . . . . . . . . . . . 56

3.2.1 Spatial distribution . . . . . . . . . . . . 56

3.2.2 Environmental conditions during heavy precipitation events 62

3.2.3 Lee zones of radar radial shear . . . . . . . . . . . 74

3.2.4 Mountain wakes in the Hauraki Gulf . . . . . . . . . . . 79

3.3 Convective/Stratiform Partitioning . . . . . . . . . . . . 90

3.3.1 Convective/Stratiform calibration . . . . . . . . 93

3.3.2 Spatial distribution of low level enhancement . . . . . . 97

3.4 Mountain wakes and precipitation enhancement . . . . . . . . 102

3.4.1 Mountain wakes and low-level precipitation enhancement 107

4 Summary and Conclusions $\quad 117$

4.1 Conclusions and Future work . . . . . . . . . . . 126

$\begin{array}{lr}\text { References } & 130\end{array}$

$\begin{array}{lr}\text { Appendices } & 139\end{array}$

Appendix A: Wake characteristics . . . . . . . . . . . . . . . 139

Appendix B: Low-level enhancement . . . . . . . . . . . . 143 


\section{List of Figures}

1.1 Map showing the study area indicating the location of automatic weather stations and the Whenuapai balloon sounding used in this study. . . . . . . . . . . . . . . . . . 4

2.1 Scanning geometry for the IRIS radar . . . . . . . . . . . 27

2.2 Velocity aliasing . . . . . . . . . . . . . . . . 33

2.3 Velocity folding . . . . . . . . . . . . . . . . . 34

2.4 Steiner et al. (1995), convective radius criterion . . . . . . . 50

3.1 Map showing barriers for which downstream zones of radar radial shear are observed. . . . . . . . . . . . . . . . . 58

3.2 Average radar radial gradients in radial velocities, Case 3, Event

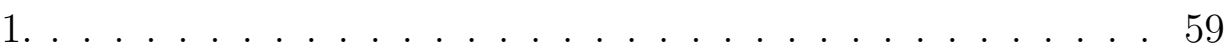

3.3 Embedded convection . . . . . . . . . . . . . . . . . . 59

3.4 Average radar radial shear, Case 4, Event 1 . . . . . . . . . 60

3.5 Average radar radial shear, Case 1, Event 2 and Case 2, Event 161

3.6 Average wind direction measured at Mokohinau Island and observed zones of radar radial shear . . . . . . . . . . . . 67

3.7 Little Barrier Island, contour map . . . . . . . . . . . . . . . 74

3.8 Great Barrier Island, contour map . . . . . . . . . . . . . . . . . 74

3.9 Mt Moehau, contour map . . . . . . . . . . . . . . . 75

3.10 Taranga Island, contour map . . . . . . . . . . . . . . . . 75 
3.11 Mountain wakes in lee of Great Barrier and Little Barrier island, $2022 \mathrm{Z} 28$ March $2007 \ldots \ldots \ldots$. . . . . . . . . . 76

3.12 Little Barrier island wake: transect line and associated RHI profile showing the depth of the Little Barrier wake, 2315Z 28th March $2007 \ldots \ldots \ldots \ldots$

3.13 Radar characteristics of the Little Barrier Island wake . . . . . . 80

3.14 Little Barrier Island wake, RHI time-series, 1900Z to 1937Z, 28

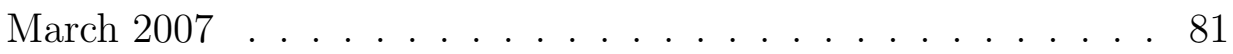

3.15 Radar characteristics of the Great Barrier Island wake . . . . . 84

3.16 Great Barrier Island wake RHI time-series, 1700Z to 1800Z 28 March $2007 \ldots \ldots \ldots$. . . . . . . . . . . . . . . 85

3.17 Radar characteristics of the Mt Moehau wake . . . . . . . . . . 87

3.18 Radar characteristics of the Taranga Island wake . . . . . . . . 89

3.19 Steiner et al. (1995), partitioning errors . . . . . . . . . . . 95

3.20 Cases 1, Event 1 and Cases 8, Event 1: Spatial distribution of enhancement. . . . . . . . . . . . . . . . 98

3.21 Case 1, Event 2: Spatial distribution of enhancement and mountain wakes. . . . . . . . . . . . . . . . . . . . . 99

3.22 Case 3, Event 2: Spatial distribution of enhancement and mountain wakes. . . . . . . . . . . . . . . . 100

3.23 Case 3, Event 2: MSL analysis . . . . . . . . . . . . . . . 104

3.24 Case 3, Event 2: Dargaville AWS record . . . . . . . . . . . 104

3.25 Case 3, Event 2: Tephigram . . . . . . . . . . . . . . 105

3.26 Case 3, Event 2: Whenuapai vertical wind profiles . . . . . . . 106

3.27 Case 3, Event 2: RHI profiles of reflectivity indicating the modification of preexisting convection as it passes over the Little Barrier Island wake. . . . . . . . . . . . . . . . . . . 111

3.28 Case 3, Event 2: Precipitation enhancement downstream of Great Barrier Island. . . . . . . . . . . . . . . . . 113 
3.29 Case 3, Event 2, RHI time-series indicating the vertical extent of precipitation enhancement due to interaction with the Great Barrier Island wake. . . . . . . . . . . . . . . . . . 113

3.30 Case 3, Event 2: RHI profiles of reflectivity indicating the development of preexisting convection as it passes over the Taranga Island wake. . . . . . . . . . . . . . . . . . . . 116 


\section{List of Tables}

2.1 Ericsson radar specifications . . . . . . . . . . . . . . . . 25

2.2 IRIS radar specifications . . . . . . . . . . . . . . 26

2.3 Automatic weather stations used in this study area . . . . . . 38

2.4 High intensity precipitation cases investigated in this study . . . 41

2.5 Summary of heavy precipitation events investigated in this study 41

3.1 Summary of the synoptic situation during heavy precipitation

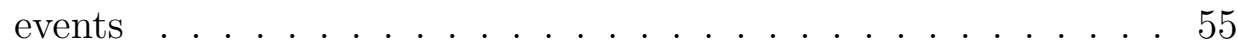

3.2 Summary of surface and mid-level winds during heavy precipitation events . . . . . . . . . . . . . . . . . 64

3.3 Summary of stability indices for the heavy precipitation events investigated ....................... 65

3.4 Summary of $0-3 \mathrm{~km}$ shearing speeds . . . . . . . . . . . . 70

4.1 Summary of radar wake characteristics . . . . . . . . . . . . . 121

A.1 Radar characteristics of the Taranga Island wake . . . . . . . . 139

A.2 Radar characteristics Great Barrier wake . . . . . . . . . . . . . 140

A.3 Radar characteristics of the Little Barrier island wake . . . . . . 141

A.4 Radar characteristics of the Mt Moehau wake . . . . . . . . . . 142

B.1 Summary of Taranga Island wake and enhancement. . . . . . . . 143

B.2 Summary of Little Barrier Island wake and enhancement. . . . . 144

B.3 Summary of Great Barrier Island wake and enhancement. . . . . 145 


\section{Chapter 1}

\section{Introduction}

\subsection{Motivation and Aims}

Synoptic conditions that bring high intensity precipitation to the Auckland and Northland regions as a result of the passage of fronts and depressions, are generally well predicted by numerical weather models (Chater 1995). Therefore warnings for heavy precipitation can be issued well in advance of the onset of precipitation. These precipitation events are predominately stratiform in nature but often have a convective component to them (Pascoe 2001, Simes 2003). In New Zealand convective precipitation is topographically, thermally and synoptically driven by horizontal flow convergence which is forced by orographic lifting, differential heating and synoptic scale effects (Sturman and Tapper 2005). If we accept that the wider Auckland region is characterised by relatively flat topography (see Section 1.2) and the particular atmospheric conditions present during heavy precipitation events are characterised by broad areas of stratiform precipitation containing areas of embedded convection, such as those studied by Simes (2003) and Pascoe (2001), we may conclude that thermal and orographic forcing are relatively unimportant. As a result factors forcing convective initiation and low-level precipitation enhancement during 
such storms remain unexplained.

This study aims to investigate the link between mesoscale mechanical forcing in the atmospheric boundary layer and low-level precipitation enhancement during high intensity precipitation events in the wider Auckland region. This is achieved through analysis of high resolution Doppler weather radar data, obtained from the Meteorological Service of New Zealand (hereafter referred to as MetService), along with supporting data from mean sea level analysis maps, automatic weather stations and balloon soundings located in the study area, see Figure 1.1. This thesis is split into four chapters to investigate this goal.

- Chapter 1 includes an description of the study area. Further, a review of the literature describing the climatology and precipitation processes experienced throughout the area is provided. This chapter goes on to review the current theory on precipitation processes and convective initiation, focusing on processes observed in maritime environments and providing relevant examples from the literature.

- Chapter 2 provides a discussion of the data and methods utilised in this study, identifying the limitations and possible errors that may be encountered. Firstly, due to the heavy reliance on weather radar data throughout this study; a brief overview of weather radar data measurement is provided. This is followed by a description of the supporting data sets used. The chapter continues by setting out the criteria by which cases of high intensity precipitation were selected for inclusion in this study and subsequently further split up into smaller heavy precipitation events for further investigation. Lastly, a description of the data processing techniques that are utilsed is provided, indicating the limitations of each method. 
- Chapter 3 presents the results of the present study. This is split into four sections (1) a case overview, this investigates the synoptic characteristics of each event. (2) an investigation into the spatial distribution of mesoscale, mechanical forcing within the atmospheric boundary layer, in the wider Auckland region. This was achieved by examining averages of radial gradients in radar radial velocity for each of the steady state, heavy precipitation events. This section goes on to investigate the relationship between environmental conditions and zones of semi-permanent radar radial shear. These conditions include, convective instability, 0-3 km wind shear, surface and mid-level wind speed and direction. Further, the relationship between these characteristics and the existence and nature of zones of semi-permanent radar radial shear is included. In addition to the relationship between environmental conditions and precipitation type, large scale precipitation motion is examined. (3) a section investigating the spatial distribution of low-level precipitation enhancement and convection throughout the study area. Identification is based on a convective/stratiform partitioning technique employed by Steiner et al. (1995). This section presents the calibration of this method and investigates the horizontal spatial frequency of low-level enhancement and convection during heavy precipitation events. (4) a case study investigating the role of zones of semi-permanent gradients in radar radial velocities in initiating and intensifying convection in the wider Auckland region.

- Chapter 4 presents a discussion and the conclusions of the results of this study. Finally areas for more work relating to this study are identified. 


\subsection{Background}

The study area as defined in Figure 1.1 is located in the upper North Island of New Zealand between $35.22^{\circ} \mathrm{S}$ and $37.39^{\circ} \mathrm{S}$. This area contains three distinct geographic regions:- the Auckland region, the Northland region, and the Coromandel Peninsula (see Figure 1.1). These are hereafter referred to as the wider Auckland region.

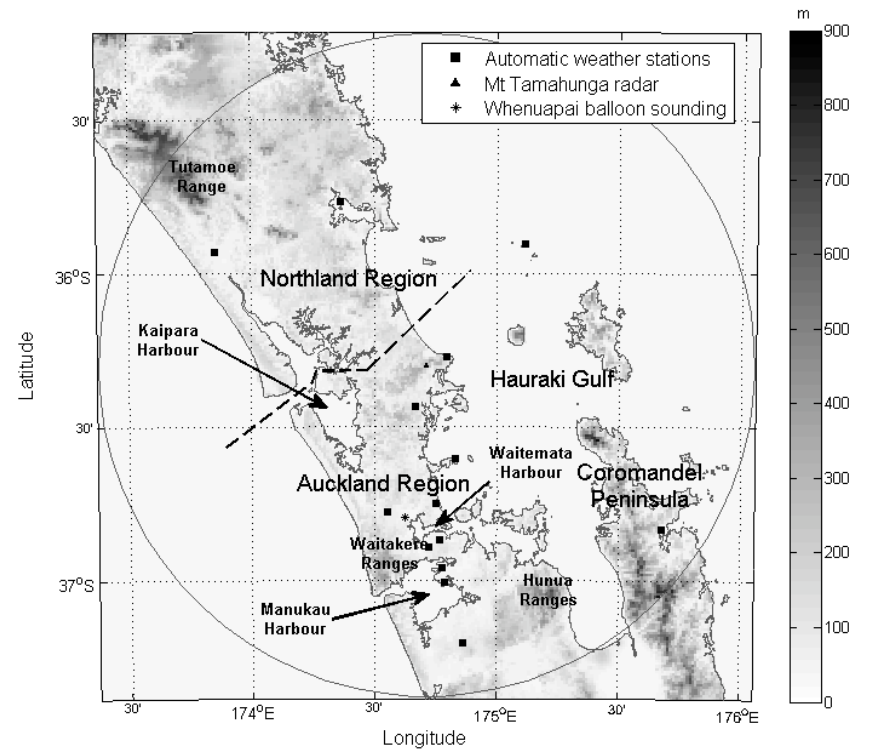

Figure 1.1: Map showing the boundaries of the study area, indicating the location of automatic weather stations and the Whenuapai balloon sounding used in this study. This region is centered at the MetService weather radar, located on Mt Tamahunga near Warkworth $\left(174^{\circ} 42^{\prime} \mathrm{E}, 36^{\circ} 18^{\prime} \mathrm{S}\right)$ and is bounded by a circle of radius $120 \mathrm{~km}$. The dashed line indicates the boundary between the Northland and the Auckland regions.

These regions differ in both physical and anthropogenic features. The Auckland region is of particular significance as it is New Zealand's largest city and contains one of New Zealand's major ports. This region is the focus of much of the literature to date. The Auckland region is located in the southern portion of the study area and extends out into the Hauraki Gulf, located to the east of 
Auckland city. This region features 49 small volcanic cones (elevation $<150 \mathrm{~m}$, AMSL). There are two main mountain ranges located in the Auckland region; the Waitakere ranges located to the west, rising to $474 \mathrm{~m}$ and the Hunua ranges to the southeast, rising to $688 \mathrm{~m}$. The Hauraki Gulf contains many small islands, with the most prominent of these in terms of elevation being Great Barrier, Little Barrier and Taranga Islands. The Northland region is located in the northern portion of the study area. This region is characterised by undulating terrain rising from $0 \mathrm{~m}$ to $770 \mathrm{~m}$ AMSL along the Tutamoe range. The Coromandel Peninsula is located in the southeast of the study area and is characterised by mountainous terrain rising to $892 \mathrm{~m}$ AMSL, at Mt Moehau located at the northern tip of the peninsula (see Figure 3.1).

The study area can be described as a subtropical maritime environment, (Hessell 1988) bounded to the west by the Tasman Sea and to the east by the Hauraki Gulf. This area contains three major harbours:- the Kaipara harbour to the northwest, the Manukau harbour to the southwest and the Waitemata harbour to the east of Auckland city (see Figure 1.1). Located within the midlatitudes, the majority of the precipitation in this region can be attributed to the passage of cyclonic systems and their accompanying set of surface fronts (Houze 1981). The frequency and evolution of these systems around the New Zealand region show some seasonal variation, with a maximum cyclogenesis and cyclone track density observed upstream of the study area in the Tasman Sea during the winter months (Sinclair 1994).

Precipitation in the wider Auckland region occurs predominately in surface flows from the northeast quadrant (Hessell 1988, Moir et al. 1986, Maunder 1974) due to cyclonic, frontal and orographic lifting, in addition to convection (Sturman and Tapper 2005). Precipitation caused by these processes is highly variable, occurring on a variety of spatial and temporal scales, from pre- 
cipitation in the vicinity of fronts $\left(10^{3} \mathrm{~km}\right.$ in length and $10 \mathrm{~km}$ in width and time scales of up to a day), to convective precipitation occurring on a scale of $\sim 1 \mathrm{~km}$ and time scales of $\sim 30$ minutes (Holton 2004). With the exception of the ranges identified in Figure 1.1 the Auckland region is characterised by relatively flat topography with the majority of the topographic features rising to elevations $\ll 900 \mathrm{~m}$. Therefore convective initiation throughout much the study area is unlikely to be forced by orographic lifting as observed in other regions around New Zealand, for example the Southern Alps (Sinclair et al. 1997). Possible exceptions to this occur in the vicinity of the Tutamoe, Waitakere and Hunua ranges and the ranges along the Coromandel Peninsula (see Figure 1.1). Despite this, the spatial extent and intensity of the precipitation in this region has been found to be influenced by the distribution of topographic features within the region, in addition to the synoptic situation. McGill (1987), Hessell (1988), McKendry (1992) present a climatology of the regions within the study area. They found that the topography of the study region has a significant influence on the distribution of precipitation, with the Coromandel Peninsula and islands in the outer Hauraki Gulf providing shelter over the inner Hauraki Gulf and Auckland city in easterly flows. The winter months of June/July are the wettest throughout the region, with stations in the Northland region and Coromandel Peninsula recording $30-45 \%$ of the total annual rainfall during June to August and $43 \%$ of the total annual rainfall during April to July respectively. Annual precipitation totals vary considerably within each region, with elevated areas such as the Tutamoe, Waitakere and Hunua ranges and, the Coromandel Peninsula, receiving totals of the order of $2000 \mathrm{~mm} /$ year, which is almost twice that of the low lying areas.

Much of the variation in the weather on a day to day scale, in the wider Auckland region, is dependent of the passage of synoptic scale mid-latitude weather systems and their associated sets of surface fronts. At low levels the atmo- 
spheric environment can be affected by topography, modifying low-level winds, which in turn affects local stability and therefore precipitation. In the summer months in anticyclonic conditions, with light winds, the wider Auckland region is prone to the development of sea breezes. Under favorable conditions mature sea breezes from the east and west coast can converge, initiating convection along this zone of convergence. In unstable atmospheric conditions this can produce intense thunder storms, bringing very localized high intensity precipitation, (McGill 1987, Hessell 1988, McKendry 1992). McKendry and Revell (1992) found that under light southeasterly gradient flow, mature sea breezes can develop, favoring the development of a mesoscale eddy over South Auckland. This can be associated with the development of convective precipitation over South Auckland.

Bradley et al. (1992) investigated orographic enhancement of precipitation over the Waitakere ranges (for location see Figure 1.1). They found that during the passage of cold fronts, enhanced precipitation was observed on the windward side, near the crest of the ranges in two of the four cases studied. They observed that rainfall at the coast was between $30-35 \%$ of that observed at elevated sites. It was suggested that the precipitation enhancement at elevated sites was a result of the seeder feeder mechanism, see Section 1.3.2.

High intensity precipitation in the Auckland region is often observed to have both stratiform and convective components, associated with the passage of fronts and depressions in the vicinity of the study area (Pascoe 2001, Simes 2003). Further, precipitation can result from isolated convection, triggered by diabatic heating and sea breeze convergence, especially during the summer months (McGill 1987). However this is not the focus of the current study.

Chater (1995), Pascoe (2001) and Simes (2003) investigated the synoptic and 
mesoscale characteristics of high intensity precipitation events in the Auckland region, resulting from the passage of fronts and depressions. Chater (1995) utilised a Primitive Equation model (PE model) developed by MetServie in addition to the European Centre for Medium-range Weather Forecasting (ECMWF) global model, to investigate heavy precipitation events in the Auckland region. It was found that these numerical weather models adequately predict favorable synoptic conditions for the occurrence of high intensity precipitation, but fail to predict the mesoscale features of such storms. The resolution of numerical models run operationally is fast changing, with some local area models run at resolutions of only a few kilometers (Kalnay 2003, pg. 12). However, cumulus convection occurs on a small scale, of the order of $\sim 1 \mathrm{~km}$ (see Section 1.3.1); therefore convection may occur on a sub-grid scale even in current generation numerical models. Convectively driven precipitation in the wider Auckland region can produce extremely high localised precipitation totals $>100 \mathrm{~mm} \mathrm{hr}^{-1}$. The maximum hourly rainfall accumulation recorded in New Zealand was recorded at Leigh $\left(109 \mathrm{~mm} \mathrm{hr}^{-1}\right.$ at $1500 \mathrm{Z}$, 29 May 2001) located $\sim 8 \mathrm{~km}$ east of Mt Tamahunga (as reported by Simes 2003). This was associated with an extremely intense convective cell located over Leigh. Larsen and Gray (2003) used weather radar to investigate short range forecasting of precipitation in the vicinity of cold fronts in the Auckland region. It was found that the small spatial components of precipitation were short lived. Further, precipitation was found to be well forecast if these small scale, convective components were left to decay independently of the larger scale precipitation components.

Simes (2003) and Pascoe (2001) identified common characteristics of successfully forecast, high intensity precipitation events and examined the forecast skill. Simes (2003) investigated events that produced $20+\mathrm{mm}$ of rain in the Auckland region from 1995-2002. The annual occurrence of these events was 
highly variable, with between 1 and 7 events annually over the study period, the majority occurring in the summer and autumn.

Pascoe (2001) found that events could be split into two groups: convective and non-convective cases. Boundary layer convergence or the presence of a baroclinic leaf are considered to be essential for heavy rain to occur over the Auckland Region. Simes (2003), found that 22 of 26 events studied involved embedded convection. For convective cases it was observed that a warm moist air mass, static instability, and a trigger to induce sufficient lifting, were required for convection to occur.

Both of these studies identified that boundary layer convergence was necessary for heavy rain to occur. However the role of these convergence zones in the Auckland region for such events has not been investigated.

These storms can have a significant impact on the Auckland region, producing surface flooding and hazardous winds. Therefore an understanding of the local factors affecting such storms could lead to improved flood forecasting throughout the region. The present study investigates the effect of boundary layer forcing of precipitation, resulting from the passage of depressions and frontal systems, that produce heavy rain in the wider Auckland region. This extends work carried out by Simes (2003) and Pascoe (2001)

\subsection{Theory}

\subsubsection{Precipitation Processes}

Precipitation is formed in regions of sufficient moisture and vertical motion of the atmosphere. Vertical motion can be dynamically forced on a mesoscale 
as a result of sea breeze convergence and on a synoptic scale, in regions of cyclonic lifting and large scale convergence in the vicinity of fronts. Further, vertical motion can be thermally forced by surface heating and mechanically forced by orographic effects (Sturman and Tapper 2005). Precipitation driven by these processes can be split into two categories, convective precipitation and stratiform precipitation, based on precipitation growth times and the strength of the updraft (Houze 1993).

Stratiform precipitation occurs in regions of weak, large-scale, vertical motion and is often observed to be wide-spread, occurring in the vicinity of fronts and as a result of orographic lifting (Rogers and Yau 1989). In these regions precipitation fall speeds are less than that of ice crystals and snow, with precipitation growth times in the order of $\sim 1-3 \mathrm{hr}$ (Houze 1993). A maximum in terms of frequency and intensity of stratiform precipitation occurs in the midlatitudes, due to the passage of extra-tropical cyclones in this region (Houze 1981). Regions of stratiform precipitation are characterised by a well-defined melting layer, which can be observed in vertical profiles of radar reflectivity as a band of increased reflectivity referred to as the radar 'bright band', see Section 2.1.3.

Moist convection occurs as a result the release of instability in the atmosphere and provides a mechanism for the vertical transport of heat, moisture and momentum, (Yanai and Johnson 1993). Convective systems are observed to have a small horizontal extent (diameter $\sim 1-20 \mathrm{~km}$, (Sauvageot and Mesnard 2003)) and produce high intensity precipitation, see Section 1.2. In these regions of convective precipitation, fall speeds are greater than that of ice crystals and snow, with precipitation growth times in the order of $\sim 0.5 \mathrm{hr}$ (Houze 1993). Instability in the atmosphere depends on the vertical profile of water vapor and the environmental lapse rate, $-\frac{\mathrm{dT}}{\mathrm{dz}}$. The atmosphere is said to 
be absolutely unstable when $-\frac{\mathrm{dT}}{\mathrm{dz}}$ is greater than the adiabatic lapse rate, $\Gamma_{\mathrm{d}}$ in dry air ${ }^{a}$, or greater than the moist adiabatic lapse rate, $\Gamma_{\mathrm{s}}$ in moist air ${ }^{b}$. Conditional instability can be present in a moist atmosphere, as is defined by, $\Gamma_{\mathrm{s}}<-\frac{\mathrm{dT}}{\mathrm{dz}}<\Gamma_{\mathrm{d}}$. Convection can be free, driven by gravitational or buoyancy forces or forced by mechanical forces. In regions of conditional instability a trigger is needed to provide sufficient lifting for an air parcel to reach saturation and become warmer than the environment. This is commonly known as the level of free convection. This theory is based on that presented by Rogers and Yau (1989).

Convection can be mechanically driven at upper levels, in the vicinity of synoptic scale fronts and depressions, due to the presence of mesoscale vortices and associated dry intrusions. In addition, convection can be driven by horizontal convergence in the boundary layer and the interaction of convective outflows with the environment on a mesoscale (Bennett et al. 2006). Strong mesoscale moisture gradients have been shown to be favorable locations for the initiation of convection, especially in the United States of America (Weckwerth and Parsons 2006). For more details see Section 1.3.2. Convective systems are cellular in nature and occur on scales of $<1 \mathrm{~km}$ for a single celled structure and up to $20 \mathrm{~km}$ for multi-cell structures (Sauvageot and Mesnard 2003). These appear in radar imagery as cellular areas of increased reflectivity or lines containing multiple peaks of high reflectivity $>40 \mathrm{dBZ}$ (Steiner et al. 1995). He also noted that this threshold is location dependent. This threshold has been found to

\footnotetext{
${ }^{\mathrm{a}} \Gamma_{\mathrm{d}}=\frac{\mathrm{g}}{\mathrm{C}_{\mathrm{p}}}$

${ }^{\mathrm{b}} \Gamma_{\mathrm{s}}=\Gamma_{\mathrm{d}} \frac{\left[1+\mathrm{L}_{\mathrm{c}} \mathrm{q}_{\mathrm{s}} / \mathrm{RT}\right]}{\left[1+\varepsilon \mathrm{L}_{\mathrm{c}}^{2} \mathrm{q}_{\mathrm{s}} / \mathrm{C}_{\mathrm{p}} \mathrm{RT} T^{2}\right]}$

where, $g$ is acceleration due to gravity, $C_{p}$ is the specific heat of dry air at constant pressure, $L_{c}$ is the latent heat of condensation, $\varepsilon=0.622$ the ratio of the molecular weight of water to that of dry air, $q_{s}$ is the saturation mixing ratio, $\mathrm{R}$ is the ideal gas constant and $\mathrm{T}$ is the temperature of the air parcel. Refer to Holton (2004) for a detailed discussion of these quantities and derivation of equations.
} 
be of some use in the wider Auckland region especially for identifying weak convection.

Low-level vertical wind shear can also have a significant effect on regions of convection. Houze (1993) discusses the role of shear on cloud formation. Houze (1993) noted that vertical wind shear plays an important role in the formation and orientation of cloud streets formed within the planetary boundary layer. He showed that in thunderstorms vertical wind shear, in addition to stability plays an important role in determining if a convective storm will be a single or multicellular structure. In low shear environments single cell structures are favored. However, in moderate to strong shear environments multicellular structures are favored. Further, vertical wind shear was noted to have an influence on the intensity and motion of these storms.

\subsubsection{Precipitation enhancement and convective initia- tion}

Mesoscale precipitation enhancement and convective initiation result from local maxima in vertical motion in the atmosphere. Further, precipitation enhancement can occur due to the seeder feeder mechanism (Houze 1993). Local regions of enhanced vertical motion can be mechanically and or thermally forced. Mechanisms that have been shown to be important around the world in enhancing precipitation and initiating convection are:- upper level forcing in the vicinity of mesoscale vortices and dry intrusions, boundary layer forcing due to flow convergence and moisture variability and secondary enhancement due to convective outflows [as reviewed by:- Bennett et al. (2006), Weckwerth and Parsons (2006, Section 2)]. Further, precipitation can be enhanced in the vicinity of topographic barriers by the following:- orographic lifting, flow blocking upstream of the barrier, mountain gravity waves, mountain valley 
thermal gradients and downstream flow convergence, as well as the 'seeder feeder' mechanism [see review by Houze (1993, pg. 501-538)]. Despite these processes being widely recognised to enhance precipitation and initiate convection, the exact location where initiation occurs is not well understood and recently this has been the focus of three major field campaigns as part of the International $\mathrm{H}_{2} \mathrm{O}$ Project (IHOP). In 2004 a campaign was launched to study convective initiation in the Great Plains of the United States of America . This had the aim of studying the convective environment in continental regions where topography is thought to be unimportant in the initiation of convection (Weckwerth and Parsons 2006). During the summers of 2004 and 2005 the Convective Storm Initiation project (CSIP) was carried out. This had the aim of investigating the convection in the maritime environment of the UK. This region is charaterised by moderate topography and coastlines (Browning et al. 2007). The third major field campaign, the Convective and Orographically Induced Precipitation Study (COPS), was designed to investigate convective initiation in regions of complex topography (Wulfmeyer et al. 2008).

The primary goal of this thesis is to investigate the role of boundary layer forcing in enhancing low-level precipitation and initiating/intensifying convection during high intensity precipitation events in the wider Auckland region. The planetary boundary layer is defined as "the part of the troposphere that is directly influenced by the presence of the earth's surface, and responds to surface forcings with a time-scale of about an hour or less" Stull (1988). Zones of convergence observed within the boundary layer may be mobile as a result of strong moisture gradients, differential heating (sea breeze fronts), synoptic scale surface fronts and gust fronts. Additionally convergence zones may also appear stationary with time, caused by abrupt changes in surface characteristics, thus modifying the low-level flow in the vicinity of coastlines and 
topographic barriers (Bennett et al. 2006, Weckwerth and Parsons 2006).

As noted in Section 2.2 the wider Auckland region is a maritime environment, with low topography throughout much of the region (most peaks $\ll 900 \mathrm{~m}$ ). The waters surrounding this region contain a number of small islands rising 400-800 m AMSL (see Figure 1.1). In regions of comparable climatic and topographic characteristics such as the United Kingdom, the dominant mechanisms acting to enhance precipitation and initiate/intensify convection are thought to be those associated with hills and coastal boundaries (Bennett et al. 2006).

\section{Coastal effects}

At coastal boundaries both thermal and/or mechanical forcing can be important. During the summer months, in conditions with light gradient winds, differential heating over the land during the day can initiate a sea breeze. Along differentially oriented coastlines such as those observed in the wider Auckland region, opposing sea breezes can collide, producing a sea breeze convergence zone. Along this zone of convergence convection can be initiated, which can develop into intense thunder storms under favorable conditions. See Simpson (1994) for a review of these processes. As noted in Section 1.2 sea breezes are an important mechanism for initiating convection in the wider Auckland region especially during the summer months (McGill 1987, Hessell 1988, McKendry 1992). This however, is not the focus of this study.

Airflow and precipitation can also be substantially modified by differential friction at the coast. Roeloffzen et al. (1986) found that vertical motion was greatest when the geostrophic wind made small angles with respect to the coast $\left(\sim 20^{\circ}\right)$. In regions of low coastal topography differential friction has been shown to enhance precipitation at low levels. Colle and Yuter (2007) used the fifth-generation Pennsylvania State University-National Center for 
Atmospheric Research Mesoscale Model (MM5) to isolate the effect of low hills (elevation $=30-250 \mathrm{~m}$ ) and differential friction at the coast on precipitation enhancement, caused by the seeder feeder mechanism and horizontal convergence during the passage of an occluded front over Long Island, New York. They found that both of these mechanisms contributed equally to enhancing the precipitation by $30-50 \%$ when compared to the surrounding areas.

\section{Topographic effects}

As mentioned above, boundary layer winds and regions of precipitation can be significantly affected by local topography. Mechanical enhancement in the vicinity of topographic features is caused by:- forced orographic lifting, upstream flow blocking, mountain gravity waves and lee side convergence. Thermal forcing by mountain/valley thermal gradients can also significantly enhance precipitation, as can the 'seeder feeder' mechanism. See Houze (1993) for a review of these processes. Precipitation in the vicinity of surface fronts is predominately stratiform in nature, therefore is often observed to be widespread (Houze 1993). Simes (2003) investigated high intensity precipitation events as a result of the passage of surface fronts and depressions passing through the Auckland region. It was observed that all the events investigated involved convection, often embedded in larger scale areas of precipitation. Due to the widespread nature of such events, precipitation enhancement due to thermal forcing will be relatively low compared to mechanical forcing.

\section{Low Hills}

The role of low hills in enhancing precipitation by the "seeder feeder" mechanism is well known. The discovery of this mechanism is widely attributed to [Bergeron (1950), as cited in Houze (1993)], who studied the behavior of orographic clouds. The seeder feeder mechanism is a process whereby precipitation formed aloft, falling through lower cloud layers will grow at the expense 
of water content in the lower cloud layers, enhancing the precipitation (Houze 1993). Houze (1993) noted that, small hills can be favorable locations for precipitation enhancement by the seeder feeder mechanism, in situations where low level stratus or small cumulus cloud forms as a result of orographic modification of low-level flow. For example, Colle and Yuter (2007) investigated the effect of the low hills (elevation ranging between 30-250 m) of Long Island, New York and southern Connecticut. It was found that precipitation in these regions was enhanced by $30-50 \%$ compared to that of the surrounding water.

\section{Isolated Barriers}

Isolated barriers can significantly perturb the low-level flow, both upstream and downstream of an obstacle. This in turn can have an effect on the cloud and precipitation at low levels in these regions. Blocking by an obstacle can produce both horizontal and vertical convergence on the windward side, while the resultant flow downstream of an obstacle is highly variable. The following description of flows that may be observed in the lee of isolated obstacles is based on that presented by Lin (2007). Flows observed in the lee of isolated obstacle can be split into three categories based on:- the degree of atmospheric stratification, the height of the obstacle and the low-level mean wind speed. These characteristics can be represented by the dimensionless Froude number ${ }^{\mathrm{a}}$. In high Froude number flows, Fr $\gg 1$ the air tends to flow over the barrier forming trapped lee waves (gravity waves), a complex pattern of transverse and divergent waves. In low Froude number flows, the flow is predominantly over the obstacle, with a small portion diverted around the barrier producing mountain wakes. These are associated with the dissipation of potential vorticity in the lee of the barrier. When the Froude number is reduced to $\mathrm{Fr}<0.5$

\footnotetext{
${ }^{\mathrm{a}} \mathrm{Fr}=\frac{\mathrm{U}}{\mathrm{HN}}$

where $\mathrm{U}$ is the mean wind speed, $\mathrm{H}$ is the height of the obstacle and $\mathrm{N}$ is the Brunt-Väisälä frequency.
} 
boundary layer separation can occur and the flow is entirely diverted around the obstacle leading to zones of downstream convergence and the generation of counter rotating lee vortices. See Lin (2007) and references therein, for a discussion of the mesoscale dynamics explaining these flows. Due to the observational nature of this study, the observed characteristics, the factors affecting these characteristics and the effect of the wakes on regions of precipitation are the focus of the remainder of this discussion.

Mountain wakes form in neutral or stable environments and are observed in the lee of isolated mountains. The wake region is defined as air parcels in the lee of an obstacle with modified Bernoulli constants or potential vorticity, resulting from wave breaking and other dissipative processes (Smith et al. 1997). When a component of the low-level flow is perpendicular to the barrier the flow is accelerated over the barrier to a super critical speed. This is followed by a hydraulic jump and potential vorticity anomalies in the lee of the obstacle (Smith et al. 1997).

Mountain wakes can be split into four categories with distinctly different resultant flow patterns. Weak mountain wakes are formed when the potential vorticity generation is weak (Smith et al. 1997). In this situation the wake in the lee of the obstacle is observed as a long straight region of low wind speed, extending large distances downstream. These wakes are characterised by sharp wake boundaries (strong horizontal shear zones) and the absence of any reverse flow within the wake region. Local topography can also have a significant impact on the wake structure close to the obstacle, whereas thermal forcing is of little importance (Smith et al. 1997). An example of a weak mountain wake is seen in the lee of St Vincent Island in the southeastern Caribbean (elevation $1 \mathrm{~km}$, AMSL) extending $\sim 300 \mathrm{~km}$ downstream of the island. Smith et al. (1997) observed that the wake region in the lee of St Vincent was cloud 
free, even when passing through preexisting trade wind cumuli. However they noted that a row of cumulus clouds developed at the wake boundaries.

When the Froude number becomes small, a small portion of the low-level flow is diverted around the obstacle (Lane et al. 2006). These wakes are characterised by zones of strong horizontal shear which define the edges of the wake and a region of reversed flow is observed near the lee of the obstacle. The vertical extent of these wakes is indicated by a zone of strong vertical wind shear (Lane et al. 2006). Examples of this type of wake are observed in the lee of Kauai and Ohau in the Hawaiian Islands, elevation, 1.6 and $1.2 \mathrm{~km}$ AMSL respectively (Yang et al. 2008, Lane et al. 2006). In addition, similar wake structures are seen in the lee of Lantua Island, Hong Kong, where mountainous peaks rise between 766-944 m, AMSL (Shun et al. 2003). These wakes are observed to extend $\sim 40 \mathrm{~km}$ downstream and approximately $1 \mathrm{~km}$ in the vertical (Yang et al. 2008, Lane et al. 2006). Yang et al. (2008) found that diurnal heating of the islands of Kauai and Ohau was important, with advection of warm air from the islands warming the wake during the afternoon providing a possible mechanism for the formation of cloud lines that are observed within the wakes in the afternoon. Shun et al. (2003) utilized extremely high resolution Doppler radar (range gate spacing, $150 \mathrm{~m}$ ) to investigate the effect of Lantua Island during the passage of tropical cyclones. This revealed highly complex flows which had not been previously observed in this region, including zones of horizontal shear, low velocity zones and reversed flow. Further, they observed small scale vortices and vortex shedding which was similar in nature to that observed in von Kàrmàn streets (see below). Shun et al. (2003) found that the precipitation field as observed by the weather radar was broad scale in nature and relatively uniform, with reflectivities between 30 and $40 \mathrm{dBZ}$. It was concluded that regions of enhanced precipitation had little effect on the wake structure. 
Low-level vertical wind shear has also been found to have a significant influence on the structure of mountain wakes, (Lane et al. 2006, Smith 1989). Smith (1989) and references within, used linear theory to investigate the effect of vertical wind shear, examining the effect of changes in wind speed only. It was found that in the case of forward shear increasing with height, the probability of a wake forming was reduced. In the case of reverse shear increasing with height, the flow was stabilized at upper levels near the region of low speed induced by the reverse shear. This resulted in an increase in the chance of stagnation and therefore a wake forming. Two distinctly different flow patterns can occur: (1) weak to moderate vertically propagating gravity waves, which are absorbed at the zero wind speed line. (2) a flow regime where a mixing zone forms just below the reversal level, in addition to strongly accelerating downward motion below this level. This occurs when the dividing streamline lies upstream of the obstructing barrier. Lane et al. (2006) found that the presence of directional shear at low levels caused the wake structure to tilt with height. This provided an important mechanism to create turbulence within the wake structure. Both authors noted that when wind shear was high, turbulent break down can occur, forming Kelvin-Helmholtz waves and altering the observed structure of the wake.

When the potential vorticity generation is stronger and the Froude number is reduced to $\operatorname{Fr}<0.5$, boundary layer separation may occur. Smolarkiewicz and Rotunno (1989) noted that for typical stratified flows in the troposphere, $\mathrm{Fr} \sim 1 / \mathrm{h}$ ( $\mathrm{h}=$ mountain height, $\mathrm{km})$, therefore boundary layer separation will occur for mountain ranges approximately $>2 \mathrm{~km}$. These wakes are characterised by the formation of two counter rotating eddies in the lee of the obstacle and a zone of convergence extending significant distances downstream, parallel to the low-level flow (Lin 2007). Examples of these wakes are observed downstream of the island of Hawaii and Taiwan, and downstream of 
the Olympus Mountains over Puget Sound, often referred to as the Puget Sound convergence zone (Smith and Grubišić 1993, Yeh and Chen 2003, Mass 1981, respectivily). These wakes are observed to modify precipitation to significant distances downstream of the obstacle. The Hawaiian Island wake is observed to extend up to $200 \mathrm{~km}$ downstream of Hawaii with cloud forming at its centre line (Smith and Grubišić 1993). In contrast, a precipitation anomaly is observed over Puget Sound, resulting from precipitation forming in the convergence zone observed within the wake region (Mass 1981). A precipitation anomaly is also observed on the southwest coast of Taiwan due the southern flow deflected around Taiwan converging with the mean flow (Yeh and Chen 2003).

Grubišić et al. (1995) investigated the effect of bottom friction on low Froude number flow $(\mathrm{Fr}<0.5)$ past isolated obstacles. It was found that increased bottom friction can have the effect of stabilising the wake. In these situations, eddies in the lee of the barrier are advected into two counter rotating, elongated eddies. When the bottom friction is weak the wake is less stable. Instability can also be introduced by asymmetric forcing of the wake flow and spontaneous disturbances (Lin 2007). If these wake eddies are destabilised vortex shedding will occur, creating striking cloud patterns commonly observed in satellite imagery, known as von Kàrmàn streets. These wakes are relatively common and for instance, have been observed under favorable conditions in the lee of the islands of La Palma and Tenerife located in the Canary Islands, in addition to Jan Mayen located in the Arctic ocean near Norway (Scorer 1986). Further, this is a well known local effect observed in the lee of Mt Taranaki, New Zealand.

An examination of the literature has shown that there are many mechanisms which may force precipitation enhancement and convection in the boundary 
layer. These mechanisms as described above, may be observed to work directly or indirectly, independently or in connection with each other. Precipitation enhancement and convective initiation are not always observed in regions of boundary layer convergence and orographic enhancement. Further, the onset of enhancement/convection is often offset from observed zones of boundary layer convergence. The resulting strength and organisation of convection/enhancement has been found to be strongly dependent on local environmental conditions such as stability and wind shear, see Section 1.3.1. In addition, it has been found that the probability of initiation of convection is increased in regions of intercepting boundaries (zones of convergence) of similar or differing origin (Wilson and Schreiber 1986). 


\section{Chapter 2}

\section{Data and Methods}

This chapter provides an overview of the data and techniques used to investigate the role of boundary layer forcing, in enhancing low-level precipitation and initiating/intensifying convection in the wider Auckland region. Firstly Section 2.1 provides an overview of data used during the course of this investigation. Section 2.2 outlines the criteria by which cases of high intensity precipitation were selected and then further split up into heavy precipitation events for further investigation. Section 2.3 describes the data processing techniques used in the course of this study, indicating the possible limitations of each technique.

\subsection{Data}

This section provides a detailed description of the data sets used in this study. Extensive use has been made of Doppler radar data, Sections 2.1.1-2.1.3 provide a description of these data sets, method of collection and sources of error. Sections 2.1.4 - 2.1.6 provide a brief description of supplementary data sets used in this study. 


\subsubsection{Weather radar}

The term radar stands for radio detection and ranging. Meteorological weather radars are of significant use to meteorologists, providing high resolution measurements of reflectivity, both spatially and temporally. Reflectivity is a measure of the power backscattered to the radar from a precipitating target. The reflectivity measured is related to the drop size and density, and therefore precipitation rate (Equation 2.2). Due to the high temporal and spatial resolution of these measurements, weather radar data provides a powerful tool to study the structure and evolution of precipitation in the atmosphere. Further, many weather radar have a Doppler capability, providing a high resolution measurement of the Doppler wind field (radial component of true wind field relative to the radar) in regions of precipitation.

Doppler radar systems such as those used by MetService have the capability to measure fine scale features of the precipitation field, with high temporal and spatial resolution. Such radar systems are commonly used to investigate the fine scale structure of both stratiform and convective precipitation, resolving mesoscale features such as gust fronts, microbursts and bow echoes. In addition, Doppler radar has the capability to detect clear air signatures from convergence zones within the atmospheric boundary layer (Rinehart 2004, pg 326-329 shows some examples).

\subsubsection{Mt Tamahunga weather radar}

Since 1989 MetService has operated a high resolution Ericsson, single polarization (horizontal), C-band Doppler weather radar, located at $174^{\circ} 42^{\prime} \mathrm{E}, 36^{\circ} 18^{\prime} \mathrm{S}$ at an elevation of $453 \mathrm{~m}$ on Mt Tamahunga, north of Auckland city. In April 2006 this system was upgraded to use Sigmet digital processors and radar/antenna controllers (IRIS radar). This system provides high resolution 
measurements of reflectivity and Doppler velocity out to a maximum range of $300 \mathrm{~km}$. The Doppler scan used for this study has a maximum range of $120 \mathrm{~km}$, covering the Auckland region, parts of the Northland region and the Coromandel Peninsula, see Figure 1.1. The 2006 upgrade provided an increase in range and horizontal resolution. For radar set up and specifications of the Ericsson and IRIS radar, see Table 2.1 and Table 2.2 below. These data were supplied by MetService and the National Institute of Water and Atmospheric Research Ltd (NIWA).

\section{Ericsson radar}

This was in operation from 17 October 1989 to 4 April 2006 and produced a Doppler scan every 15 minutes for both radial velocity and reflectivity, see Table 2.1.

\begin{tabular}{|l|l|}
\hline & Doppler scan \\
\hline Wavelength & $5.36 \mathrm{~cm}$ \\
\hline Pulse repetition frequency & $900 / 1200 \mathrm{~Hz}$ \\
\hline Pulse transmission width & $0.5 \mu \mathrm{s}$ \\
\hline Antenna elevation angles & $0.5,0.9,1.4,2,3,4.5,6,7,8,9,11,15,20^{\circ}$ \\
\hline Scanning rate & $2 \mathrm{rpm}$ \\
\hline Maximum unambiguous range & $124.9 \mathrm{~km}$ \\
\hline Max unambiguous velocity & $47.9 \mathrm{~m} \mathrm{~s}^{-1}$ \\
\hline Radial resolution & $1 \mathrm{~km}$ \\
\hline Azimuthal resolution & $0.85^{\circ}$ \\
\hline
\end{tabular}

Table 2.1: Ericsson radar specifications

\section{IRIS radar}

This radar has been in operation from 9 April 2006 to the present and produces three volume scans every 7.5 minutes, one of which is the Doppler scan used in this study. The Doppler scan consists of multiple Plan Position Indicators (PPI), which are the basis of two volume scans PPI Vol A and PPI Vol B (see 
Figure 2.1). These provide both radial velocity and reflectivity data. Because of the different set ups of the Ericsson and IRIS radar, since the 2006 upgrade the IRIS radar data has been converted to the Ericsson format to allow for continuity of radar processing. This involves interpolating the IRIS data to a $1 \mathrm{~km}$ radial resolution. These data sets are used in this study. For radar set up and specifications see Table 2.2 .

\begin{tabular}{|l|l|l|}
\hline \multirow{2}{*}{} & \multicolumn{2}{|c|}{ Doppler Scan } \\
\cline { 2 - 3 } & PPI Vol A & PPI Vol B \\
\hline Wavelength & $5.36 \mathrm{~cm}$ & $5.36 \mathrm{~cm}$ \\
\hline Pulse repetition frequency & $400 / 600 \mathrm{~Hz}$ & $800 / 1200 \mathrm{~Hz}$ \\
\hline Pulse transmission width & $0.5 \mu \mathrm{s}$ & $0.5 \mu \mathrm{s}$ \\
\hline Antenna elevation angles & $0.5,0.9,1.4,2,3,4.5,6,7,8,9^{\circ}$ & $10,12,15,20^{\circ}$ \\
\hline Scanning rate & $2 \mathrm{rpm}$ & $4 \mathrm{rpm}$ \\
\hline Maximum unambiguous range & $249.8 \mathrm{~km}$ & $124.9 \mathrm{~km}$ \\
\hline Max unambiguous velocity & $16.2 \mathrm{~m} \mathrm{~s}^{-1}$ & $32.4 \mathrm{~m} \mathrm{~s}^{-1}$ \\
\hline Radial resolution & $125 \mathrm{~m}$ & $125 \mathrm{~m}^{\circ}$ \\
\hline Azimuthal resolution & $0.86^{\circ}$ & $0.86^{\circ}$ \\
\hline
\end{tabular}

Table 2.2: IRIS radar specifications

\section{Scanning geometry}

Radar scanning geometry and data acquisition are unique to each radar. For the Ericsson radar each fixed elevation scan is made up of 419 azimuths, each of which contain 120 range cells in the radial direction. The dimensions of each range cell are defined by the radar set up and the post processing that is applied. For the Ericsson radar each range cell is an average of 18 pulses in the azimuthal direction and 12 pulses in the radial direction, creating a cell with dimensions of $1 \mathrm{~km}$ in the radial direction and $0.86^{\circ}$ in the azimuthal direction. As mentioned in the previous section the IRIS radar data used in this study has been interpolated to match this resolution. For resolution of the raw IRIS data see Table 2.2 . 
Radar data are commonly displayed in one of two ways:- as PPI scans or as Constant Altitude Plan Position Indicators, CAPPI levels. PPI images display individual fixed elevation scans on a two dimensional cartesian grid. CAPPI levels display radar data at fixed altitudes.

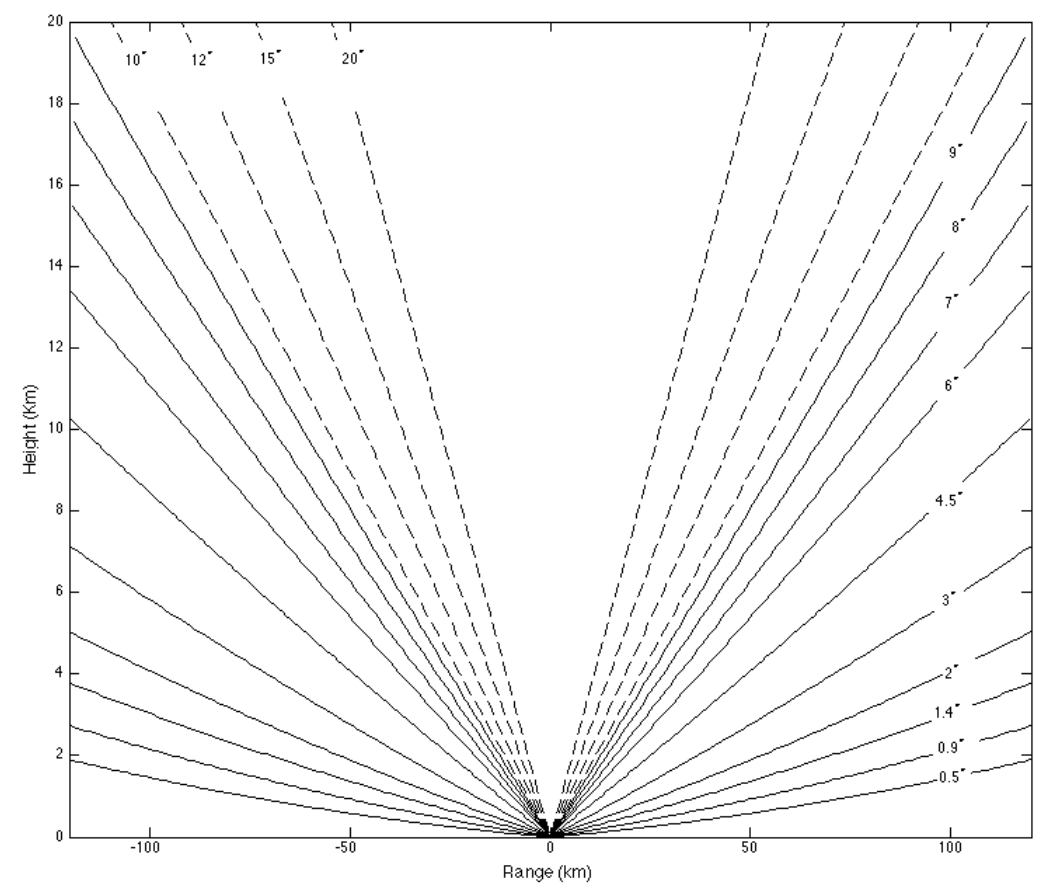

Figure 2.1: This diagram shows a vertical slice through the center of the radar volume for the IRIS radar. It can be seen that the volume is made up of 14 fixed elevation scans. The solid lines represent PPI Vol A and the dashed lines represent PPI Vol B.

The code to create CAPPI levels was written by the author using MATLAB ${ }^{\circledR}$, following the method presented by Mohr and Vaughan (1979). This method produces CAPPI levels from radar polar volumes. Firstly a cartesian grid of the desired resolution is transformed into polar coordinates, making corrections for the curvature of the earth and beam refraction in a 'standard atmosphere' (see section on error sources, pg 34). The radar data are then mapped on 
the grid, using a bilinear interpolation horizontally and a linear interpolation vertically.

\subsubsection{Radar parameters and derived values}

The following is a summary of radar theory based on that presented by Rinehart (2004). Other references are noted where appropriate. Radar systems consist of a transmitter, antenna, receiver and processor. To obtain measurements of a target at a point in space, a radio pulse (pulse volume) is sent out and the returned signal from the target is measured. Weather radar are calibrated to transmit signals between $\lambda=0.8-10 \mathrm{~cm}$. At these wavelengths scattering and absorption by meteorological targets such as rain, snow and hail is large compared to that of atmospheric gases and other airborne anthropogenic particles such as dust and pollution. The chosen transmission signal of a meteorological radar is based on the intended target. Shorter wavelengths are used for studying smaller drop sizes such as fog or cloud particles. Larger wavelengths, up to $10 \mathrm{~cm}$ are used in regions where large drop sizes and high intensity precipitation is common, such as in tropical regions.

\section{Reflectivity}

The power of the signal returned from a precipitating target within a pulse volume is described by the following commonly used equation.

$$
\bar{P}_{r}=\frac{C|K|^{2} Z}{r^{2}}
$$

where $\bar{P}_{r}$ is the average power returned from distributed targets in a precipitating volume, $C$ is a constant dependent of the radar setup, $|K|$ is the magnitude of the parameter related to the complex index of refraction of the target, $Z$ is the reflectivity factor and $r$ is the slant range from the radar. 
In the derivation and application of this equation it is assumed that:- the target fills the entire pulse volume, the target consists of particles that can be approximated by spheres, the particles are small compared to the wavelength transmitted by the radar such that Rayleigh scattering can be applied, $|K|^{2}$ and $Z$ are approximately homogeneous in the sampled volume, the beam intensity can be approximated by a Gaussian function, polarization of the incident and backscattered waves is linear and multiple scattering is negligible. For practical purposes the value of $|K|^{2}$ for water between $0-20^{\circ} \mathrm{C},|K|^{2}=0.93$ is applied universally.

Often a target is composed of water in a mixture of phases with a range of drop diameters. Such a target is referred to as a hydrometer. When measuring the reflectivity of a hydrometer it is assumed that the target consists of liquid water drops which are small compared to the transmitted wavelength of the radar. For a hydrometer of unknown properties the reflectivity factor is calculated using the assumptions listed above and is referred to as the equivalent reflectivity factor, hereafter referred to as the reflectivity factor.

The presence of ice and/or snow in a sampling volume leads to an underestimate in the calculated reflectivity of the hydrometer. This is due to the increased mass of the particles, the incorrect refractive index and melting of the particles as they fall. The use of $|K|^{2}$ for water instead of ice creates a $\sim 7 \mathrm{dBZ}$ underestimate of the measured reflectivity of the hydrometer. On occasion hail can also get large enough to invalidate the assumption that particles are small compared to the transmitted wavelength of the radar causing Mie scattering to dominate over Rayleigh scattering. This occurs when the diameter of a particle is $>0.1$ times the wavelength.

Precipitation formed through cold precipitation processes contains snow and 
ice particles above the melting level. As these particles fall below the freezing level they begin to melt, causing a layer of water to form on the outside of the particle. The density of liquid water is greater than that of snow particles; causing the terminal velocity of the particles to increase. Thus the number of drops per unit volume decreases as they melt causing a decrease in the reflectivity as melting progresses. Large particles now with the correct refractive index and a decrease in the number of particles per unit volume below the melting level, results in a distinct band of increased reflectivity peaking 100-400 m below the $0{ }^{\circ} \mathrm{C}$ isotherm (Battan 1973). This is a distinct feature of stratiform precipitation in the mid-latitudes as measured by weather radar, and is known as the radar bright band.

The returned power is then converted to a radar reflectivity factor $(z)$ for interpretation and display. This is defined by

$$
z=\sum_{i=1}^{n} N_{i} D_{i}^{6}
$$

where the particle sizes are measured over $n$ intervals, $N_{i}$ is the number of particles with drop diameter $D_{i}$ in a unit volume.

Measured reflectivity factors for precipitation targets are observed to have an extremely large variation. The Mt Tamahunga radar is capable of measuring reflectivities between $10^{-3}$ and $10^{9} \mathrm{~mm}^{6} \mathrm{~m}^{-3}$. To help visualise this a logarithmic scale is used

$$
Z=10 \log _{10}\left(\frac{z \mathrm{~mm}^{6} \mathrm{~m}^{-3}}{1 \mathrm{~mm}^{6} \mathrm{~m}^{-3}}\right)
$$

where $Z$ is the reflectivity of the target in $\mathrm{dBZ}$ and $z$ is the reflectivity factor of the target in $\mathrm{mm}^{6} \mathrm{~m}^{-3}$. 


\section{Radial velocity}

The Doppler effect occurs when a moving target or source shifts the phase of an electromagnetic signal with respect to the source signal by an amount proportional to the speed of the target.

The phase shift of the returned signal with respect to the initial phase is described by

$$
\phi=\phi_{0}+\frac{4 \pi r}{\lambda}
$$

where $\phi$ is the phase of the returned signal, $\phi_{0}$ is the phase of the transmitted signal, $\lambda$ is the wavelength of the transmitted signal and $r$ is the slant range to the target.

This is related to the frequency shift between the transmitted and returned signal by

$$
f=\frac{d \phi}{d t} \frac{1}{2 \pi}
$$

where $f$ is frequency and $\frac{d \phi}{d t}$ is the change in phase with time.

Doppler radar systems are capable of determining the component of the velocity field in the radial direction relative to the radar. This can be calculated by measuring the phase shift between the transmitted and returned signal from a moving hydrometer. Equation 2.6 can then be used to calculate the radial component of velocity

$$
V_{r}=\frac{f \lambda}{2 \cos (\alpha)}
$$

where $V_{r}$ is the radial component of velocity, $f$ is the frequency shift caused by 
the moving target and $\alpha$ is the angle between the true velocity and its radial component.

This method of measuring the velocity field is capable of producing measurements of radar radial velocity with high spatial and temporal resolution, but has some limits on the maximum velocity that can be measured and the range from which this can be measured. This is referred to as the Doppler dilemma.

The maximum unambiguous velocity, $V_{\max }$ that the radar can measure, also referred to as the Nyquist Velocity is determined by the pulse repetition frequency (PRF) and the wavelength, $\lambda$ of the radar.

$$
V_{\max }= \pm \frac{\lambda P R F}{4}
$$

Any velocities greater than this value are aliased and folded back into the measurable range with the opposite sign, see Figure 2.2.

This problem can be reduced by using dual pulse repetition frequencies, the maximum unambiguous velocity becomes

$$
V_{\text {max }}= \pm \frac{\lambda}{4\left(\frac{1}{P R F_{2}}-\frac{1}{P R F_{1}}\right)}
$$

The PRF also defines the maximum unambiguous range of the radar, the range which both radial velocity and reflectivity measurements can be uniquely defined

$$
r_{\max }=\frac{c}{2 P R F}
$$


where $r_{\max }$ is the maximum unambiguous range, $c$ is the speed of light and PRF is the pulse repetition frequency of the radar (Rinehart 2004, Equation $6.11)$.
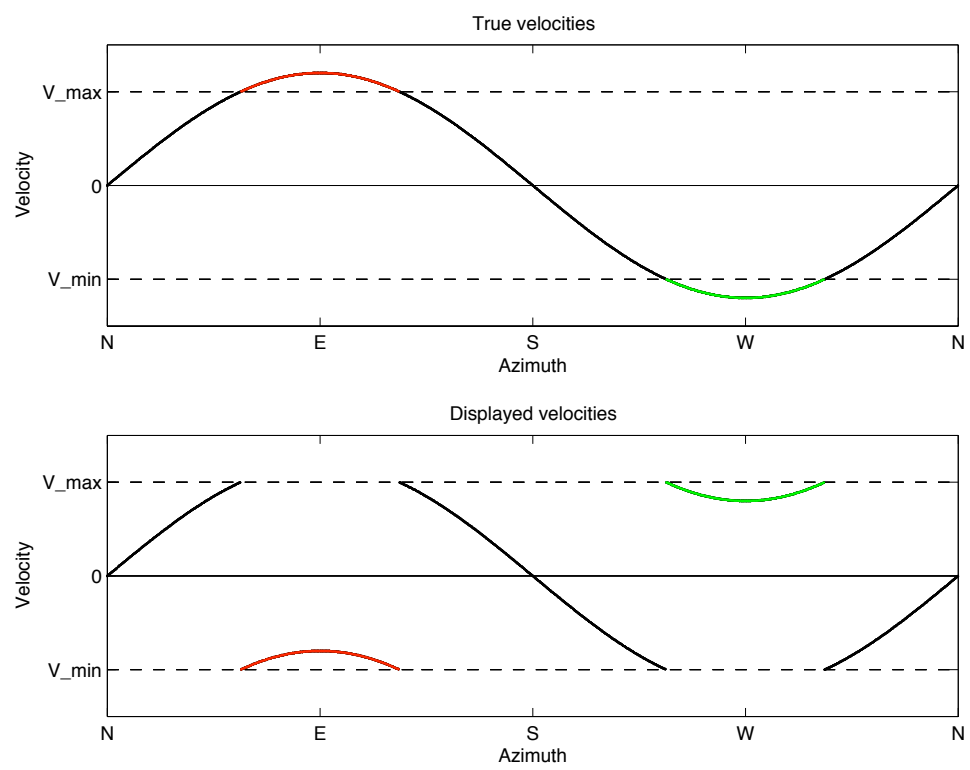

Figure 2.2: This diagram shows the radial velocity components as measured by the radar for each azimuth for a uniform wind field blowing from the west at a speed greater than $V_{\max }$. By convention negative velocities are directed towards the radar and positive velocities are directed away from the radar. The top diagram shows the true radial velocities at each azimuth, the bottom diagram shows the aliased velocities. The red and green lines can be interpolated between figures. Diagram modified from Figure 6.6, Rinehart (2004).

Despite using dual pulse repetition frequencies, velocity aliasing is a significant problem for MetService. The Ericsson radar had $V_{\max }=47.9 \mathrm{~m} \mathrm{~s}^{-1}$, which creates minimal problems with velocity aliasing over the wider Auckland region. However this is a significant problem for the IRIS radar, $V_{\max }=16.2 \mathrm{~m} \mathrm{~s}^{-1}$. Wind speeds above this are often observed in the radar area and regions of velocity folding can be observed in many of the images displayed in this study; an example showing regions of velocity folding can be seen in Figure 2.3. A considerable amount of work has been put into developing methods to auto- 
matically de-alias radial velocity data. This is often case specific and highly complicated. A technique to de-alias radar radial velocity volumes has not been achieved yet in New Zealand, as this is a relatively new problem and is beyond the scope of this project.

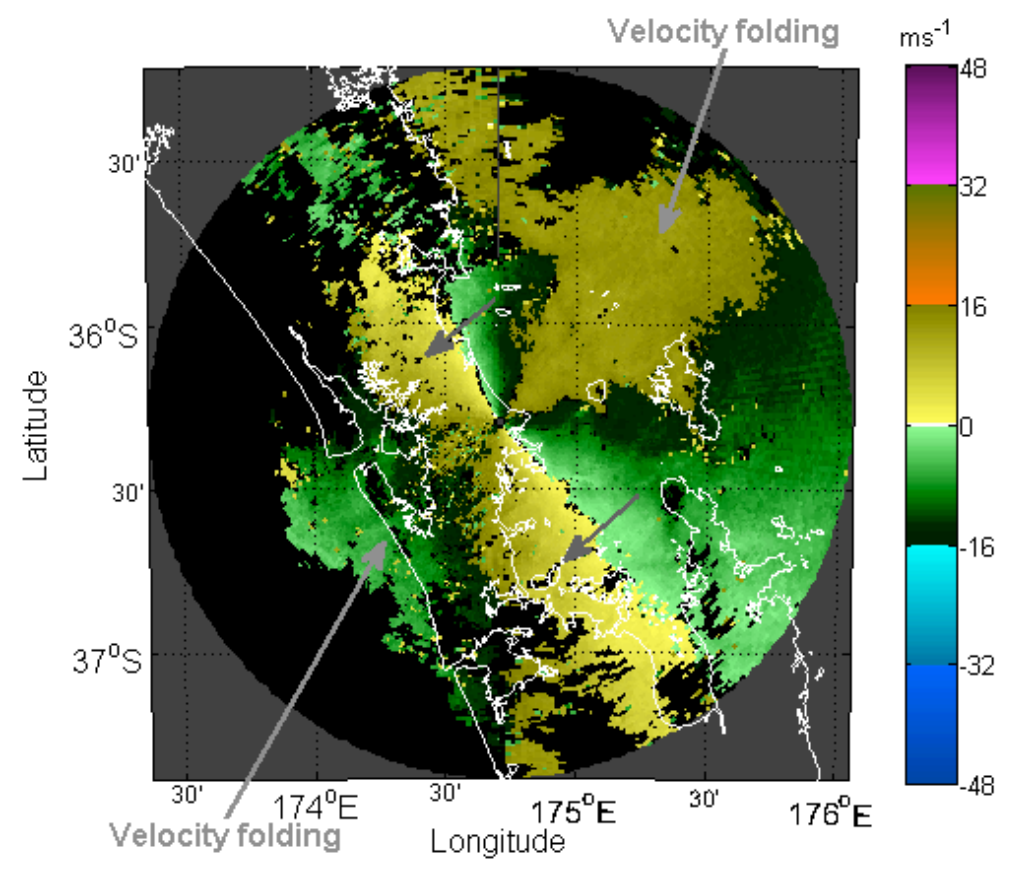

Figure 2.3: This diagram shows the appearance of velocity folding in PPI images of Doppler velocity. Regions of folding have been labeled, the wind direction indicated by the grey arrows. Image shown: $0.5^{\circ} \mathrm{PPI}, 28 \mathrm{th}$ March $20072352 Z$.

\section{Error sources}

An outline of common sources of error in reflectivity and radial velocity fields is given in the following section; for a full description the reader is referred to Rinehart (2004). Errors observed in Doppler radar systems result from the set up and placement of the radar, assumptions made in processing and the local atmospheric conditions. Errors occurring due to the set up and placement of the radar system are:- ground and sea clutter, multi-trip echoes, velocity fold- 
ing and topographic screening. Ground clutter is caused by reflections from the surface. This has a distinct pattern which is unique to each radar; it can be removed through post processing. Sea clutter is observed as low intensity echoes over the ocean. This is observed at low levels and results from reflections of the radar beam sidelobes. Multi-trip echoes result from hydrometers detected from beyond the maximum unambiguous range of the radar and appear as long thin echoes in the radial direction. Velocity folding is caused by an incorrect sampling of the velocity field (see previous section) and can be identified by large horizontal gradients in radar radial velocity. Topographic screening is caused by blocking of the radar beam by topographic features. This causes a decrease in the observed reflectivity of hydrometers detected beyond the range of the obstacle at an azimuth. This is not a big problem in the wider Auckland region because of the relatively flat topography. However partial beam blocking does occur at Little Barrier Island (722 m AMSL, $30 \mathrm{~km}$ straight line distance), and Mt Moehau (892 m AMSL, $62 \mathrm{~km}$ straight line distance).

Errors due to the assumptions made in processing are (1) $|K|^{2}=0.93$ and is approximately homogeneous in the sampled volume and (2) particles are small compared to the wavelength of the radar. These assumptions break down when large hail, ice or snow is present in a sampled volume just below the freezing level, causing a 'bright band' in the vertical profile of reflectivity in regions of stratiform precipitation.

The local atmospheric conditions can have a major effect on the errors observed in a radar volume scan. Local conditions can cause effects such as attenuation, anomalous propagation and low-level evaporation or enhancement (seeder feeder) of precipitation. Attenuation is the reduction in radar energy with range. This is caused by the scattering and absorption of the radar energy 
as the pulse volume travels through the atmosphere, the severity depending on the wavelength of the signal. The Mt Tamahunga radar has a wavelength, $\lambda=5.32 \mathrm{~cm}$. At this wavelength attenuation by precipitating hydrometers is much greater than that caused by atmospheric gases and clouds. High attenuation is experienced in rain and hail and is dependent on the size and density of the drops in the sampled volume. Therefore attenuation is a greater problem as the rain rate increases. Anomalous propagation is caused by a departure of the vertical profile of refractive index from 'standard conditions'. Sub-refraction is caused by a smaller decrease than expected in the refractive index with height causing the beam to bend downward less than that predicted in a standard atmosphere, resulting in an underestimate of beam height. This occurs in unstable conditions. Super-refraction is the opposite, caused by a greater increase in the refractive index with height than predicted in a standard atmosphere. Here the beam bends more toward the earth's surface, resulting in an over estimate of echo height. In extreme cases total internal refraction can occur, causing the beam to become trapped in a layer in the atmosphere. This is referred to as ducting. This can occur in stable conditions at low levels in the atmosphere leading to an increase in ground clutter. In convective precipitation, in regions of convective down drafts the reflectivity is underestimated. Austin (1987) found that in convective precipitation due to cold and stationary fronts, reflectivity was underestimated by 4-5 dBZ. Low-level evaporation can occur if there is dry air under a precipitating hydrometer. This causes the radar to overestimate the inferred surface rain rate. In addition, precipitation enhancement can occur below the radar beam at low-levels, resulting from rain drop growth in stratus or fog. In these cases the radar may underestimate the inferred surface rain rate, (Austin 1987).

Errors that are considered to be important in this study are:- sea clutter, velocity folding, attenuation and anomalous propagation. Other sources of error 
may occur within the data set used for this study but are not expected to be persistent, typically occurring in individual frames. As part of the MetService's radar post processing package, radar polar volumes have undergone clutter removal, reducing the errors caused by ground clutter, and corrections for beam refraction in a 'standard atmosphere' and curvature of the earth have been applied.

Despite the increase in resolution provided by weather radar relative to the current rain gauge networks in the wider Auckland region neither data set is perfect. Therefore a question needs to be considered in regards to the representativeness of each data set. At any given time rainfall intensities have been shown to vary considerably over small distances. Hosking and Stow (1987) found that rainfall intensity during precipitation events at Ardmore (located in the Auckland region) varied significantly on a scale $<400 \mathrm{~m}$ with observed fluctuations in intensity of $\sim 1 \mathrm{~mm} \mathrm{hr}^{-1} \mathrm{~s}^{-1}$. Further, radar measurements represent a horizontal area average over $1 \mathrm{~km}$ (Mt Tamahunga radar) and are made almost instantaneously. Rain gauge measurements represent an accumulation of rainfall at a point. Because of these rapid fluctuations in intensity of precipitation in both time and space, weather radar and rain gauge networks are not fully representative of the precipitation field. Therefore, to gain an understanding of the state and evolution of a precipitation field, taking into account errors inherent in each data set, both weather radar and rain gauge records can be useful when investigating the structure and/or evolution of precipitation fields.

\subsubsection{Surface observations}

A network of 14 surface-based automatic weather stations were used in this study, see Figure 1.1. These surface stations provide hourly measurements of 
temperature, pressure, relative humidity, precipitation, wind speed and wind direction throughout the study period. These data were obtained from the National Climate Database, National Institute of Water and Atmospheric Research Ltd (NIWA). One minute wind speed and direction data from Mokohinau Island were supplied by MetService. See Table 2.3

\begin{tabular}{|l|l|l|}
\hline Agent Number & Station Name & Observing Authority \\
\hline 1340 & Leigh 2 & N/A \\
\hline 17838 & Warkworth EWS & NIWA \\
\hline 1400 & Whangaparaoa AWS & MetService \\
\hline 1412 & Albany & N/A \\
\hline 26492 & ARC Kumeu EWS & ARC \\
\hline 9654 & Mokohinau AWS & MetService \\
\hline 22164 & Khyber Pass & ARC \\
\hline 1468 & Owairaka & N/A \\
\hline 1287 & Whangarei Aero AWS & MetService \\
\hline 22719 & Mangere EWS & NIWA \\
\hline 1962 & Auckland Aero & N/A \\
\hline 25119 & Dargaville 2 EWS & NIWA \\
\hline 2006 & Pukekohe Ews & NIWA \\
\hline 1520 & Whitianga Aero AWS & MetService \\
\hline
\end{tabular}

Table 2.3: Automatic weather stations used in this study. ARC = Auckland Regional Council, NIWA = National Institute of Water and Atmospheric Research Ltd.

\subsubsection{Upper Air data}

Upper air data were obtained from balloon soundings located at Whenuapai Aerodrome, see Figure 1.1. Balloon flights occur twice daily at 0000Z and 1200Z, producing measurements of temperature, dew point temperature, wind speed and wind direction, vertically through the atmosphere. These data were supplied by MetService. 


\subsubsection{Mean sea level analysis}

Mean sea level analysis charts were obtained from MetService. These charts are created four times a day at 0000Z, 0600Z, 1200Z and 1800Z, indicating the position of synoptic scale surface features such as surface fronts and troughs in the mean sea level pressure field.

\subsection{Case Selection}

As mentioned previously, synoptic conditions that bring high intensity precipitation to the Auckland and Northland regions, resulting from the passage of fronts and depressions, are generally well predicted by numerical weather models (Chater 1995, Pascoe 2001, Simes 2003). For a more detailed overview of the results from these studies see Section 1.2. These storms often have a convective component. This convective component may present as a prefrontal convective line, bow echoes and regions of embedded convection. Conditions that force regions of embedded convection remain unexplained. The following section presents the criteria that were chosen to investigate the potential forcing mechanisms for embedded convection during these storms.

\subsubsection{Case Selection}

Cases of high intensity precipitation in the wider Auckland region were chosen to include those for which (1) a severe weather warning was issued by MetService for the Northland and/or Auckland regions, as defined by local government New Zealand and (2) $20+\mathrm{mm} \mathrm{hr}^{-1}$ was measured at one or more rain gauges in the study area (see Figure 1.1). These criteria were selected so that results could be compared with the previous work of Chater (1995), Pascoe (2001) and Simes (2003). 
It was noted that for zones of radar radial shear indicating regions of low-level horizontal wind shear or convergence to be well resolved in $0.5^{\circ} \mathrm{PPI}$ images, broad regions of precipitation need to be present in the radar scanning area. To maximize the probability of this occurring each case was then split into a subset of shorter 'heavy precipitation' events for further analysis based on the following criteria:-

- $6+\mathrm{mm} / \mathrm{hr}$ at one or more rain gauges in the study area

- Length of each event was $>1$ hour.

- The end of event occurred at the point when hourly rainfall accumulations for all stations in the study area dropped below $6 \mathrm{~mm}$ for a period of 2 hours or more.

- Events where heavy precipitation was due to the passage of a front were split into prefrontal and postfrontal events, with the boundary located at the surface wind shift resulting from frontal passage.

Nine cases which fitted these criteria between January 2004 and May 2008 were identified. Two of these cases were omitted from this study as a result of substantial gaps in the availability of data from the Mt Tamahuga radar. The remaining cases are summarised in Table 2.4. It was seen as appropriate to include an extra case (Case 8) as it was of particular interest. During this case the New Zealand record for hourly rainfall accumulation was measured. At 1500Z, 29 of May 2001, the Auckland University rain gauge located at Leigh measured $109 \mathrm{~mm}$ (Simes 2003). 


\begin{tabular}{|c|c|c|}
\hline \multirow{2}{*}{ Case } & \multicolumn{2}{|c|}{ Date (UTC) } \\
\cline { 2 - 3 } & Start & End \\
\hline 1 & 1200,13 April 2008 & 1200,16 April 2008 \\
\hline 2 & 1200,14 July 2007 & 1300,15 July 2007 \\
\hline 3 & 1200,27 March 2007 & 1200,30 March 2007 \\
\hline 4 & 1100,5 February 2007 & 1100,7 February 2007 \\
\hline 5 & 1200,30 September 2006 & 1200,2 October 2006 \\
\hline 6 & 1200,26 April 2006 & 1200,28 April 2006 \\
\hline 7 & 1200,30 April 2004 & 1200,2 May 2004 \\
\hline 8 & 1200,28 May 2001 & 1200,30 May 2001 \\
\hline
\end{tabular}

Table 2.4: Summary of high intensity precipitation cases investigated in this study.

These events were then classified as steady state or variable based on the surface wind direction measured at automatic weather stations located in the study area, see Table 2.5. Events were defined to be variable where the surface wind direction measured at automatic weather stations within the study area changed due to the passage of a surface front or trough. For the location of surface stations, see Figure 1.1.

\begin{tabular}{|c|c|c|c|c|c|}
\hline Case & Event & \multicolumn{2}{|c|}{ Period (UTC) } & Classification & Comments \\
\hline 1 & 1 & 1700, 13 April 2008 & 1900, 13 April 2008 & Steady state & \\
\hline 1 & 2 & 2100,14 April 2008 & 0200,15 April 2008 & Steady state & \\
\hline 2 & 1 & 0900, 15 July 2007 & 1300,15 July 2007 & Steady state & \\
\hline 3 & 1 & 0900, 28 March 2007 & 1300, 28 March 2007 & Steady state & \\
\hline 3 & 2 & $\begin{array}{l}\text { 1600, } 28 \text { March } 2007 \\
1100,29 \text { March } 2007\end{array}$ & $\begin{array}{l}\text { 1100, } 29 \text { March } 2007 \\
1400,29 \text { March } 2007\end{array}$ & $\begin{array}{l}\text { Steady state } \\
\text { Variable }\end{array}$ & $\begin{array}{l}\text { Pre-frontal } \\
\text { Post-frontal }\end{array}$ \\
\hline 3 & 3 & 1700, 29 March 2007 & 0000,30 March 2007 & Variable & \\
\hline 4 & 1 & 1100,6 February 2007 & 2300, 6 February 2007 & Steady state & \\
\hline 5 & 1 & $\begin{array}{c}2200,30 \text { September } 2006 \\
2300,1 \text { October } 2006\end{array}$ & $\begin{array}{l}2300,1 \text { October } 2006 \\
1100,2 \text { October } 2006\end{array}$ & $\begin{array}{l}\text { Steady state } \\
\text { NA }\end{array}$ & $\begin{array}{l}\text { Pre-frontal } \\
\text { Post-frontal }\end{array}$ \\
\hline 6 & 1 & 0500,27 April 2006 & 2000,27 April 2006 & Variable & \\
\hline 7 & 1 & 0000,01 May 2004 & 1800, 01 May 2004 & Steady state & \\
\hline 8 & 1 & 1000, 29 May 2001 & 1800,29 May 2001 & Steady state & \\
\hline
\end{tabular}

Table 2.5: Table summarising the periods covered by each heavy precipitation event along with the classification of each event, see Section 2.2.1. 


\subsection{Data Processing}

This section provides a description of the methods we use to investigate the link between boundary layer forcings and enhanced precipitation during heavy precipitation events in the wider Auckland region, see Table 2.5. Methods to investigate, atmospheric stability, the spatial distribution and vertical extent of zones of radar radial shear resulting from zones of horizontal wind shear and/or zones of horizontal convergence are described. In addition, methods to investigate the spatial distribution of low-level precipitation enhancement are presented. Sections 2.3.1-2.3.4 provide a description of each method, indicating any assumptions made and in some cases potential errors.

\subsubsection{Gradient in radial velocities}

To investigate the spatial distribution of zones of horizontal convergence and horizontal wind shear in the planetary boundary layer, gradients in the radar radial velocities were calculated along each azimuth for all $0.5^{\circ}$ elevation scans (see Equation 2.10). These were then averaged over each steady state heavy precipitation event to identify regions of mechanical forcing.

$$
\nabla V_{r}=\frac{\partial V_{r}}{\partial r} e_{r}+\frac{\partial V_{r}}{\partial \phi} e_{\phi}
$$

where $\nabla V_{r}$ is the gradient in radar radial velocity, $\frac{\partial V_{r}}{\partial \phi}$ is the gradient in the radar radial velocity calculated between adjacent range cells with the same range, $\frac{\partial V_{r}}{\partial r}$ is the gradient of the radar radial velocity calculated between adjacent range cells with the same azimuthal direction, $r$ is the slant range from the radar to the target and $\phi$ is the angle between north and the radar beam. $e_{r}$ and $e_{\phi}$ are unit vectors in the radial $(\mathrm{r})$ and azimuthal direction $(\phi)$ respectively. 
Investigation showed that azimuthal gradients in radar radial velocity were extremely noisy and did not adequately resolve mesoscale features of the Doppler velocity field. Therefore only the gradients in the radial direction were used in this investigation, hereafter referred to as zones of radial shear.

For IRIS radar volumes, velocity folding is a problem. In these cases it was noted that in regions of folding, values of radar radial shear are large compared to mesoscale zones of radar radial shear caused by flow convergence/divergence and zones of horizontal wind shear. These mesoscale features are caused by vertical motion within convective systems and low-level, orographic flow modification. Investigation showed that radar radial shear zones, due to velocity aliasing, could be filtered without detriment to mesoscale features of the lowlevel flow. Accordingly, gradients in the range, $\left|\frac{\partial V_{r}}{\partial r}\right|>3 \mathrm{~s}^{-1}$ were filtered out.

Gradients in radar radial and azimuthal velocity are observed to exist in regions of divergence/convergence and horizontal wind shear. Mesoscale convergence zones are of significant importance in the initiation of severe convection, especially during the summer months. These features have been extensively studied in regions that commonly experience this type of weather, such as the Southern Great Plains of the United States of America. However, in these areas severe convection is observed to be isolated, forming as a result of the release of air-mass instability, sometimes triggered in the vicinity of zones of boundary layer convergence zones (Weckwerth and Parsons 2006). These zones of convergence commonly occur under fair weather conditions and light winds. Under such conditions a clear air radar reflectivity signal can be observed; this signal is the result of scattering of the radar beam, caused by reflections from passive, non-meteorological targets such as dust and insects (Rinehart 2004, pg. 171). Convergence zones (or boundaries) are observed as thin lines of enhanced reflectivity. In the United states of America these boundaries are 
observed to reach $Z=10$ to $20 \mathrm{dBZ}$ (Wilson and Schreiber 1986). However, in New Zealand the radar reflectivity signal is less, approximately $Z=-10$ to 10 dBZ (J. Crouch, MetService, personal communication, 26 November 2008). Under fair weather conditions convergence zones appear as extremely fine scale features in the radar radial velocity signal, which are not easy to discern in conventional displays, (Koch and Ray 1997). The identification of zones of horizontal wind shear is important for identifying regions of turbulence. Strong horizontal shear zones are characteristic features of turbulent flows such as mountain wakes, see Section 1.3.2.

The development of high resolution boundary layer retrievals from weather radar and high resolution numerical weather models have provided alternative methods for determining boundary layer divergence fields. These methods include volume velocity processing (VVP) schemes, such as velocity azimuth display, VAD (Lhermitte and Atlas 1961) and extended-VAD (Srivastava et al. 1986, Matejka and Srivastava 1991). Improvements in high resolution numerical models through the assimilation of radar and surface data, have provided a means to obtain reliable estimates of the true wind direction in the boundary layer and thus divergence fields (Alberoni et al. 2003). This means that gradients in radar radial velocities are not often used alone to identify zones of boundary layer radar radial shear resulting from zones of horizontal convergence and horizontal shear. Methods to determine the true direction of the boundary layer wind field are beyond the scope of this project.

Throughout this study widespread precipitation and moderate to strong winds were observed. This means that the use of clear air reflectivity signatures for the identification of zones of mesoscale convergence is not viable. Under these conditions gradients in radar radial velocity are better resolved, making the use of gradients in radar radial velocity to identify horizontal zones of boundary 
layer divergence/convergence and wind shear a realistic option. The use of volume velocity processing and high resolution models is beyond the scope of this project.

\subsubsection{Stability indices and low-level wind shear}

To assess atmospheric stability, indices such as convective available potential energy (CAPE), Total Totals (TT) and towering cumulus (TQ) were calculated from the Whenuapai balloon sounding. In addition, these indices were used to examine the relationship between atmospheric stability and the existence and nature of semi-permanent gradients in radar radial velocities and low-level enhanced precipitation.

\section{Convective available potential energy (CAPE)}

Convective available potential energy (CAPE) is a vertically integrated measure of an air parcel's buoyant energy and is defined by Equation 2.11.

$$
\mathrm{CAPE}=\mathrm{g} \int_{\mathrm{z}_{\mathrm{LFC}}}^{\mathrm{z}_{\mathrm{EL}}}\left(\frac{T_{\mathrm{p}}-T_{\mathrm{e}}}{T_{\mathrm{e}}}\right) \mathrm{d} z
$$

where $g$ is the acceleration due to gravity, $z_{L F C}$ is the level of free convection, $z_{E L}$ is the equilibrium level, $T_{p}$ is the temperature of the air parcel and $T_{e}$ is the temperature of the environmental air.

In the derivation of CAPE parcel theory is assumed; thus it is assumed that (1) the parcel is thermally insulated from the environment and therefore the parcel rises moist adiabatically, with no entrainment of air from the environment as the parcel rises, (2) the condensation products fall out of the parcel as they are made, i.e. there is no liquid water or ice loading (3) the parcel pressure is equal to the environmental pressure at each level. In practice one 
or more of these assumptions are violated in common atmospheric motions. Although CAPE is a measure of an air parcel's buoyant energy it is often used as a measure of instability in the atmosphere (Blanchard 1998). By definition CAPE is integrated from the level of free convection to the equilibrium level and is therefore sensitive to both parcel buoyancy and the depth of integration. In different atmospheric conditions the same value of CAPE can represent different magnitudes of instability (Blanchard 1998). Therefore when using CAPE as a measure of instability care needs to be taken when comparing between storms. Due to the potential errors involved in deriving values for CAPE and the difficulty in comparing these values between events, CAPE values during each event were investigated but were not used to compare the instability between events.

Simes (2003) reported that based on MetService forecaster experience, it has been found that,

- $\mathrm{CAPE}$ values $<800 \mathrm{~J} \mathrm{~kg}^{-1}$ indicate weak buoyancy.

- CAPE values between $800-1800 \mathrm{~J} \mathrm{~kg}^{-1}$ indicate moderate buoyancy.

- CAPE values $>2000 \mathrm{~J} \mathrm{~kg}^{-1}$ indicate large amounts of buoyancy.

\section{Total Totals (TT)}

Total Totals is a measure of stability between $850 \mathrm{hPa}$ and $500 \mathrm{hPa}$ and is defined by Equation 2.12. This is commonly used at MetService and is applied to situations such as severe thunderstorms and convection embedded in synoptic scale systems, surface-based convection in cool air masses and topographically enhanced flow over the Southern Alps, (Henry 2000).

$$
\mathrm{TT}=T_{850}+T_{\mathrm{d} 850}-2 T_{500}
$$


where $T_{850}$ and $T_{d 850}$ are the temperature and dew point temperature respectively at $850 \mathrm{hPa}$ and $T_{500}$ is the temperature at $500 \mathrm{hPa}$.

Henry (2000) reported that based on forecaster experience, it has been found that for warm season air masses in New Zealand,

- $\mathrm{TT}<45^{\circ} \mathrm{C}$ indicates stable stratification.

- $\mathrm{TT}>55^{\circ} \mathrm{C}$ severe thunderstorms are likely.

The Total Totals index indicates the amount of buoyant energy between $850 \mathrm{hPa}$ and $500 \mathrm{hPa}$. The values obtained in the Total Totals index show a seasonal dependence, overestimating the instability or buoyant energy in cool air masses, (Henry 2000). Although Total Totals is widely used in New Zealand to obtain a measure of air-mass instability it doesn't effectively represent low-topped instability which is common in New Zealand, (Henry 2000).

\section{Towering cumulus (TQ)}

This stability index is designed to resolve instability capped between $500 \mathrm{hPa}$ and $700 \mathrm{hPa}$, (Henry 2000). This is defined by Equation 2.13 below.

$$
\mathrm{TQ}=T_{850}+T_{\mathrm{d} 850}-1.7 T_{700}
$$

where $T_{850}$ and $T_{d 850}$ are the temperature and dew point temperature respectively at $850 \mathrm{hPa}$ and $T_{700}$ is the temperature at $700 \mathrm{hPa}$.

Henry (2000) found that,

- $\mathrm{TQ}>12{ }^{\circ} \mathrm{C}$ indicates high instability for events with strong diabatic heating and a boundary layer moisture supply. 
- For events where stratiform cloud is present TQ approximately $>17^{\circ} \mathrm{C}$ is an indicator for low-topped embedded convection.

The TQ index was designed to show no seasonal dependence but does show sensitivity to upper level moisture, overestimating instability in the presence of stratiform cloud, (Henry 2000). Therefore care needs to be taken when interpreting the values of TQ.

\section{Low-level wind shear}

Wind shear was calculated between Mokohinau Island automatic weather station at the surface and Whenuapai upper level winds at $3 \mathrm{~km}$. The $0-3 \mathrm{~km}$ wind shear was used to investigate the relationship between low-level wind shear and zones of radar radial shear, in addition to the relationships with large scale precipitation motion and type in the wider Auckland region. Mokohinau Island was used as the lower boundary as it was considered to be representative of the low-level winds over the Hauraki Gulf during the cases investigated in this study, see Section 3.2.2.

\subsubsection{Radar vertical profiles}

Vertical profiles displaying radar data commonly called range height indicators (RHI), were created from the Mt Tamahunga radar PPI volumes. Code to create these vertical profiles is part of the MetService radar analysis suite. This was adapted to allow processing of Doppler polar volumes for both reflectivity and radial velocity. This code allows the selection of a transect anywhere within the radar scanning area, selecting the nearest range cells to the transect plane up to a height of $12 \mathrm{~km}$ above the radar. This code makes standard corrections for the curvature of the earth and beam refraction in a "standard atmosphere'. 


\subsubsection{Convective Stratiform Partitioning}

To investigate the spatial distribution of mesoscale precipitation enhancement during high intensity precipitation events, MATLAB ${ }^{\circledR}$ code was written by the author to identify areas of enhanced precipitation within the radar reflectivity field. This was based on the technique employed by Steiner et al. (1995). To classify the reflectivity pattern as convective or stratiform precipitation, they assumed that convective precipitation is cellular in nature and will produce high intensity rainfall rates which are generally greater than those observed in stratiform rain. Convective precipitation was defined by the following criteria:-

\section{- Intensity $Z \geq 40 \mathrm{dBZ}$}

The intensity criterion is a reflectivity threshold above which it is always considered to be representative of convective precipitation.

\section{- Peakness}

This criterion takes into consideration the horizontal gradients in reflectivity. This compares the reflectivity at a point to a background value. The background value is defined as the linear average of all points (range cells) within an $11 \mathrm{~km}$ radius of the point in question. Any point where $\Delta \mathrm{Z}$ is greater than or equal to that defined in Equation 2.14 is classified as convective. Steiner et al. (1995) found that Equation 2.14 was the most effective in the monsoon environment in Darwin, Australia.

$$
\Delta Z= \begin{cases}10 & , Z_{b g}<0 \\ 10-\frac{Z_{b g}^{2}}{180} & , 0 \geq Z_{b g}<42.43 \\ 0 & , Z_{b g} \geq 42.43\end{cases}
$$

where $\Delta Z$ is the decibel $(\mathrm{dB})$ difference between the point being considered and the background and $Z_{b g}$ is the background reflectivity (dBZ). 


\section{- Convective Radius}

This criterion is applied last and considers all points identified as convective based on the two previous criteria. The range cells at radius, $r$ around each convective pixel are also defined as convective. The value of $r$ is based on the value of the background reflectivity. This is variable, depending on the desired result, see Figure 2.4.

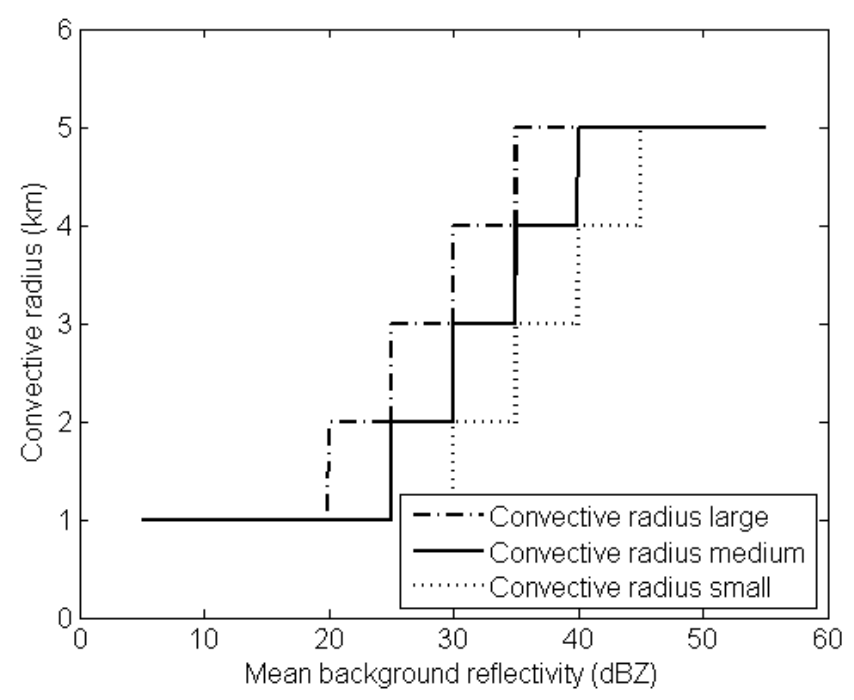

Figure 2.4: Diagram showing the convective radius criterion as defined by Steiner et al. (1995).

These criteria are location specific, resulting from changes in the environment in which precipitation is formed. For example, precipitation growth by warm, cold or mixed phase processes alters the drop size distribution. Further, changes in the freezing level with location have the effect of altering the nature of the measured reflectivity field. The method for partitioning convective and stratiform precipitation echoes developed by Steiner et al. (1995), was developed in a monsoon environment in Darwin, Australia. Precipitation growth in this environment is predominately by warm phase processes. Therefore when applying this method to the mid-latitudes where precipitation growth is predominately by cold and mixed phase processes, the thresholds for 
identifying convective precipitation need to be recalibrated, (Biggerstaff and Listemaa 2000, Llasat and Rigo 2004). See Section 3.3.1 for the calibration of this method for the wider Auckland region. 


\section{Chapter 3}

\section{Results}

This chapter presents the results obtained in this study. Section 3.1 provides an overview of the synoptic conditions during each of the cases studied. Section 3.2 examines the spatial distribution of mechanical forcing in the boundary layer during steady state heavy precipitation events. Mechanical forcing is observed as zones of semi-permanent radar radial shear. The relationship between the existence and nature of these features and environmental conditions at mid to low levels in the atmosphere is examined, in addition to the effect of these environmental conditions on low-level precipitation type and large scale motion. Section 3.3 discusses the advantages of identifying enhanced precipitation and investigates the spatial distribution of low-level enhanced precipitation based on radar data from the Mt Tamahunga radar. Lastly to investigate the role of boundary layer forcing in the initiation and intensification of convection, an in depth case study of Case 3, Event 2 is presented in Section 3.4.

\subsection{Case Overview}

Eight cases of high intensity precipitation were investigated in this study. All of the cases investigated were characterised by regions of both stratiform and 
convective precipitation as observed in the Mt Tamahunga radar data. This is consistent with results obtained by Simes (2003) and Pascoe (2001). The convective component of these storms is observed in radar images as convective lines, regions of embedded convection, bow echoes and isolated convective cells. Convective lines are predominantly dynamically forced in frontal regions, whereas regions of embedded convection and bow echoes are often forced on a mesoscale. Additionally isolated convective cells are often observed to be forced on a mesoscale, see Section 1.3.2. Convective precipitation observed during storms of this nature can bring localised high intensity precipitation, $>100 \mathrm{~mm} \mathrm{hr}^{-1}$, to the affected area (Simes 2003). Of the 11 heavy precipitation events investigated (Table 2.5), 10 events have strong dynamic forcing observed in the vicinity of synoptic scale surface fronts and troughs. One case is forced on a smaller scale by a weak surface trough. In this case multiple convective lines are initiated oriented perpendicular to the surface trough. For a summary of the synoptic conditions during each heavy precipitation event, see Table 3.1.

It can be seen from Table 3.1 that all eight cases studied, have a component of dynamic forcing, with precipitation developing in the vicinity of surface-based fronts and troughs. These features are associated with the passage of midlatitude depressions centred mainly to the north and west of the study area, consistent with results obtained by Simes (2003), Pascoe (2001) and Chater (1995). 


\begin{tabular}{|c|c|c|c|c|c|c|c|c|c|c|c|c|}
\hline 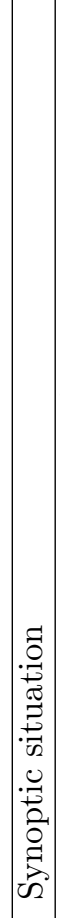 & 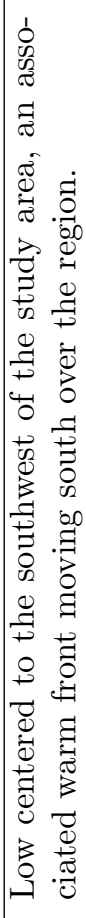 & 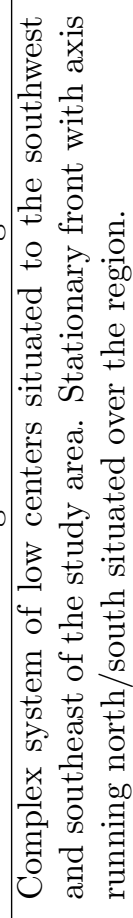 & 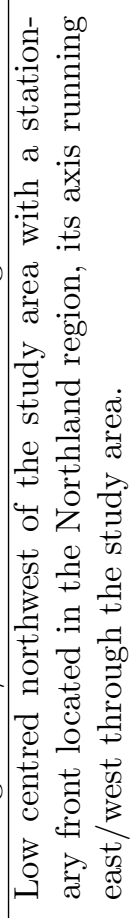 & 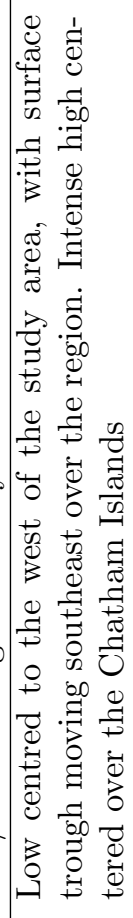 & 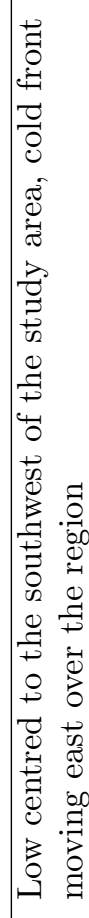 & 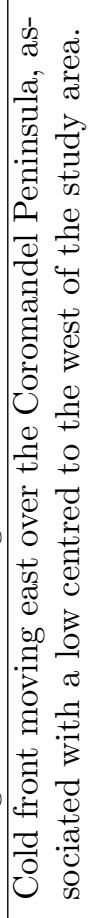 & 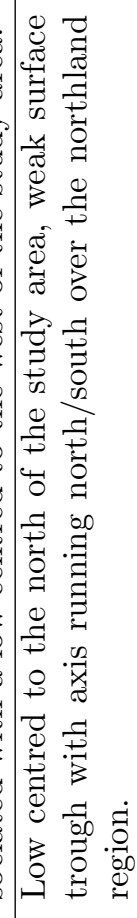 & 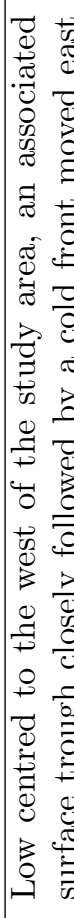 & & 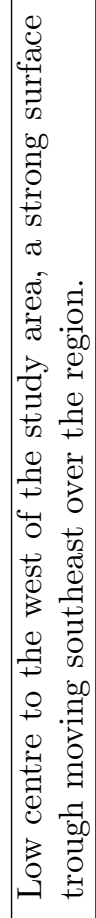 & 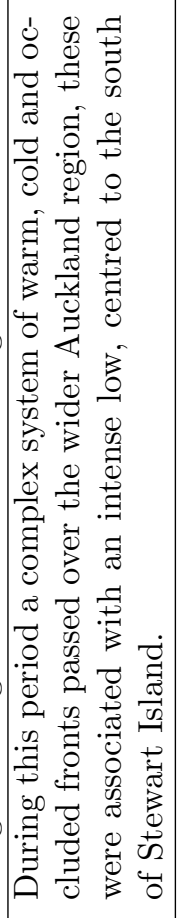 & 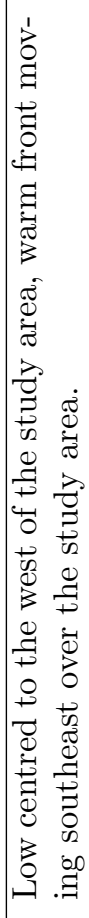 \\
\hline 0 & 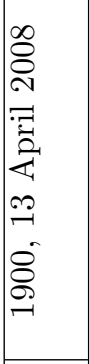 & 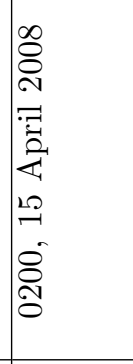 & 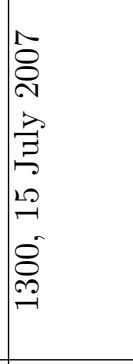 & 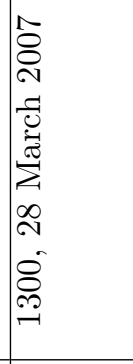 & 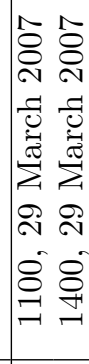 & 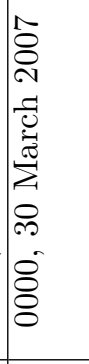 & 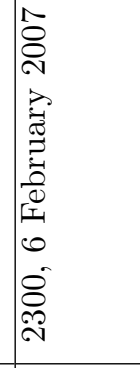 & 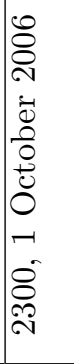 & 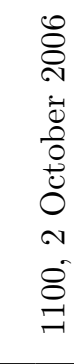 & 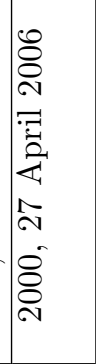 & 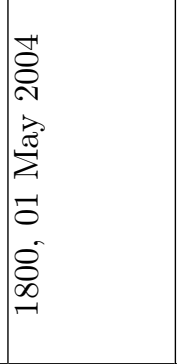 & 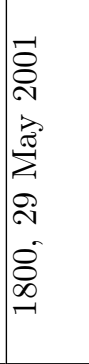 \\
\hline 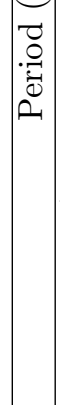 & 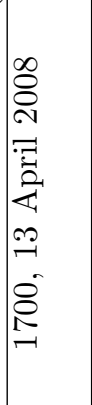 & 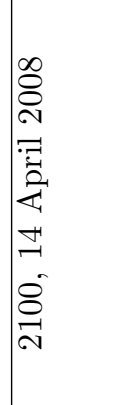 & $\begin{array}{l}\hat{1} \\
8 \\
0 \\
2 \\
2 \\
3 \\
0 \\
0 \\
-1 \\
8 \\
8 \\
0 \\
0\end{array}$ & 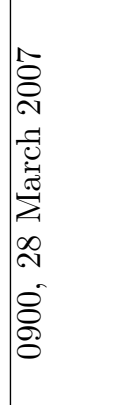 & 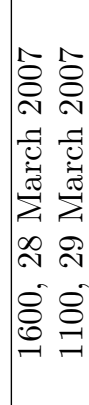 & 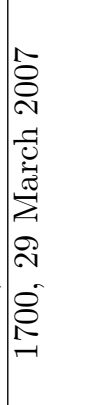 & 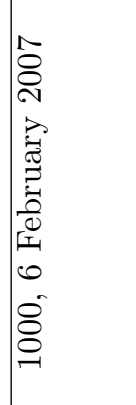 & 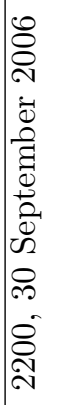 & 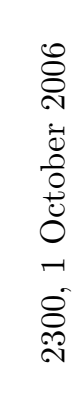 & 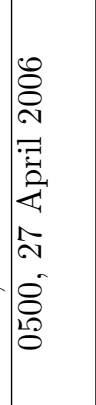 & 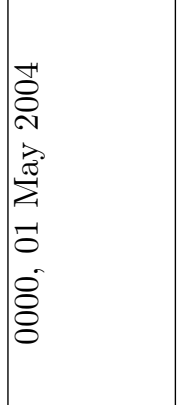 & 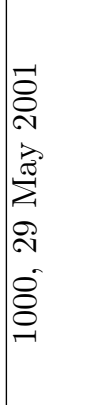 \\
\hline 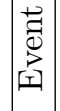 & 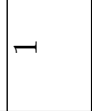 & $\sim$ & -1 & $\dashv$ & $\sim$ & $\infty$ & -1 & - & & - & -1 & 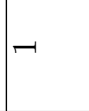 \\
\hline రు & -1 & - & $\curvearrowright$ & $\infty$ & $\infty$ & $\infty$ & $F$ & 10 & & 0 & $\Lambda$ & $\infty$ \\
\hline
\end{tabular}




\subsection{Boundary layer forcing}

As mentioned in Section 1.3.2, boundary layer forcing resulting from zones of horizontal shear and convergence can be associated with low-level flow modification in the vicinity of topography. These features can play an important role in enhancing low-level precipitation and the initiation/intensification of convection. The following section utilises heavy precipitation events (Table 2.5) to examine the spatial distribution of semi-permanent zones of radar radial shear, see Section 3.2.1. Section 3.2.2 summarises environmental conditions during these storms, including convective instability, surface wind speed/direction, $700 \mathrm{hPa}$ wind speed/direction and low-level wind shear during periods of semipermanent zones of radar radial shear observed in data from the Mt Tamahunga radar. The relationship between these conditions and zones of semi-permanent radar radial shear is considered, in addition to large scale precipitation type and motion. In Section 3.2.3 we examine the radar characteristics of semipermanent zones of radar radial shear observed in the lee of Great Barrier, Little Barrier and Taranga Islands and Mt Moehau. Further, the vertical extent of these zones of radar radial shear and the synoptic conditions during the observed maxima in vertical extent of these features is investigated.

\subsubsection{Spatial distribution}

To investigate the spatial distribution of boundary layer forcing, the radial gradients in radar radial velocity, $\frac{\partial V_{r}}{\partial r}$, (radar radial shear) were taken along each azimuth, for all $0.5^{\circ}$ fixed elevation scans. Investigation of these data showed that zones of radar radial shear were either transient, moving across the radar scanning area with time, or semi-permanent, appearing at the same location for consecutive radar scans. For the purposes of this study semipermanent zones of radar radial shear are defined to be shear zones which are detected in the same location for consecutive radar scans, within an event 
characterised by steady low-level wind direction. However, in some cases these shear zones are not well defined. Further precipitation echoes can become noisy, limiting the detection of these features. Consequently these zones are referred to as semi-permanent zones of radar radial shear. To investigate the spatial distribution of semi-permanent zones of radar radial shear, individual frames of radial gradients in radar radial velocity were averaged in time for each of the steady state events identified in Table 2.5. In instances where there was no datum measured in a range cell, this point was omitted from the average. An example of average values of radar radial shear is shown in Figure 3.2 .

Multiple semi-permanent zones of radar radial shear are observed within the study area:

- Pairs of positive and negative shear lines are observed in the lee of Great Barrier, Little Barrier and Taranga islands in the Hauraki Gulf, in addition to downstream of Mt Moehau, Coromandel Peninsular, see Figures 3.1, 3.2 and 3.5. These features show evidence of a wake like structure, see Section 1.3.2.

- On the windward side of Great Barrier and Little Barrier islands, and on the windward side the of Coromandel ranges, see Figure 3.2 and 3.5 (bottom image).

- Along the west coast of the Auckland region, see Figure 3.2.

- In the Hauraki Gulf extending in the azimuthal direction, at a constant range, close to the radar location, see Figure 3.4. 


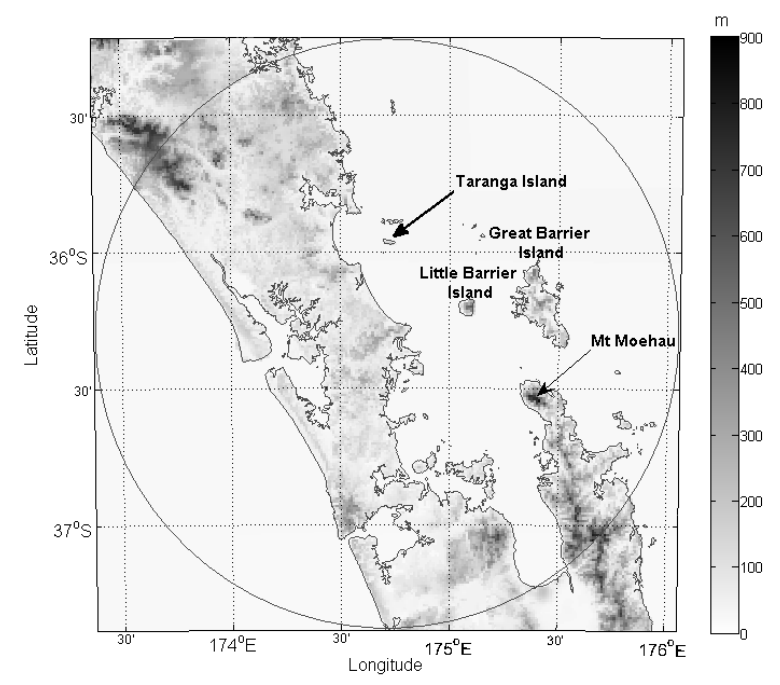

Figure 3.1: Map showing the barriers for which downstream zones of radar radial shear are observed. Barriers are defined as isolated topographic features where under favorable conditions the low-level flow will interact with the topographic feature forming a wake in the lee of the obstacle.

Semi-permanent zones of radar radial shear were observed in five of the nine identified, steady state heavy precipitation events, see Table 3.3. Seven of the steady state heavy precipitation events investigated were characterised by broad areas of stratiform precipitation with relatively smaller areas of embedded convection (cellular areas of enhanced reflectivity $Z>40 \mathrm{dBZ}$ ), observed in the Mt Tamahunga radar. An example of this is shown in Figure 3.3. This provided conditions where there is a high probability of mesoscale zones of radar radial shear being detected by the Mt Tamahunga weather radar. The remaining two of the nine events were characterised by patchy or nonexistent precipitation echoes over the Hauraki Gulf, as observed in $0.5^{\circ}$ PPI images of radar reflectivity, thus limiting the detection of zones of radial shear by the Mt Tamahunga radar. These events were:- Case 4, Event 1, 1000Z 6 February 2007 to $2300 Z 6$ February 2007 and Case 5, Event 1, $2200 Z 30$ September 2006 to $2300 \mathrm{Z} 1$ October 2006. 


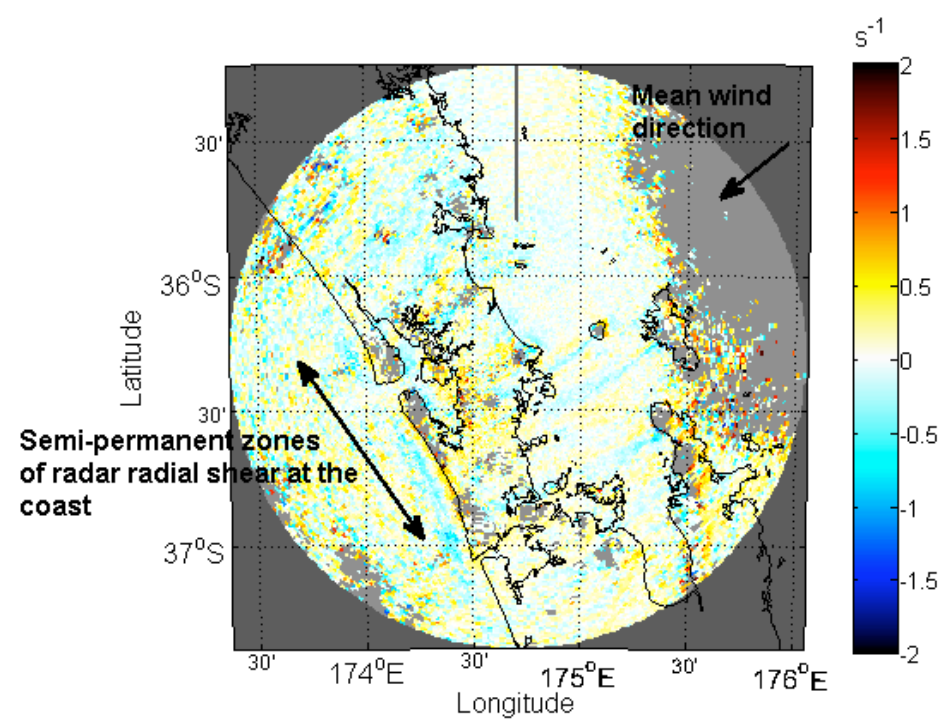

Figure 3.2: Map showing the average radar radial shear over the study area, Case 3, Event 1, 0900 Z to 1300Z, 28 March 2007. During this period the synoptic scale low-level wind was from the northeast. Zones of radar radial shear are observed on the west coast of the Auckland region, in addition to the windward side of Great Barrier, and Little Barrier islands and the Coromandel Peninsula. Further, pairs of shear lines one positive and one negative are observed in the lee of Mt Moehau and Little Barrier, Great Barrier and Taranga Islands.

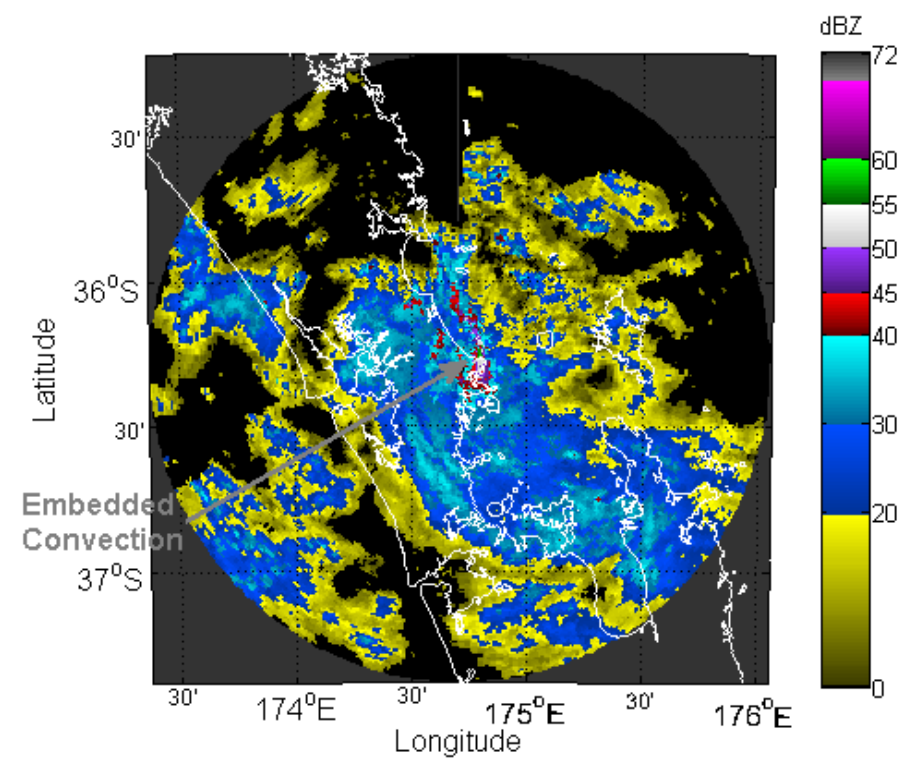

Figure 3.3: Diagram showing the appearance of embedded convection in $0.5^{\circ}$ PPI images of reflectivity, characteristic of the cases studied. Case 8 Event 1 , $0.5^{\circ}$ PPI image of radar reflectivity, 1402Z 29 May 2001 
Images of average radar radial shear can become noisy at the edges of precipitation echoes (see Figure 3.5 bottom image). This can be a particular problem over the Hauraki Gulf during periods of patchy precipitation echoes. In this region sea clutter is a problem. When precipitation echoes pass through regions affected by sea clutter, gradients in radar radial velocity are observed at the boundary between sea clutter and the precipitation echoes. These are non-physical and are an artifact of the method used. This is not a big problem during the heavy precipitation events investigated, due to the short time periods over which this effect is observed. Artificial semi-permanent zones of radar radial shear are observed to extend in the azimuthal direction, at a fixed distance from the radar in the Hauraki Gulf. This feature is observed as a negative gradient in the radar radial velocity and is only observed if no precipitation echoes are present, in regions of sea clutter. Due to its fixed range this feature is not expected to be caused by physical processes, however it is of unknown origin. An example of this can be seen in Figure 3.4.

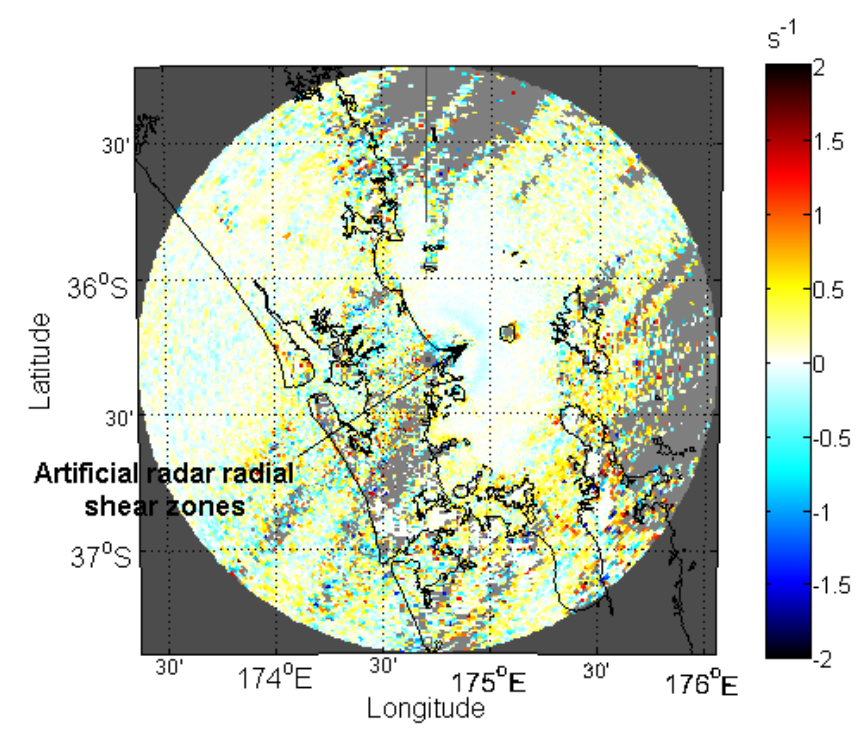

Figure 3.4: Map showing the average radar radial shear over the study area, Case 4, Event 1, 1000Z to 2300Z, 6 February 2007. During this period the synoptic scale low-level wind was from the east. Artificial zones of divergence are observed to extend in the azimuthal direction at a constant range (appearing as a blue ring) in the Hauraki Gulf . 

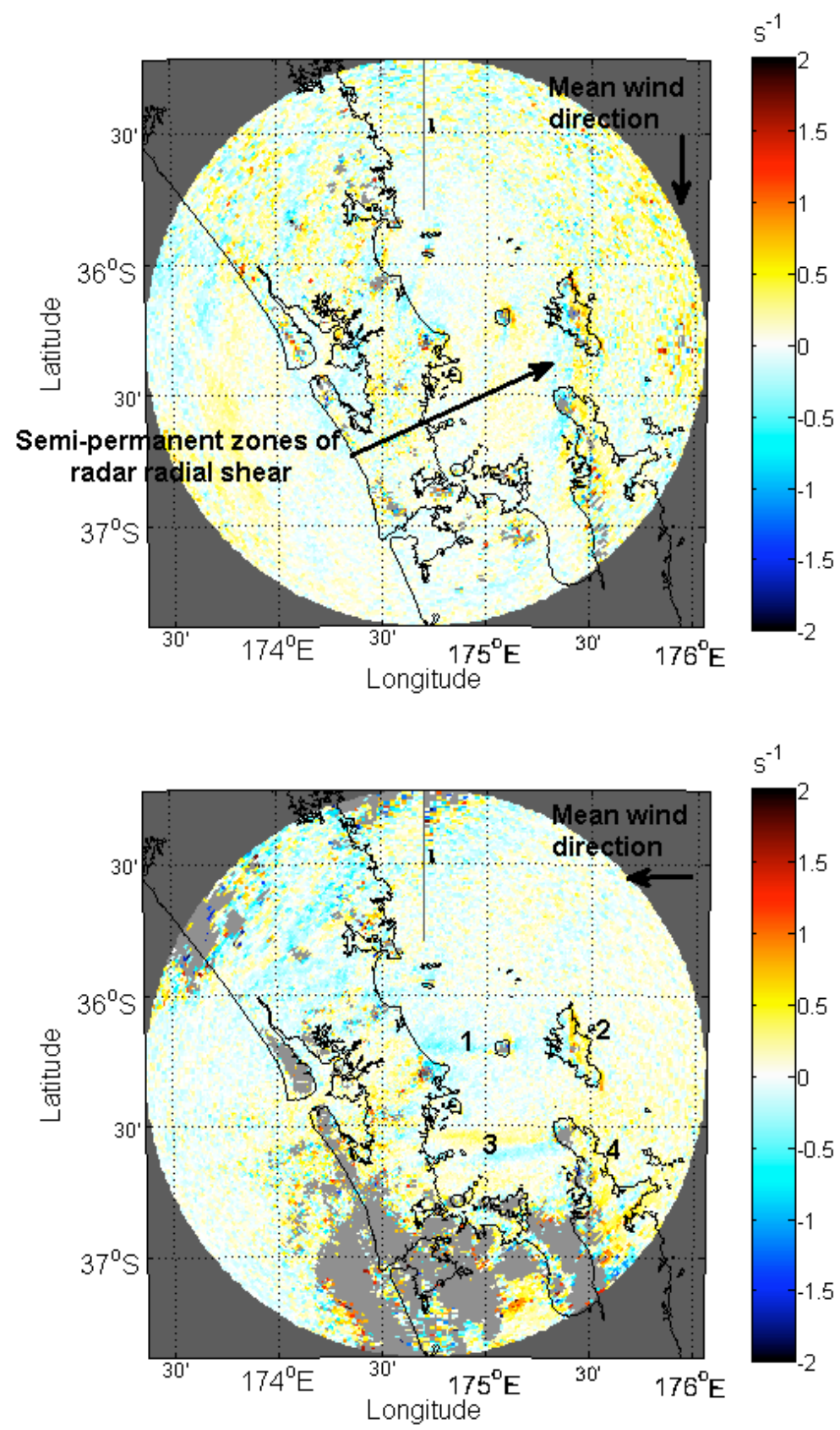

Figure 3.5: Map showing the average radar radial shear, Case 1, Event 2, 2100Z, 14 April 2008 to 0200Z, 15 April 2008 (top) and Case 2, Event 1, 0800Z to 1300Z, 15 July 2007 (bottom). During Case 1, Event 2 the synoptic scale flow was from the north whereas, in Case 2, Event 1 the synoptic scale flow was from the east. Zones of radar radial shear are observed downstream of Great Barrier and Taranga islands in the Hauraki Gulf, observed as a pair of shear lines one positive and one negative (top). In the bottom image, zones of radar radial shear are observed downstream of Little Barrier Island (1) and Mt Moehau (3), located at the tip of the Coromandel Peninsula, see Figure 3.1. In addition, zones of radar radial shear are observed on the windward side of Great Barrier Island (2) and the Coromandel Peninsula (4) 
Flow modification due to interaction with topography and coastlines, and its effect on precipitation is well known, see Section 1.3.2. This can lead to orographic enhancement and in some cases enhancement by the seeder feeder effect. Despite the relatively flat topography of the wider Auckland region relative to other areas of New Zealand, topographic features such as the Waitakere, Hunua and Coromandel ranges have an effect on the distribution of precipitation, see Section 1.2. The relative strength and persistence of the radar radial shear zones observed in the lee of Mt Moehau and Great Barrier, Little Barrier and Taranga islands, were unexpected and have not previously been documented in this area. These features therefore became the focus of the remainder of this study.

The position of these features in the lee of each obstacle, along with their spatial dimensions, suggests a mountain wake structure, see Section 1.3.2. Semipermanent zones of radar radial shear are observed in five of the seven heavy precipitation events for which persistent precipitation echoes were measured over the Hauraki Gulf, see Table 3.3. From Figure 3.5 and Table 3.3 we observe that the existence and position of each wake varies between events. Factors influencing the existence and position of these features are investigated further below.

\subsubsection{Environmental conditions during heavy precipita- tion events}

This section discusses the environmental conditions at low to mid levels in the atmosphere, during steady state, heavy precipitation events. Air-mass characteristics such as stability, surface and mid-level wind speed/direction and low-level wind shear are investigated, along with the relationship between these characteristics and low-level precipitation type and large scale precipi- 
tation motion. In addition, investigation is made of the relationship with the existence and observed characteristics of zones of radar radial shear observed in the lee of Mt Moehau and, Little Barrier, Great Barrier and Taranga islands. From mean sea level analysis maps, geostrophic flow during steady state heavy precipitation events was observed to vary between flows from the northeast quadrant. Taking this into account, it was considered that Mokohinau Island automatic weather station provided a representative estimate of the surface flow over the Hauraki Gulf. For these wind directions there is minimal topographic modification of the flow upstream of Mokohinau Island. Wind shear between the surface and $\sim 3 \mathrm{~km}$ over the Hauraki Gulf was estimated by calculating the wind shear between Mokohinau Island at the surface and the Whenuapai balloon sounding data at $3 \mathrm{~km}$. Further, mid-level winds and estimates of air-mass stability, were obtained from the Whenuapai balloon sounding. Total Totals, TQ and CAPE were used to estimate air-mass stability, see Section 2.3.2. Table 3.2 and Table 3.3 summarise these characteristics and indicate whether lee zones of radar radial shear were observed for each of the steady state, heavy precipitation events investigated.

From Table 3.3 we can see that semi-permanent lee zones of radar radial shear were observed in five of the nine heavy precipitation events studied. Two events:- Case 7, Event 1, 0000Z 1 May 2004 to 1800Z 1 May 2004, and Case 8, Event 1, 1000Z 29 May 2001 to 1800Z 29 May 2001, show no evidence of lee radar radial shear zones. The remaining two events (Case 4 Event 1 and Case 5 Event 1) were characterised by patchy or non existent precipitation echoes over the Hauraki Gulf, limiting the probability of detection of zones of radar radial shear by the Mt Tamahunga radar. 


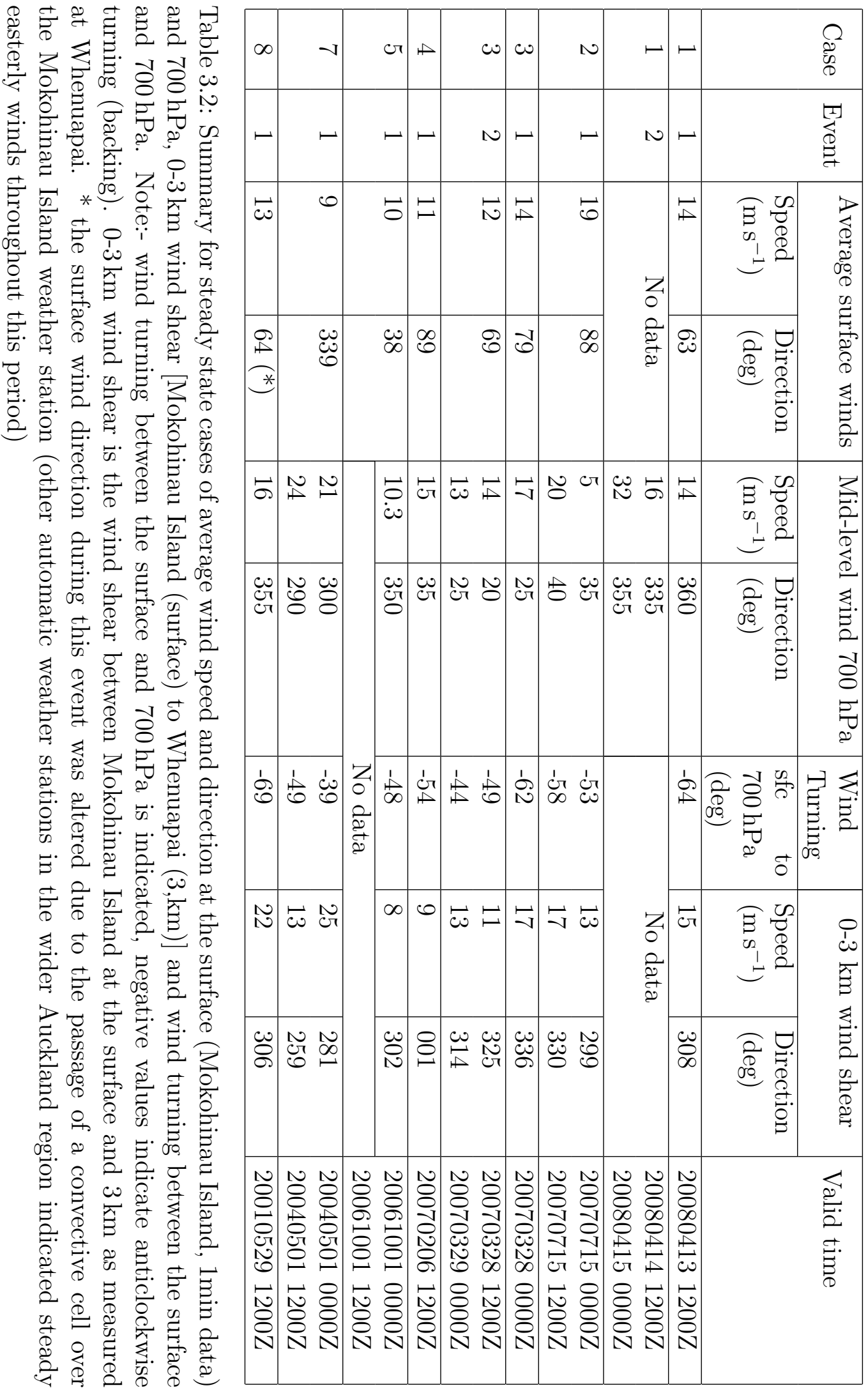




\begin{tabular}{|c|c|c|c|c|c|c|c|c|c|c|}
\hline & 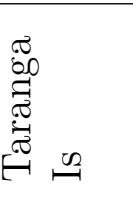 & & * & & & * & 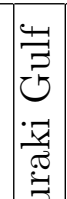 & 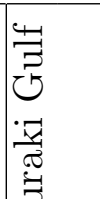 & & \\
\hline & 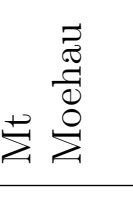 & & & $*$ & $*$ & & 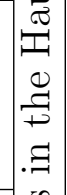 & 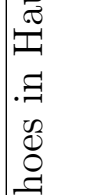 & & \\
\hline & 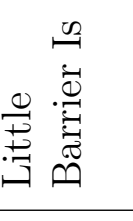 & * & & * & * & $*$ & 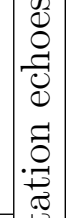 & 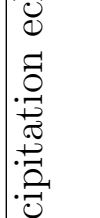 & & \\
\hline & 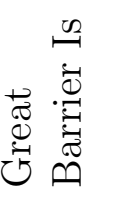 & & * & & * & * & $\mid \begin{array}{l}\vec{a} \\
\vec{u} \\
0 \\
\vdots \\
0 \\
0 \\
z \\
z\end{array}$ & 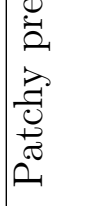 & & \\
\hline & 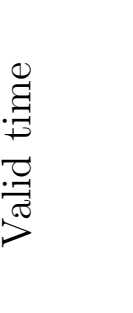 & 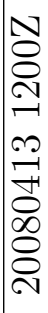 & $\begin{array}{l}\text { ㄱ. } \\
8 \\
8 \\
8 \\
8 \\
10 \\
ت \\
\\
0 \\
0 \\
8 \\
8 \\
0\end{array}$ & 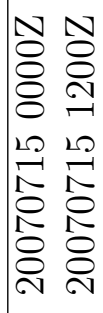 & 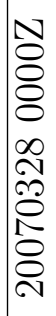 & 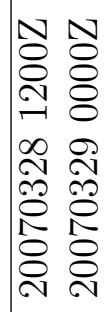 & 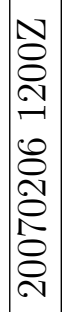 & 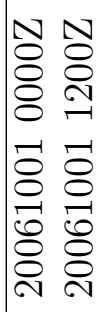 & 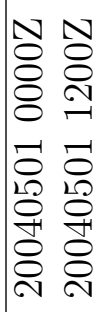 & 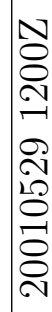 \\
\hline & 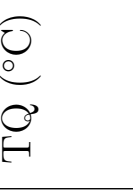 & $\begin{array}{l}\infty \\
\infty \\
-1 \\
-1\end{array}$ & 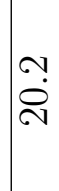 & $\begin{array}{ll}\sim & \infty \\
\stackrel{\infty}{\rightarrow} & \stackrel{\infty}{\rightarrow}\end{array}$ & $\begin{array}{l}0 \\
0 \\
0\end{array}$ & 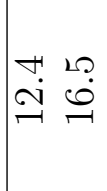 & $\begin{array}{l}0 \\
\\
-1\end{array}$ & 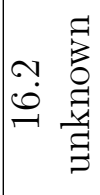 & 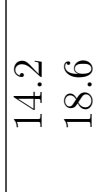 & $\stackrel{\sim}{\stackrel{N}{L}}$ \\
\hline & 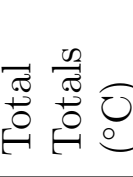 & $\stackrel{\sim}{\stackrel{F}{\not}}$ & 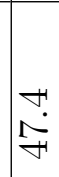 & $\begin{array}{ll}12 & 0 \\
0 & 0 \\
10 & 9\end{array}$ & o & 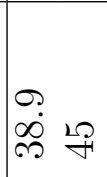 & $\sqrt{20}$ & 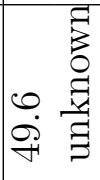 & Fr & $\begin{array}{l}0 \\
\dot{\infty} \\
\stackrel{+}{1}\end{array}$ \\
\hline & 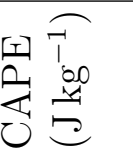 & $\stackrel{\infty}{\sim}$ & 8 & $0 \stackrel{-1}{1}$ & $\mathscr{8}$ & 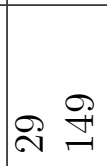 & $\underset{\mathscr{O}}{\mathscr{O}}$ & ڤి & 100 & $\stackrel{0}{\circ}$ \\
\hline & & $\neg$ & $\sim$ & $\neg$ & - & $\sim$ & -1 & $\neg$ & -1 & - \\
\hline & & $\neg$ & -1 & $\sim$ & $\infty$ & $\infty$ & 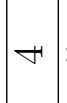 & 10 & $N$ & $\infty$ \\
\hline
\end{tabular}




\section{Surface and Mid-level winds}

Surface and mid-level wind speed and direction were examined for each of the heavy precipitation events. Measurements of 1 minute wind speed/direction from Mokohinau Island at the surface and the $700 \mathrm{hPa}$ wind speed/direction from the Whenuapai balloon soundings were considered to be representative of the flow over the Hauraki Gulf at the surface and $700 \mathrm{hPa}$ respectively. Table 3.2 shows that the average surface wind direction varied from the north to the east. From Figure 3.6 it can be seen that there is no strong trend between the occurrence of semi-permanent zones of lee radar radial shear and surface wind direction. However, from Figure 3.5 it was observed that the mean position of these shear zones is aligned parallel to the mean surface wind direction, as measured at Mokohinau Island. There are two semi-permanent zones of radar radial shear which can be observed in the lee of Great Barrier Island. These can be seen to originate from Mt Tataweka, located at the northern end of the island, and Mt Hobson, located in the centre of the island (see Figure 3.8). It can be seen from Figure 3.1 that Great Barrier Island is situated approximately $18 \mathrm{~km}$ to the east of Little Barrier Island. Therefore in easterly surface flows the lee zones of radar radial shear originating from $\mathrm{Mt}$ Tataweka are blocked by Little Barrier Island, whereas in flows from the east to southeast radar radial shear zones originating from Mt Hobson are blocked.

Average surface wind speeds as measured at Mokohinau Island were also investigated (see Table 3.2). These varied between $9 \mathrm{~m} \mathrm{~s}^{-1}$ and $19 \mathrm{~m} \mathrm{~s}^{-1}$. However no significant trend between surface wind speed and the existence of zones of radar radial shear was observed.

From Table 3.2 it can be seen that the wind between the surface and $700 \mathrm{hPa}$, backed by angles between $39^{\circ}$ and $69^{\circ}$. This has the potential to produce high 
directional shear between the surface and $700 \mathrm{hPa}(\sim 3 \mathrm{~km})$. Further, it was observed that large scale motion of low-level precipitation was approximately in the direction of the mid-level $(700 \mathrm{hPa})$ flow, as observed in radar data. This has implications for the interaction between low-level precipitation and observed lee zones of radar radial shear in the Hauraki Gulf.

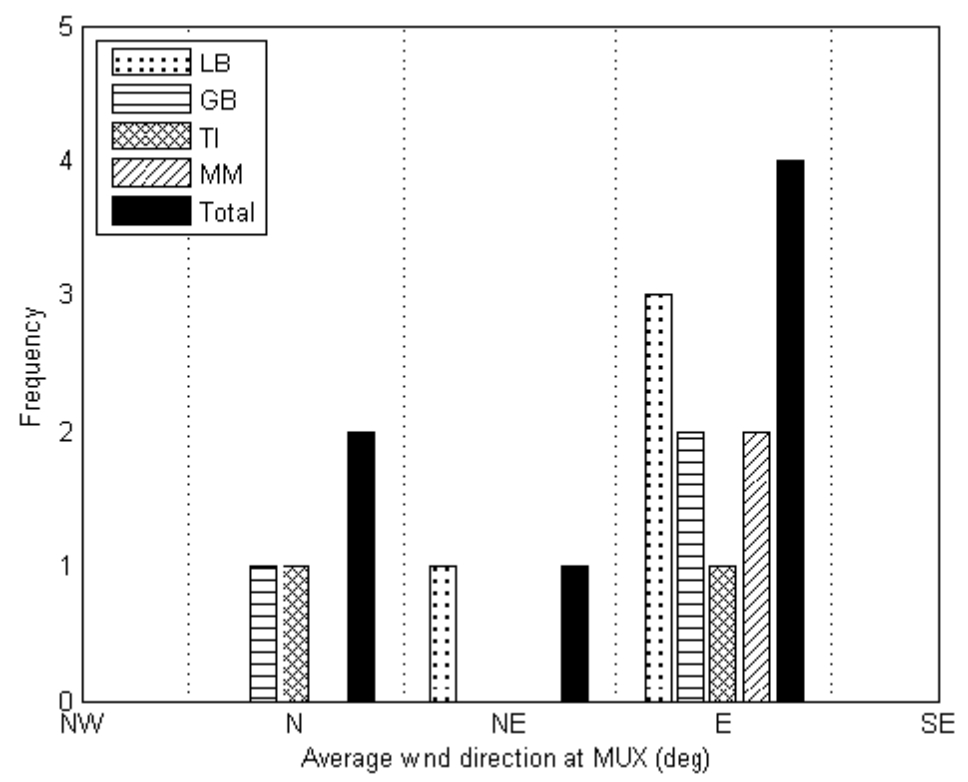

Figure 3.6: Diagram showing the frequency of zones of radar radial shear in the lee of Mt Moehau (MM) and Little Barrier (LB), Great Barrier (GB)and Taranga (TI) islands from wind directions observed at Mokohinau Island (MUX) during steady state heavy precipitation events. The total number of events investigated for each wind direction is indicated by the black bar. Note: wakes in the lee of multiple obstacles are often observed in a single event (Figure 3.5), therefore the total number of events for each wind direction represents the maximum number of observations at each location.

\section{Convective instability}

Convective instability of the environment was assessed using the stability indices CAPE, TQ and Total Totals. Total Totals and TQ indices provide a measure of stability from $850 \mathrm{hPa}$ to $500 \mathrm{hPa}$ and $700 \mathrm{hPa}$ respectively. However, CAPE provides a measure of deep instability, see Section 2.3.2. Section 2.3.2 
discusses the use of stability indices in New Zealand, concluding that the usefulness of stability indices is limited and is highly dependent on the synoptic conditions. Therefore careful consideration is needed when comparing stability indices. From Table 3.3 we can see that for events in which semi-permanent, lee zones of radar radial shear were observed, CAPE values range from 0 to $601 \mathrm{~J} \mathrm{~kg}^{-1}$, with the majority $<170 \mathrm{~J} \mathrm{~kg}^{-1}$, indicating weak convective instability. In contrast to this, Total Totals displayed values ranging from $36.0^{\circ} \mathrm{C}$ to $50.5^{\circ} \mathrm{C}$ indicating weak to moderate convective instability. The TQ index ranged between $12.4^{\circ} \mathrm{C}$ and $20.2{ }^{\circ} \mathrm{C}$, indicating moderate to high convective instability below $700 \mathrm{hPa}$.

Due to the highly variable nature of air-mass characteristics among the events investigated in this study, it is difficult to compare stability indices between events. Total Totals was considered to be most representative of stability in all the situations, because of its suitability in a wide range of applicable atmospheric conditions, see Section 2.3.2. Therefore Total Totals was used to compare stability across all the events studied.

Values of Total Totals indicated weak to moderate convective instability $\left(\mathrm{TT}>45^{\circ} \mathrm{C}\right.$ ) for the majority of the events investigated, with the exception of Case 1, Event 1 and Case 3, Event 1. Tephigrams for Case 3, Event 1 showed low-topped instability capped at $700 \mathrm{hPa}$; therefore the TQ index is considered a better indicator of stability. In this instance $\mathrm{TQ}=16^{\circ} \mathrm{C}$ indicating an unstable atmosphere at between $850 \mathrm{hPa}$ and $700 \mathrm{hPa}$. In Case 1, Event 1 there was no capping inversion. However radar imagery for this period showed broad regions of light to moderate precipitation with small areas of embedded convection, $\mathrm{TQ}=13.8^{\circ} \mathrm{C}$, indicating weak convective instability between $850 \mathrm{hPa}$ and $700 \mathrm{hPa}$. This is less than what Henry (2000) suggested as an indicator of embedded convection, thus showing a need to calibrate this index for regions 
of precipitation. However this is beyond the scope of this study. With the exception of Case 1, Event 1, which shows weak convective instability, all cases exhibit moderate to high convective instability, depending on the index considered. Yet the occurrence of semi-permanent zones of radar radial shear in the lee of Mt Moehau and, Little Barrier, Great Barrier and Taranga islands, are not observed in all heavy precipitation events. Case 7 Event 1 and Case 8 Event 1, both show periods of moderate to high convective instability, yet no semi-permanent zones of radar radial shear are observed. For a summary of stability indices for steady state heavy precipitation events in the wider Auckland region see Table 3.3. All of the steady state, heavy precipitation cases studied displayed some degree of convective instability. This is consistent with the observations in $0.5^{\circ} \mathrm{PPI}$ imagery of radar reflectivity, where all of the cases investigated show regions of both convective (cellular areas of enhanced reflectivity $Z>40 \mathrm{dBZ}$ ) and stratiform precipitation. However there was no direct relationship observed between the existence of semi-permanent zones of radar radial shear measured over the Hauraki Gulf and convective instability.

\section{Low-level vertical wind shear}

As mentioned previously, winds between Mokohinau Island at the surface and $3 \mathrm{~km}$ as measured in the Whenuapai sounding were observed to back between $39^{\circ}$ and $69^{\circ}$, thus creating a highly directionally sheared environment between 0 and $3 \mathrm{~km}$. A summary of the shear vectors between 0 and $3 \mathrm{~km}$ for all of the heavy precipitation events investigated can be found in Table 3.2. The following section provides a discussion of the shearing speeds measured over the Hauraki Gulf. A wide range of $0-3 \mathrm{~km}$ shearing speeds were measured during the heavy precipitation events investigated, ranging between 11 and $25 \mathrm{~m} \mathrm{~s}^{-1}$ (over $3 \mathrm{~km}$ ). High shearing speeds, $\geq 22 \mathrm{~m} \mathrm{~s}^{-1}$ where observed in Case 7 Event 1 (0000Z, 01 May 2004) and Case 8 Event 1. It is interesting to note that during these events, lee zones of radar radial shear were not observed. During 
Case 7 Event 1 there was an anomalously low value of $13 \mathrm{~ms}^{-1}$ measured at 1200Z, 1 May 2004. However after 1200Z, 1 May 2004 the radar echoes over the Hauraki Gulf were patchy, resulting in no zones of lee radar radial shear being observed. $0-3 \mathrm{~km}$ shearing speeds ranged from 11 to $17 \mathrm{~m} \mathrm{~s}^{-1}$ for events where semi-permanent zones of radar radial shear were observed. A summary of the range of shearing speeds for which semi-permanent zones of radar radial shear were observed in the lee of Little Barrier, Great Barrier, Taranga islands and Mt Moehau, is shown in Table 3.4. It is interesting to note that semi-permanent zones of radar radial shear in the lee of Taranga Island only occurred in events where weak vertical wind shear was recorded between Whenuapai $(3 \mathrm{~km})$ and Mokohinau Island.

\begin{tabular}{|c|l|l|}
\hline & \multicolumn{2}{|c|}{$0-3 \mathrm{~km}$ Wind shear } \\
\cline { 2 - 3 } & $\begin{array}{l}\text { Minimum Speed } \\
\left(\mathrm{m} \mathrm{s}^{-1}\right)\end{array}$ & $\begin{array}{l}\text { Maximum Speed } \\
\left(\mathrm{m} \mathrm{s}^{-1}\right)\end{array}$ \\
\hline Little Barrier Is & 11 & 17 \\
\hline Great Barrier Is & 11 & 17 \\
\hline Taranga Is & 11 & - \\
\hline Mt Moehau & 13 & 17 \\
\hline
\end{tabular}

Table 3.4: Table summarising the $0-3 \mathrm{~km}$ shearing speed between Mokohinau Island at the surface and Whenuapai at $3 \mathrm{~km}$ for events where semi-permanent lee zones of radar radial shear were observed

There appears to be a relationship between vertical wind shear, specifically between $0-3 \mathrm{~km}$, and the existence of semi-permanent zones of radar radial shear. Events where these shear zones were not observed showed relatively high values of $0-3 \mathrm{~km}$ shearing speeds, $>22 \mathrm{~m} \mathrm{~s}^{-1}$, while events for which zones of radar radial shear were observed, displayed lower $0-3 \mathrm{~km}$ shearing speeds, $\leq 17 \mathrm{~m} \mathrm{~s}^{-1}$. Despite the small number of heavy precipitation events investigated, these results show evidence that wind shear between 0 and $3 \mathrm{~km}$ may plays a role in the development of zones of radial shear over the Hauraki Gulf. However a larger sample set would be required to draw stronger links between 
wind shear and semi-permanent zones of radar radial shear observed in the lee of Little Barrier, Great Barrier and Taranga Islands and Mt Moehau.

The next section examines the radar characteristics of these lee zones of radar radial shear. These features show characteristics similar to those observed in mountain wakes, see Section 1.3.2. Much of the literature suggests that the dimensionless Froude number calculated from upper air soundings, upstream of the obstacle, can provide a useful tool for diagnosing the type and therefore characteristics of a wake which is expected to be observed in the lee of a barrier, see Section 1.3.2. The Froude number incorporates stability and upstream wind speed at elevations up to the height of the barrier, in addition to barrier height, see Section 1.3.2. In this study the only nearby upper air sounding available was located at Whenuapai Aerodrome, inland and to the northwest of Auckland city at an elevation of $30 \mathrm{~m}$ AMSL. For the heavy rain events investigated the average surface wind direction as measured at Mokohinau Island was from the northeast quadrant. This places Whenuapai airdrome downstream of the obstructing barriers. Additionally as Whenuapai is located inland, some increased frictional retardation of the low-level flow is expected, resulting from the passage over the land surface.

Wakes observed in the Hauraki Gulf originate from mountains and islands ranging in elevation from 419 to $894 \mathrm{~m}$, AMSL. Because of the low elevation of these obstacles and the relative position of the Whenuapai sounding, it was considered that the sounding at these levels was not representative of the conditions upstream of the barriers. Attempts were made to calculate Froude numbers from the Whenuapai soundings for the events investigated. However, it was found that in some cases the Brunt-Väisälä frequency was imaginary, thus indicating that the sounding was statically unstable at this level and therefore wakes could not form in the lee of barriers in the Hauraki Gulf. This contra- 
dicts observations from Mt Tamahunga radar data. Therefore soundings from Whenuapai were considered to be non-representative of stability at these levels during the events investigated. Further, it is expected that variables such as wind speed, stability and wind shear up to the mountain height are extremely important in the formation and modification of these wakes. However such an investigation was unable to be carried out in the current study.

\section{Summary: Environmental conditions}

Environmental conditions during steady state heavy precipitation events are summarised below, in terms of surface and mid-level winds, convective instability and vertical wind shear between 0 and $3 \mathrm{~km}$. Further, this summary includes the relationship between these characteristics and precipitation type and large scale motion, in addition to the occurrence of lee zones of radar radial shear observed in the Hauraki Gulf.

- Surface wind speed and direction appear to have very little correlation with the existence of lee zones of radar radial shear during the events investigated (note: wind direction varied between flows from the northeast quadrant). However these zones of radar radial shear are observed to be aligned parallel with the surface wind direction. In east and southeast flows the radar radial shear zones observed in the lee of Great Barrier Island are blocked by Little Barrier Island, modifying the zones of radar radial shear downstream of both Little Barrier and Great Barrier Islands.

- $700 \mathrm{hPa}$ wind speed and direction show little correlation with the existence of zones of observed lee radar radial shear. Winds between the surface and $700 \mathrm{hPa}$ were found to back by $39^{\circ}$ to $69^{\circ}$, creating high levels of directional shear at low levels in the atmosphere. However it was noted that low-level precipitation was observed to move in the direction of the mid-level winds. 
- Moderate to weak convective instability was observed during events investigated, depending on the stability index used to measure convective instability. This was consistent with observations of low-level precipitation type, with all steady state heavy precipitation events characterised by regions of both stratiform and convective precipitation. However, no direct relationship between convective instability and the existence of semi-permanent, lee zones of radar radial shear was observed.

- A relationship between 0-3 km wind shear recorded between Mokohinau Island at the surface and Whenuapai at $3 \mathrm{~km}$ and existence of lee zones of radar radial shear, was observed in this study. In events with 0$3 \mathrm{~km}$ shearing speeds $\geq 22 \mathrm{~m} \mathrm{~s}^{-1}$, semi-permanent lee zones of radar radial shear were not observed. Further, zones of radar radial shear were observed in the lee of Taranga Island when 0-3 km shearing speeds were relatively weak. However, as a result of the small sample set and the limitations imposed from the resolution of the radar data used in this study, a rigorous investigation into the affect of wind shear on the mesoscale structure of these zones of semi-permanent radar radial shear could not be made, nor could the statistical significance of the limits in shearing speed mentioned above, be determined. 


\subsubsection{Lee zones of radar radial shear}

As mentioned in the previous section, semi-permanent zones of radar radial shear were observed in the lee of Great Barrier, Little Barrier and Taranga Islands, in addition to Mt Moehau, located at the northern tip of the Coromandel Peninsula. Each of these obstructing barriers are characterised by regions of complex topography see Figures 3.7-3.10. This section presents a summary of the spatial and temporal characteristics of these zones of radar radial shear. Further, the relationship between these features and surface wind speed, stability, and low-level vertical wind shear is investigated.

Figure 3.7: Contour map showing Little Barrier Island. Little Barrier Island is characterised by a single major peak rising to $722 \mathrm{~m}$ AMSL with a smaller peak to the south rising to $648 \mathrm{~m}$ AMSL.

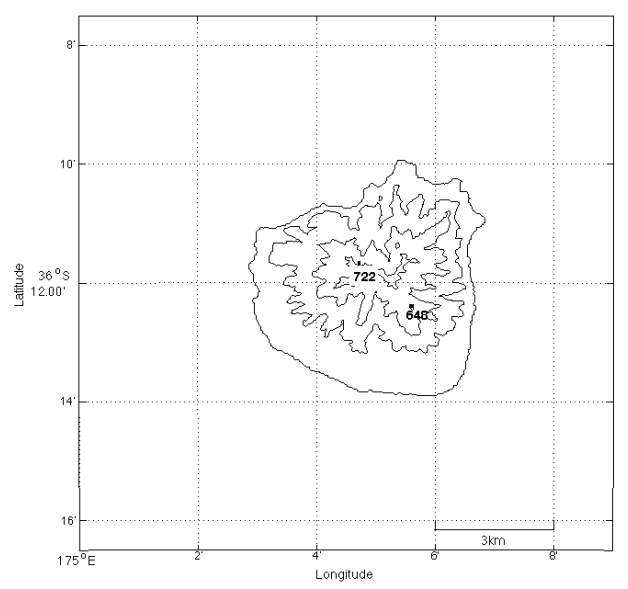

Figure 3.8: Contour map showing Great Barrier Island. Great Barrier Island is a region of complex terrain, with two distinct peaks, Mt Tataweka (525 m AMSL) located at the northern end of the island and Mt Hobson (627 m AMSL) located in the centre of the island.

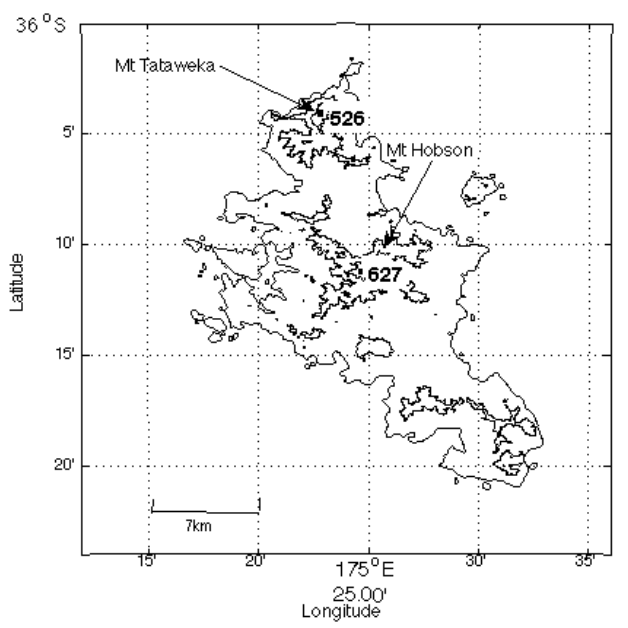


Figure 3.9: Contour map showing Mt Moehau, located at the northern tip of the Coromandel Peninsula along the Moehau range. This region is characterised by rugged terrain. This area consists of a number of peaks rising to a maximum of $894 \mathrm{~m}$ AMSL at Mt Moehau $\sim 100 \mathrm{~m}$ higher than its surroundings.

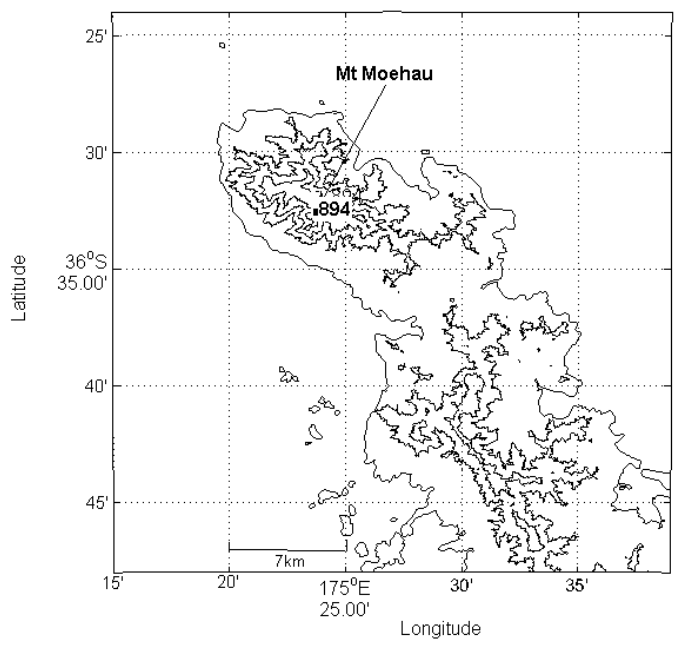

Figure 3.10: Contour map showing Taranga Island. Taranga Island is a long, thin, volcanic cone with peaks rising to $417 \mathrm{~m}$ AMSL along an east/west oriented ridge running the length of the island.

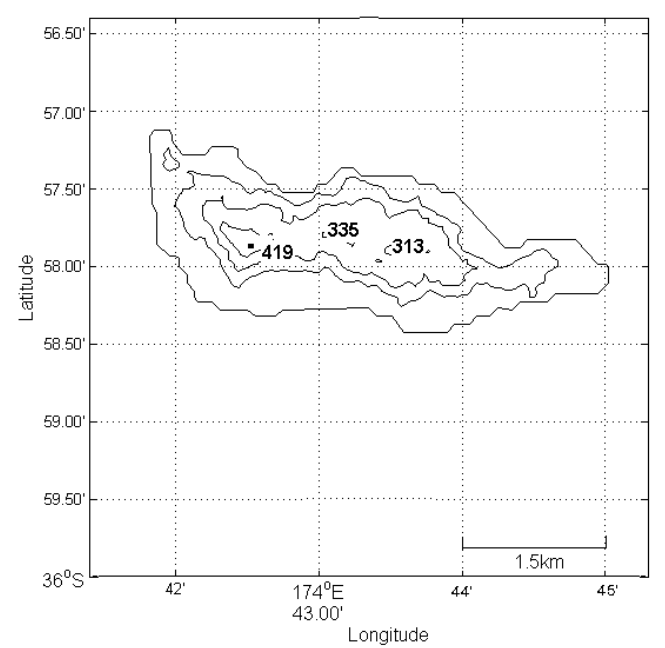

\section{Radar characteristics and structure of lee wakes}

Zones of radar radial shear observed in the lee of Mt Moehau, Great Barrier, Little Barrier and Taranga islands are best seen in low level fixed elevation scans of radial gradients in radar radial velocity. These features are observed as pairs of shear zones one positive and one negative located in the lee of each barrier, orientated parallel to the low-level flow. However, these are also observed in low level PPI images of radar radial velocity, as low velocity zones 
embedded in the large scale flow. An example of this can be seen in Figure 3.11. These characteristics are consistent with radar observations of mountain wakes in the lee of Lantau Island, Hong Kong (Shun et al. 2003), thus suggesting the existence of mountain wakes in the lee of each obstacle in the Hauraki Gulf, with the boundaries of each wake defined by the zones of radar radial shear. These zones of radar radial shear are hereafter referred to as mountain wakes.

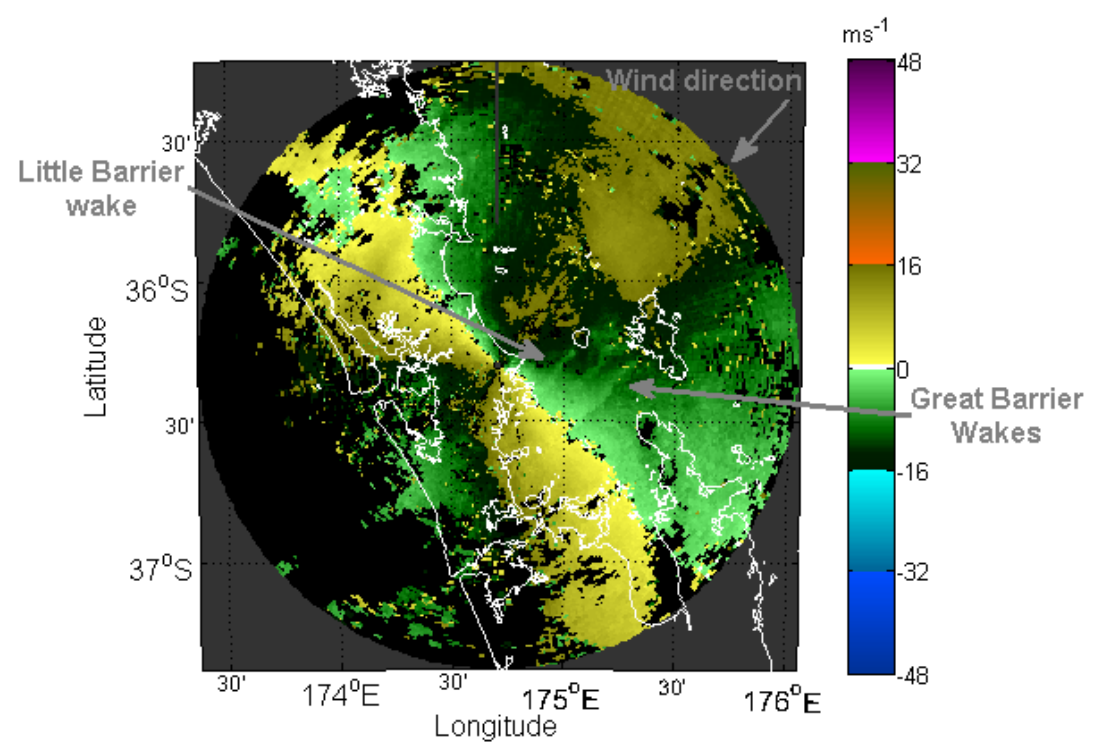

Figure 3.11: Diagram showing the appearance of mountain wakes in $0.5^{\circ} \mathrm{PPI}$ images of radar radial velocity, 2022Z 28 March 2007. Wakes can be seen downstream of Great Barrier and Little Barrier islands as indicated

The spatial and temporal characteristics of mountain wakes observed in the Hauraki Gulf were investigated using radar data obtained from the Mt Tamahunga radar. These wakes appeared as extremely fine scale features which were difficult to observe in conventional PPI images and RHI profiles. Figure 3.11 and Figure 3.12 show an example of a well defined deep wake observed in the lee of Little Barrier Island. As a result of the fine scale structure of these features, the estimates of the spatial characteristics of these features are only approximate. To obtain more accurate estimates of the spatial characteristics of these wakes, high resolution numerical modeling or higher resolution radar 
data would be required. This is beyond the scope of this study.

The vertical extent of each wake was estimated by the depth of the low velocity zone as observed in RHI profiles, see Section 2.3.3. The horizontal extent of each wake was estimated from the length and width of the zones of radar radial shear which define the boundaries of each wake, as observed in images of radial gradients in radar radial velocity. This was due to the low velocity zone being hard to distinguish in PPI images of radar radial velocity, especially through the zero line. For each of the obstacles in the Hauraki Gulf (Mt Moehau, Great Barrier, Little Barrier and Taranga islands) for which mountain wakes were observed, $0.5^{\circ} \mathrm{PPI}$ images of radar radial velocity were inspected and periods for which a low speed zone occurred in the lee of each barrier were identified, see Appendix A. Data from the Mt Tamahanga radar were examined for each of the periods identified in Appendix A to determine the spatial characteristics of each wake, identifying periods where a well defined deep wake was observed. For the purposes of this study deep mountain wakes were defined to be periods where the vertical extent of the low velocity zone was observed to exceed twice the height of the barrier, $\pm 0.4 \mathrm{~km}$. Great Barrier Island is the furthest of the obstacles from the radar located at a range of $\sim 65 \mathrm{~km}$. Taking into account that the beams spread out with distance from the radar and that mountain wakes are observed to a maximum height of $2.5 \mathrm{~km}$, the error in the estimation of the depth of the wake is $\sim 0.5$ times the maximum beam separation at a range of $65 \mathrm{~km}$ in a standard atmosphere, equating to $0.4 \mathrm{~km}$.

Time-series plots of RHI profiles, showing the vertical extent of mountain wakes, were constructed for the periods identified in Appendix A. These profiles were used to examine changes in the vertical extent of the observed wakes with time and to identify periods of deep mountain wakes. Examples of interest are presented below. 

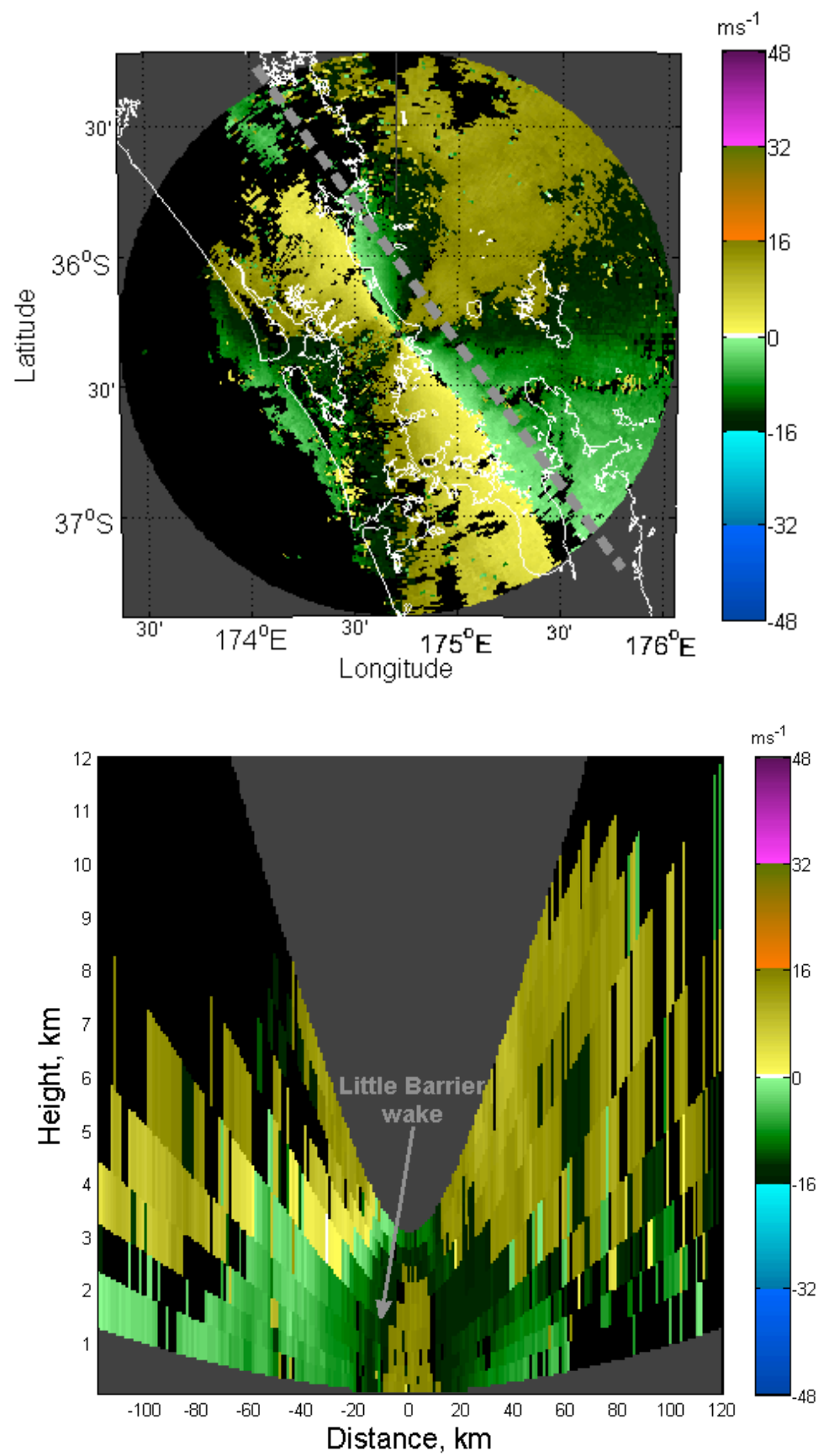

Figure 3.12: RHI profile showing the depth of the Little Barrier Island wake indicated by the grey arrow (bottom image). The position of the RHI profile is indicated by the grey line in the top image. Case 3, Event 2, $0.5^{\circ}$ PPI $2315 \mathrm{Z}$ 28 March 2007 


\subsubsection{Mountain wakes in the Hauraki Gulf}

As mentioned previously, wake like structures were observed in the lee of $\mathrm{Mt}$ Moehau, and Little Barrier, Great Barrier and Taranga islands in the Hauraki Gulf. These wakes are all characterised by a low velocity zone embedded in the large scale flow, situated in the lee of each of the obstacles. These features are observed to extend perpendicular to the zero line in PPI images of radar radial velocity, indicating that the wake is aligned parallel to the low-level flow. The wake boundaries are defined by zones of strong radar radial shear, as observed in images of gradients in radar radial velocity. No reverse flow was observed within the wakes observed in the Hauraki Gulf.

\section{Little Barrier Island wake}

Little Barrier's wake was the most persistent of the mountain wakes observed in the study area. This was observed to be semi-permanent in four of the five steady state events in which wakes were observed, see Table 3.3.

Inspection of $0.5^{\circ} \mathrm{PPI}$ images of radar radial velocity showed that the Little Barrier wake was measured at varying strengths. Of the events investigated, Case 1 Event 1, Case 2 Event 1, Case 3 Event 1 and Case 3 Event 2, showed evidence of a semi-permanent wake in the lee of Little Barrier Island, see Table A.3. An example of the appearance of the Little Barrier wake is shown in Figure 3.13.

Table A.3 summarises the appearance of the Little Barrier wake in the Mt Tamahunga radar imagery. It was observed that:-

- The Little Barrier wake extended 28 to $30 \mathrm{~km}$ in the lee of the island, parallel to the surface wind flow. This wake dissipated at the coast. 

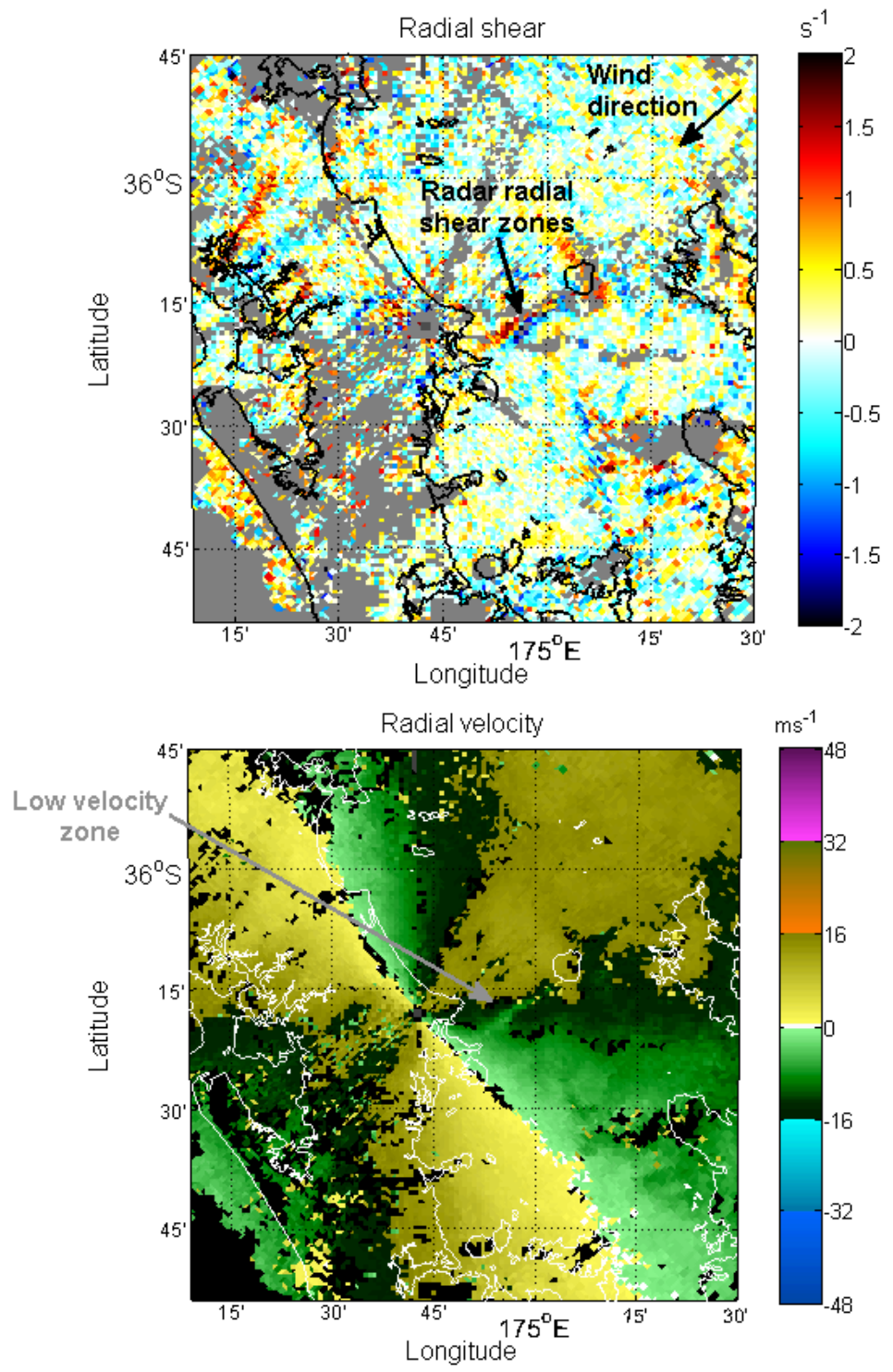

Figure 3.13: Figure showing the characteristics of the Little Barrier Island wake as observed by the Mt Tamahunga radar. Case 3 Event 2: $0.5^{\circ} \mathrm{PPI}$ image of radar radial velocity (bottom) and radar radial shear (top), 2315Z 28 March 2007 
- The width of the wake varied between 4 to $10 \mathrm{~km}$ and spread out slightly with distance from Little Barrier Island.

- The depth of the Little Barrier wake varied with time, from being almost unrecognisable, appearing in the first one or two beams, to reaching a maximum at approximately $2.5 \pm 0.4 \mathrm{~km}$ AMSL in Case 3, Event 2. For Little Barrier Island a deep wake was defined to be that for which the low velocity zone was observed to extend $>1.5 \pm 0.4 \mathrm{~km}$ in the vertical. Figure 3.14 shows an example of the appearance of a deep wake in the lee of Little Barrier Island and its evolution with time as observed in RHI profiles.
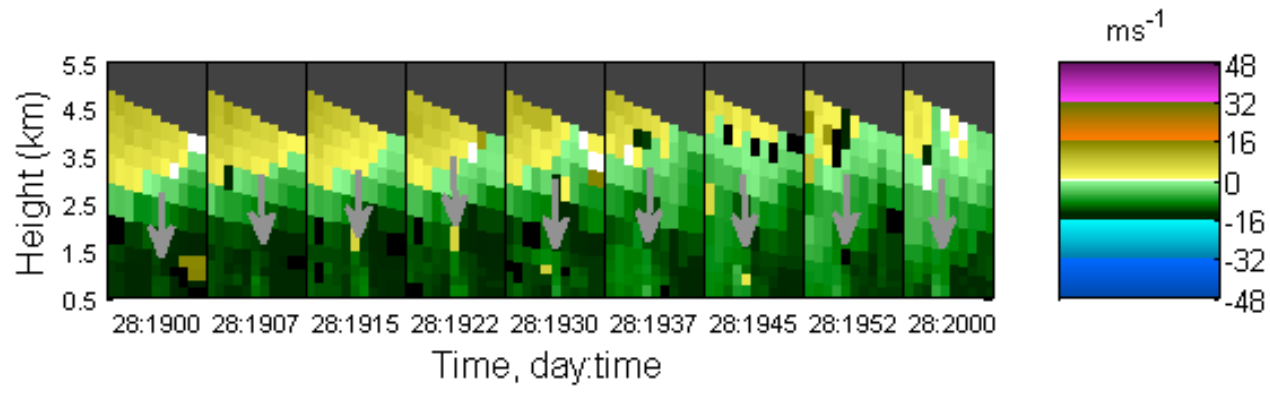

Figure 3.14: Diagram showing the RHI time-series for the transect indicated in Figure 3.12 (top image). The position of the Little Barrier Island wake is indicated by the grey arrows, Case 3, Event 2, RHI profiles 1900Z to 1937Z, 28 March 2007

Three distinct periods of a deep wake in the lee of Little Barrier Island were observed, all of which occurred in Case 3 Event 2. These periods ranged in length from 30 to 45 minutes. During Case 3 Event 2 the average surface wind direction as measured at Mokohinau Island was from the east, with an average wind speed $=12 \mathrm{~m} \mathrm{~s}^{-1}$. Table 3.2 shows $0-3 \mathrm{~km}$ shearing speeds measured between Mokohinau Island and Whenuapai, of $11 \mathrm{~m} \mathrm{~s}^{-1}$ to $13 \mathrm{~m} \mathrm{~s}^{-1}$ were recorded during this event. The event was also characterised by weak to moderate convective instability measured by the Whenuapai balloon sounding, depending 
on the stability index investigated. Total-Totals ranged between $38.9^{\circ} \mathrm{C}$ and $45^{\circ} \mathrm{C}$, indicating weak convective instability. At 1200Z 28 March 2007 the lowest $0-3 \mathrm{~km}$ shearing speed $\left(11 \mathrm{~m} \mathrm{~s}^{-1}\right)$ among events for which wakes were observed in the Hauraki Gulf was recorded.

\section{Great Barrier Island wake}

Two wakes were often observed in the lee of Great Barrier Island, originating from two distinct peaks on the island, see Figure 3.8. These were observed to be reasonably persistent throughout the events studied, but were often observed to be weak and intermittent in $0.5^{\circ} \mathrm{PPI}$ images of radar radial velocity. Wakes in the lee of Great Barrier Island were observed to be semi-permanent in three of the five events, see Table 3.3.

Investigation showed that for two of the cases in Table A.2 wakes could not be resolved in RHI profiles, due to noisy data and poorly defined wake boundaries. The period from 0100Z to $0200 \mathrm{Z}$ on the 15 July 2007 was characterised by noisy radial velocity radar volumes over the Hauraki Gulf. During the period from $1222 \mathrm{Z}$ to $1252 \mathrm{Z}, 28$ March 2007 wakes in the lee of Great Barrier Island are weak; thus making it difficult to resolve the Great Barrier wake in RHI profiles.

The Great Barrier Island wake was the most complex of the wakes observed in the Hauraki Gulf. This is thought to result from the complex topography of Great Barrier Island. Two separate wakes are observed in the lee of Great Barrier and are thought to originate from Mt Tataweka and Mt Hobson, see Figure 3.8. The low velocity zone originating from Mt Tataweka is blocked by Little Barrier Island in easterly flows. When this wake is observed in $0.5^{\circ} \mathrm{PPI}$ images of radial velocity it is often observed to have poorly defined boundaries and therefore appears to be weak and intermittent. The wake originating from Mt Hobson in the center of the island is observed to have well defined 
boundaries and is therefore better resolved in radar radial velocity scans. The structure of this wake was often not observed directly in the lee of Great Barrier Island (65 km from the radar). This is possibly a consequence of the scan geometry of the radar. At these distances the $0.5^{\circ}$ radar beam is $\sim 1.3 \mathrm{~km}$ AMSL, and therefore is possibly over shooting the wake in this area. It is expected that the wake is continuous, extending to the peak of Mt Hobson. Figure 3.15 shows an example of a well defined wake in the lee of Great Barrier Island, as seen by the Mt Tamahunga radar. Due to the limitations mentioned above, the wake originating from Mt Tataweka located at the northern end of the island, was not investigated further.

Table A.2 summarises the radar characteristics of the Great Barrier Island wake. It was observed that

- The wake in the lee of Mt Hobson, Great Barrier Island, extended 38 to $57 \mathrm{~km}$ in the lee of the island, oriented parallel to the surface wind flow. The southern shear line was much stronger than the northern shear line. This could be due to the irregularity of the topography of Great Barrier Island, see Figure 3.8.

- The width of the wake varied between 3 to $7 \mathrm{~km}$. An exception to this was the wake in Case 1 Event 2, which was $12 \mathrm{~km}$ wide. This is probably due to the different upstream wind direction which alters the geometry of the obstacle relative to the wind.

- The depth of the Great Barrier Island wake varied greatly with time reaching a maximum depth of $\sim 2 \pm 0.4 \mathrm{~km}$, in Case 3 Event 2 .

Deep wakes in the lee of Mt Hobson were defined to be wakes in which the low velocity zone was observed to exceed $1.3 \pm 0.4 \mathrm{~km}$ in height. Three periods were 

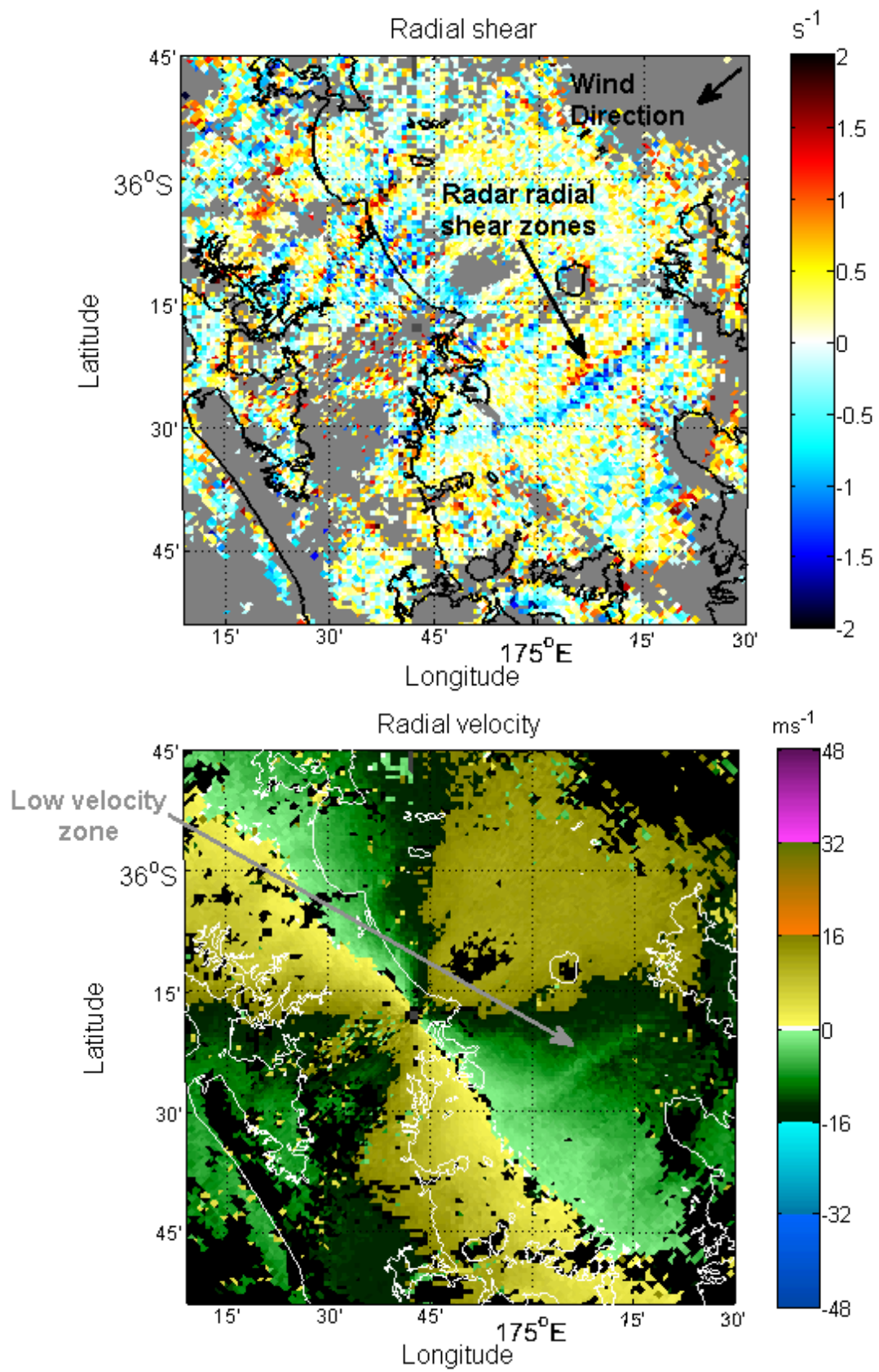

Figure 3.15: Figure showing the characteristics of the Great Barrier Island wake as observed by the Mt Tamahunga radar. Case 3 Event 2, $0.5^{\circ} \mathrm{PPI}$ image of radar radial velocity (bottom) and radar radial shear (top), 1737Z 28 March 2007 
identified where a deep wake was observed in RHI profiles, reaching a maximum altitude of $2 \pm 0.4 \mathrm{~km}$. These were observed to persist for time periods ranging from 22.5 minutes (three frames) to 52 minutes. An example of the appearance of a deep wake in the lee of Mt Hobson is shown in Figure 3.16. All of the periods for which deep wakes were observed occurred during Case 3 Event 2. As mentioned previously, during this event the average surface wind direction measured at Mokohinau Island was from the east, with an average wind speed of $12 \mathrm{~m} \mathrm{~s}^{-1}$. 0-3 km wind shearing speeds measured between Mokohinau Island at the surface and Whenuapai at $3 \mathrm{~km}$, were between $11 \mathrm{~m} \mathrm{~s}^{-1}$ and $13 \mathrm{~m} \mathrm{~s}^{-1}$. In addition, this event was characterised by weak to moderate convective instability depending on the stability index used, with Total-Totals ranging between $38.9^{\circ} \mathrm{C}$ and $45^{\circ} \mathrm{C}$. At $1200 \mathrm{Z} 28$ March 2007 the lowest $0-3 \mathrm{~km}$ shearing speed $\left(11 \mathrm{~m} \mathrm{~s}^{-1}\right)$ among events for which wakes were observed in the Hauraki Gulf was recorded.
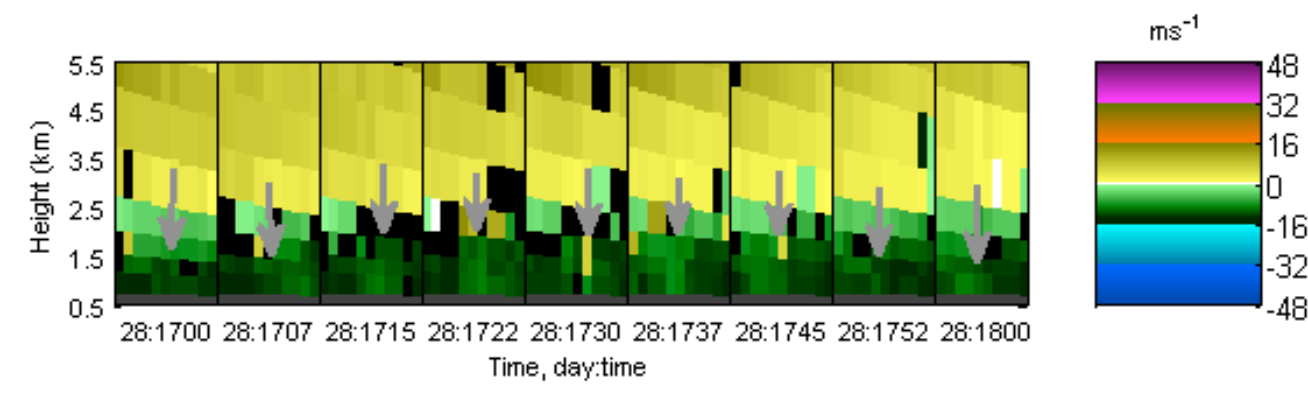

Figure 3.16: Diagram showing a time-series of the vertical extent of the Great Barrier Island wake, indicated by the grey arrow. Case 3 Event 2, RHI profiles $1700 Z$ to $1800 \mathrm{Z} 28$ March 2007

\section{Mt Moehau wake}

The Mt Moehau wake was the least persistent of the the mountain wakes observed in the wider Auckland region, see Table A.4. This wake was observed to be semi-permanent in two of the five cases for which semi-permanent wakes 
were observed, see Table 3.3. This wake proved to be difficult to locate in $0.5^{\circ}$ PPI images of radar radial velocity as it was often observed to have poorly defined wake boundaries. However a relatively well defined wake was observed during Case 2 Event 1, see Figure 3.17.

The Mt Moehau wake was not well defined in the RHI profiles, but appeared to be well defined in the $0.5^{\circ} \mathrm{PPI}$ images for the period of $0900 \mathrm{Z}$ to $1052 \mathrm{Z}$ on the 15 July 2007. During this period it was observed that the average width of the wake was $4 \mathrm{~km}$. However, it was observed to spread out with distance from the coast of the Coromandel Peninsula. The extent of this was hard to determine as the best examples of this wake were observed at the edge of a broad scale region of precipitation echoes. The length of this wake was variable; the wake was well defined out to $22 \mathrm{~km}$, but visible out to $40 \mathrm{~km}$. It was observed that the northern shear line was better defined and extended further than the southern shear. This is possibly due to the complexity and asymmetric nature of the topography around Mt Moehau.

For the period where the Mt Moehau wake was observed, the average surface wind direction as measured at Mokohinau Island was from the east, with an average wind speed $=19 \mathrm{~m} \mathrm{~s}^{-1}$. A $0-3 \mathrm{~km}$ shearing speed of $13 \mathrm{~m} \mathrm{~s}^{-1}$ and $17 \mathrm{~m} \mathrm{~s}^{-1}$ was recorded between Mokohinau Island at the surface and Whenuapai at $3 \mathrm{~km}$, at $0000 \mathrm{Z}$ and $1200 \mathrm{Z} 15$ July 2007 respectively. In addition, this period was characterised by moderate convective instability with Total Totals $\sim 50^{\circ} \mathrm{C}$, see Table 3.2 . 

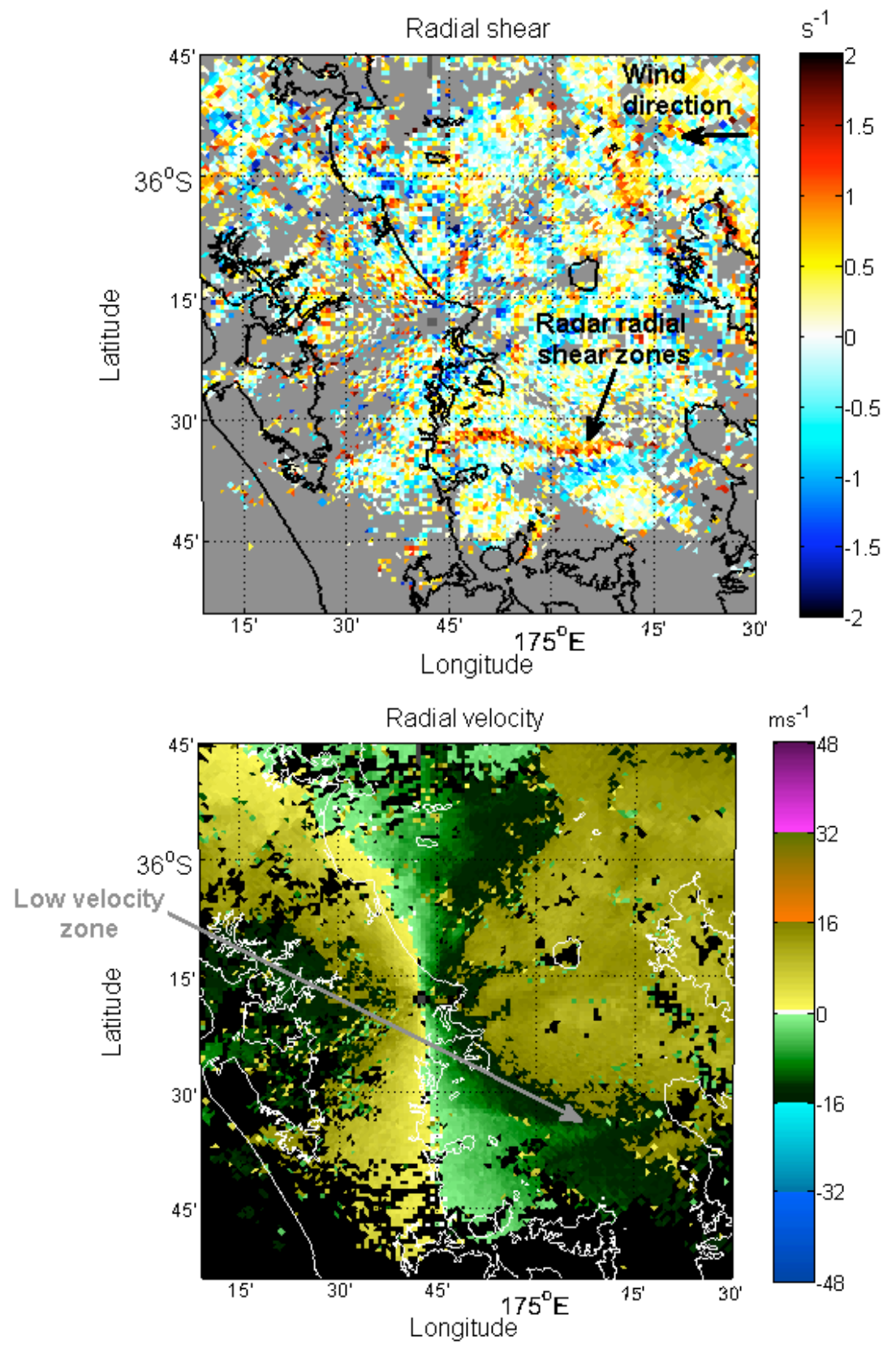

Figure 3.17: Figure showing the characteristics of the Mt Moehau wake as observed by the Mt Tamahunga radar. Case 2, Event 1: $0.5^{\circ}$ PPI image of radar radial velocity (bottom) and radar radial shear (top), 0922Z 15 July 2007 


\section{Taranga Island wake}

Taranga Island is the lowest peak for which wakes were observed in the Hauraki Gulf. This wake was only observed during events when the low-level wind shear measured between Mokohinau Island and Whenuapai was low, $\sim 11 \mathrm{~m} \mathrm{~s}^{-1}$ over $3 \mathrm{~km}$.

Table A.1 summarises the radar characteristics of the Taranga Island wake. It was observed that

- The wake in the lee of Taranga Island extended distances between 18 and $22 \mathrm{~km}$ in the lee of the island, parallel to the surface wind flow. This wake dissipated 1 to $2 \mathrm{~km}$ inland from the coast.

- The width of this wake varied from 4 to $6 \mathrm{~km}$.

- The Taranga Island wake was not well defined in the RHI profiles, however in low-level PPI images of radial velocity, it appears in the first two beams $\left(0.5^{\circ}\right.$ and $\left.0.9^{\circ}\right)$ therefore has a height of up to $1.1 \pm 0.4 \mathrm{~km}$.

For Taranga Island a deep wake was defined as a wake for which the low velocity zone was observed to extend greater that $0.7 \pm 0.4 \mathrm{~km}$ high. Taranga Island is located $\sim 40 \mathrm{~km}$ from the radar, therefore only a deep wake can be observed in $0.5^{\circ} \mathrm{PPI}$ images of radial velocity. By this definition there were two periods for which a deep wake was observed, see Table A.1. Figure 3.18 shows an example of the radar characteristics of the Taranga Island wake. 


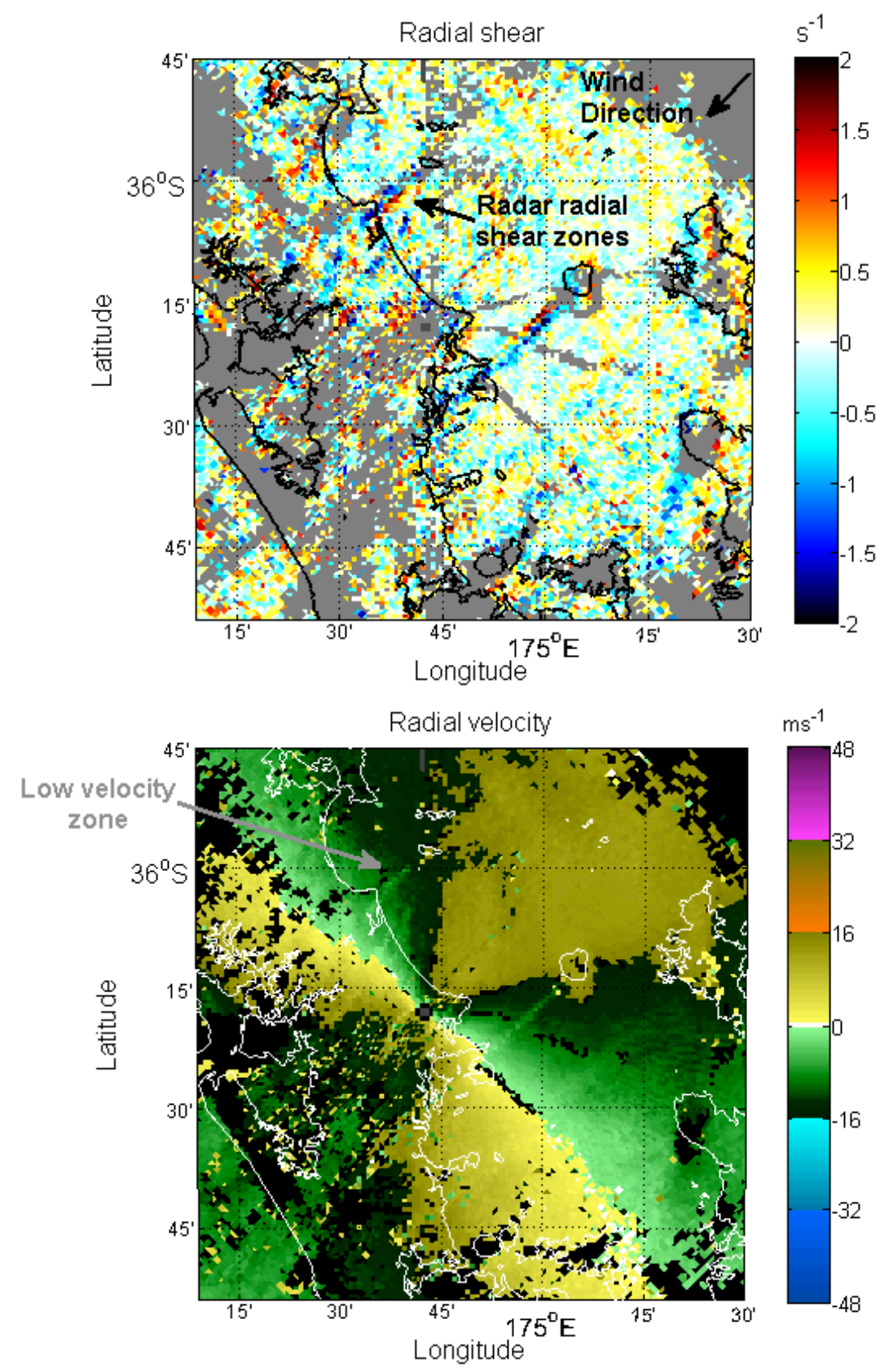

Figure 3.18: Figure showing the characteristics of the Taranga Island wake as observed by the Mt Tamahunga radar. Case 3, Event 2: $0.5^{\circ} \mathrm{PPI}$ image of radial velocity (bottom) and radial shear (top), 1907Z 28 March 2007 
Note: One minute wind speed and wind direction data at Mokohinau Island were used to investigate the relationship between surface wind speed and mountain wakes for all steady state events. No correlation was observed between surface wind speed fluctuations at Mokohinau Island and the existence or intensity of wakes in the lee of Mt Moehau and Great Barrier, Little Barrier and Taranga Islands. Data not shown.

\subsection{Convective/Stratiform Partitioning}

In this section the advantages of identifying enhanced precipitation is discuss and the spatial distribution of low-level enhanced precipitation based on Mt Tamahunga radar data is investigated. Enhancement is identified using the method presented by Steiner et al. (1995), see Section 2.3.4. Section 3.3.1 discusses the calibration of the Steiner et al. (1995) algorithm for the wider Auckland region, while Section 3.3.2 examines the frequency and spatial distribution of the low-level precipitation enhancement in the study area, as identified by the convective/stratiform partitioning described in Section 3.3.1.

Extreme precipitation events arising from the passage of fronts and depressions have the potential to produce high precipitation totals over a large area, causing widespread flooding throughout the region affected. As mentioned previously storms of this nature occurring in the study area often have a convective component to them which can produce localised, extremely high intensity precipitation. The spatial and temporal characteristics of such convective components are observed to vary at a greater spatial and temporal frequency than the larger scale precipitation features, such as broad areas of stratiform precipitation (Larsen and Gray 2003).

Due to the highly variable nature and extremely high precipitation totals that 
convective storms can produce, it can be useful to consider separately, areas of convective and stratiform precipitation. This is often referred to as convective/stratiform partitioning. Identifying the convective and stratiform components of a precipitation field and tracking these two components separately, has been shown to increase the accuracy of short term nowcasts (Wilson et al. 1998). In addition, it can be useful to consider separately, convective components for high accuracy calculations of rainfall accumulation and statistical analysis (Collier 1989). There are many methods to identify convective precipitation based on radar data. These are based mainly on convective thresholds and/or background-exceeding techniques (Montopoli et al. 2006, Llasat and Rigo 2004, Biggerstaff and Listemaa 2000, Johnson et al. 1998, Steiner et al. 1995, Demott et al. 1995, Dixon and Wiener 1993, Collier 1989, techniques from late 80 s to present). These methods can be split into two groups; those which are based in two dimensions (Montopoli et al. 2006, Llasat and Rigo 2004, Steiner et al. 1995), and those which consider the full 3-dimensional radar volumes (Biggerstaff and Listemaa 2000, Johnson et al. 1998, Demott et al. 1995, Dixon and Wiener 1993). For the purposes of this study, the method employed by Steiner et al. (1995) was chosen to investigate the spatial distribution of the low-level precipitation field and identify low-level enhancement and convective precipitation during the heavy precipitation events.

The method proposed by Steiner et al. (1995) was chosen for its simplicity and computational speed (Llasat and Rigo 2004). This algorithm was originally developed to use reflectivity data formatted in CAPPI levels, thus investigating the reflectivity field at a constant altitude. The level at which the partitioning is applied ('working level') is chosen in order to minimize bright band contamination (Steiner et al. 1995). This method has previously been successfully applied to low-level fixed elevation scans, (Llasat and Rigo 2004). Section 2.3.4 provides a summary of the classification criteria used by Steiner 
et al. (1995) to identify convective precipitation echoes.

This method is prone to some misclassification. Biggerstaff and Listemaa (2000) found that misclassification may occur at the leading edge of squall lines and around the edges of isolated convective precipitation. In these regions precipitation is likely to have formed in the convective updraft, therefore should be classified as convective. Misclassification may also occur in the trailing anvil regions of squall lines where local peaks are sometimes misclassified as convective, appearing as areas of embedded convection. These regions have a random distribution and their position is unpredictable. In regions of isolated convection, newly developing and dying cells may also be misclassified as stratiform precipitation. Convective regions identified by this method may include one or more convective cores, representing individual cells or multi-cellular convective structures (Steiner et al. 1995).

Further, care needs to be taken when choosing an appropriate 'working level' to perform partitioning in order to minimised bright band contamination. The radar 'bright band' is a region of increased reflectivity peaking 100-400 m below the $0{ }^{\circ} \mathrm{C}$ isotherm (Battan 1973), see Section 2.1.3. This can cause precipitation echoes affected by bright band contamination to be misclassified as convective. However the radar bright band is a distinct feature of stratiform precipitation as measured by weather radar (see Section 2.1.3), therefore should be classified as stratiform. It has been found that the freezing level varies considerably with both season and location. Steiner et al. (1995) noted that the freezing level in the tropics is observed at approximately $5 \mathrm{~km}$ whereas in the mid-latitudes the freezing level is much more variable. Further, significant evaporation may occur at low-levels in the atmosphere. There has been some effort to model the average horizontal profile of convective cells. It was found that in the midlatitudes the distribution of rain rate in convective cells observed by radar 
decayed as a Gaussian function or a combination of an exponential function and Gaussian function (Montopoli et al. 2006, and references within). In the tropics, on average, the rain rate decreased exponentially from the peak (von Hardenberg et al. 2003). Due to these variations, in order to minimize bright band contamination and therefore misclassification of the radar observed precipitation field, there is a need to consider this 'working level' carefully, and to calibrate the intensity and peakness criteria (see Section 2.3.4) for the location of interest.

\subsubsection{Convective/Stratiform calibration}

Case 3, 28 to 30 March 2007 was used as a calibration data set for criteria used by Steiner et al. (1995) to identify regions of convection in the radar reflectivity field. This data set was chosen as it is typical of the cases studied. PPI images of reflectivity showed broad scale regions of stratiform precipitation with areas of embedded convection. In addition, a prefrontal convective line passed over the region near the end of this event. The Steiner et al. (1995) algorithm was applied to the $2 \mathrm{~km}$ CAPPI level in its original form (see Section 2.3.4). The $2 \mathrm{~km}$ CAPPI level was chosen as the 'working level' to minimize bright band contamination. Similar to the results of Biggerstaff and Listemaa (2000) it was found in this study that this algorithm was prone to some misclassification. Misclassification of precipitation echoes in the Mt Tamahunga reflectivity data were observed:-

1. Around the edges of the prefrontal convective line where precipitation was likely to be associated with the updraft/downdraft regions of the convective cells and therefore should be classified as convective (see Figure 3.19).

2. At local peaks in regions of stratiform precipitation. These appear falsely as areas of embedded convection. This occurs when $\Delta \mathrm{Z}$ is too low 
for reflectivities representing heavy stratiform precipitation (30-55 dBZ). These regions were noted to have small spatial extents, often only affecting one or two adjacent points, with no predictable pattern (see Figure 3.19).

3. Near the edges of stratiform precipitation at discontinuities in the CAPPI level, see Figure 3.19. This is a difficulty inherent in the production of CAPPI levels and requires horizontal smoothing to fix. Smoothing algorithms are often utilised and provide a good general overview of the reflectivity field. However these can cause misrepresentation of the reflectivity field. Smoothing was not attempted in this study.

The misclassification of precipitation echoes measured by the Mt Tamahunga radar mentioned above, suggests a need for the algorithm presented by Steiner et al. (1995) to be calibrated for the wider Auckland region. Errors (1) and (2), defined above, show the need for the peakness and intensity criteria suggested by Steiner et al. (1995) to be investigated further. Further, misclassification (3) showed the need for either, horizontal smoothing of the CAPPI levels or the method to be applied to the measurement format (polar coordinates), ie to a low level fixed elevation scan.

The accuracy of the peakness criterion was investigated by applying the Steiner et al. (1995) partitioning algorithm to the $0.5^{\circ}$ fixed elevation scan. Investigation by Biggerstaff and Listemaa (2000) showed that the intensity criterion did not substantially affect the result of the partitioning, unless it was set too low. This had the effect of increasing the amount of bright band contamination and misclassification of local peaks in regions of stratiform precipitation. As a result only the peakness and convective radius tests were examined in this calibration, (Biggerstaff and Listemaa 2000). However, it was noted that 

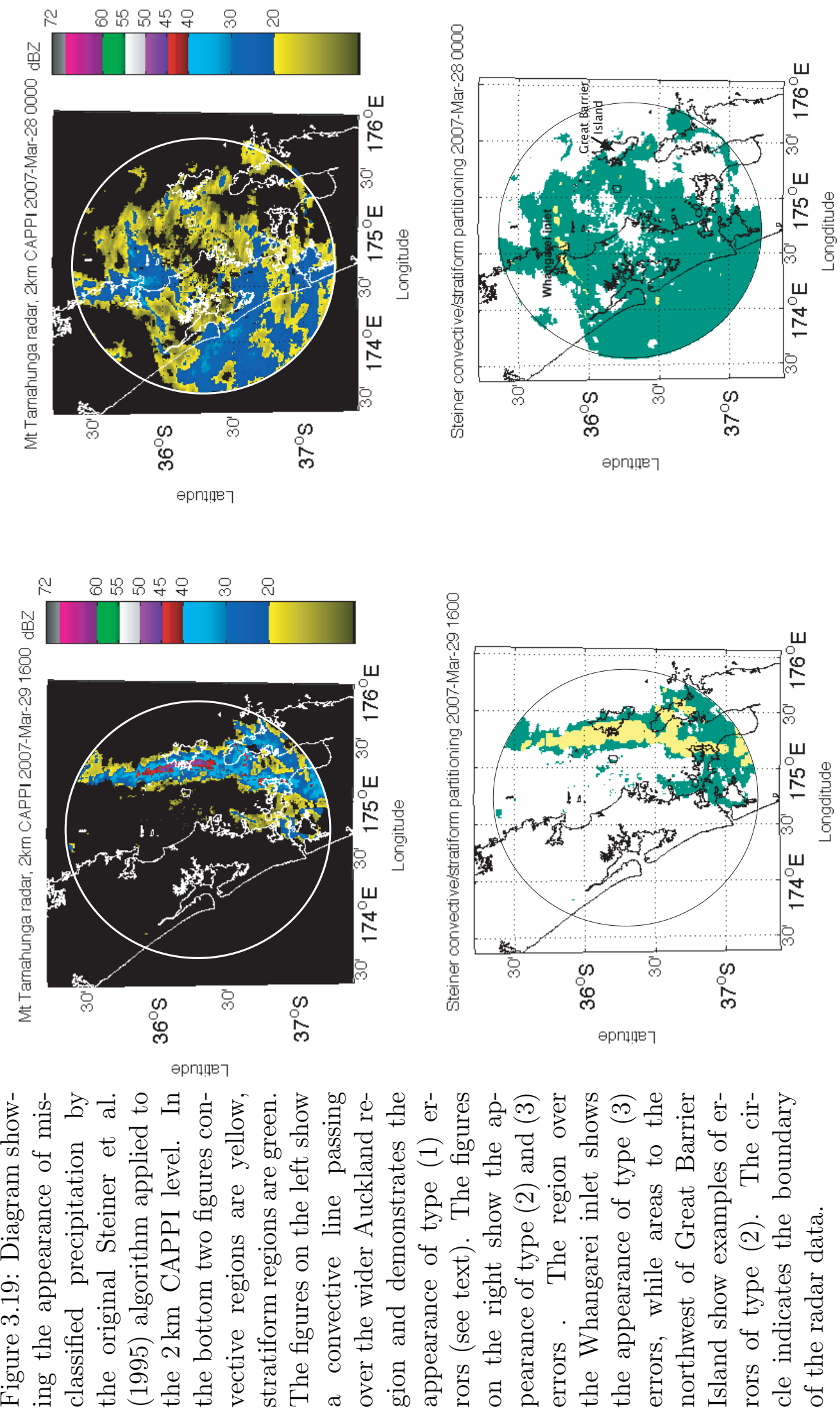
in New Zealand echoes reaching $50 \mathrm{dBZ}$ are considered to be convective (J. Crouch, MetService, personal communication, November 2008). Therefore the intensity criterion was set to $50 \mathrm{dBZ}$. This criterion was not used in the classification but was added in once the calibration was complete. It was found that when areas identified as convective precipitation were compared to the reflectivity field, the horizontal extent of embedded convection was overestimated in the case where the convective radius was set to 'large', as defined in Figure 2.4. As a result the convective radius was set to medium as defined by Steiner et al. (1995) for all 'peakness' tests.

It was found that misclassification was minimised if the peakness criterion was set to,

$$
\Delta Z= \begin{cases}10 & , Z_{b g}<0 \\ 10-\frac{Z_{b g}^{2}}{250} & , 0 \geq Z_{b g}<50 \\ 0 & , Z_{b g} \geq 50\end{cases}
$$

where $\Delta Z$ is the decibel $(\mathrm{dB})$ difference between the point being considered and the background and $Z_{b g}$ is the background reflectivity (dBZ).

In addition, the peakness criterion was found to misclassify local peaks in regions of stratiform precipitation as convection. Peakness criteria were tested where $\Delta \mathrm{Z}$ was increased for reflectivities representing heavy stratiform precipitation (30-55 dBZ). However, it was found that when the results of these partitioning tests were compared with the reflectivity field, the edges of strong convection became misclassified as stratiform precipitation. It was noted that misclassification due to local peaks in regions of stratiform precipitation often affected only one point. As a result an extra criterion was added, which limited the size of the convective regions identified by the peakness test to a region 
consisting of at least two adjacent points. No attempt was made in this study to link the vertical structure of the reflectivity field with areas identified as convective by this method.

It was considered that the regions identified as convective by this method were both convective cells and low-level enhanced precipitation, due to low beam height when at close range to the radar. Low-level enhancement occurs in regions of enhanced vertical motion, resulting from zones of horizontal convergence where the low-level flow interacts with orographic features such hills and coastlines. Further, precipitation may be enhanced at low levels in the vicinity of topographic features by the seeder feeder effect. These are thought to be the dominant mechanisms for low-level precipitation enhancement during heavy precipitation events investigated in the wider Auckland region, see Section 1.3.2. In addition, vertical motion can be enhanced in the vicinity of mountain wakes, see Section 1.3.2. Under favorable conditions these areas of low-level enhancement have the potential to develop into convective cells. As a result regions identified as 'convective' by the partitioning algorithm developed above, are hereafter referred to as regions of low-level enhancement to include areas of both orographic enhancement and convection for the purposes of this study.

\subsubsection{Spatial distribution of low level enhancement}

To investigate the spatial distribution of low-level precipitation enhancement, frequency plots of enhancement were created from individual time steps of partitioned radar data. These were created for each of the steady state events, to investigate the spatial distribution of mechanical enhancement on a mesoscale. Examples of interest are presented below. 
It was noted that a distinct pattern in the spatial distribution of enhancement is not always observed. This may result from differing atmospheric conditions and the varying length of the events studied. Despite this, there are some regions of enhancement worth considering. Regions of enhancement are represented by local maxima in the spatial distribution of frequency of low-level enhancement. Regions of enhancement are observed as follows:

- At the centre of the radar scan area, see Figures 3.20, 3.21 and 3.22.
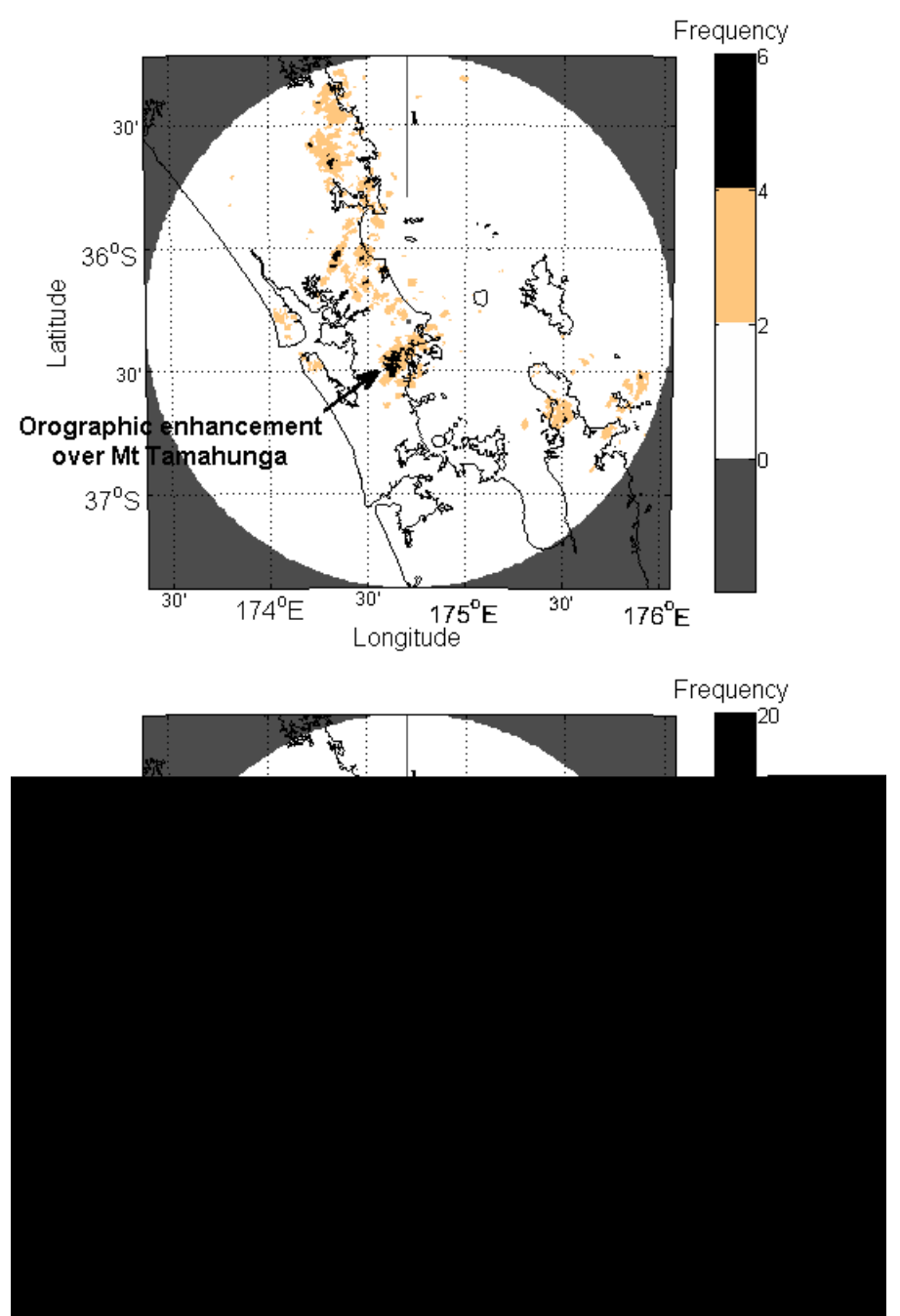

Figure 3.20: Diagrams showing the spatial distribution and frequency of lowlevel enhancement. Case 1, Event 1, 1700Z, 13 April 2008 to 1900Z, 13 April 2008 (top) and Case 8, Event 1, $1000 \mathrm{Z}$ to 1800Z, 28 May 2001 (bottom). 
- In Case 1, Event 1 and Case 8, Event 1 and Case 3 Event 2, show an enhancement maximum over the Coromandel peninsula, see Figure 3.20 and Figure 3.22.
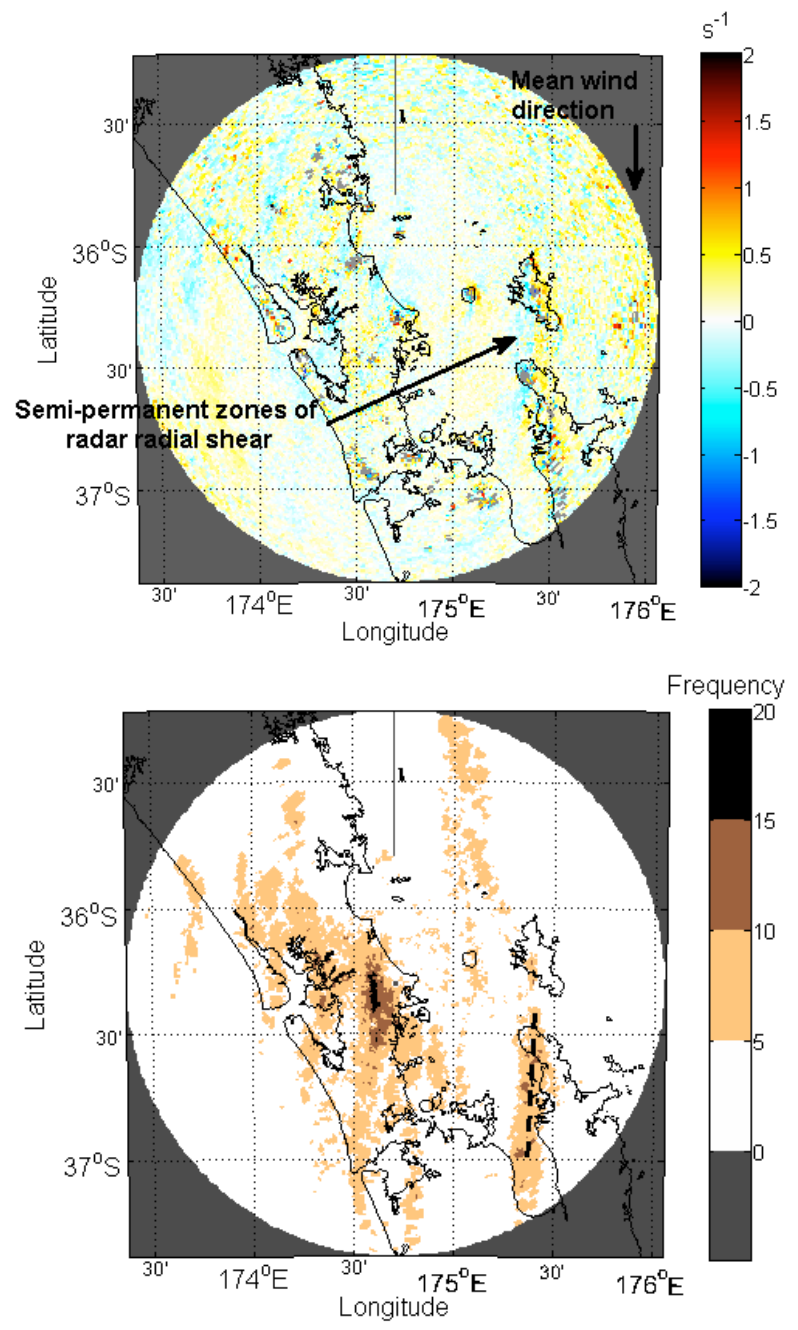

Figure 3.21: Diagrams showing the spatial distribution of low-level enhancement (bottom) and average position of the mountain wake in the lee of Great Barrier Island (top). Case 1, Event 2, 2100Z, 14 April 2008 to 0200Z, 15 April 2008. The black dashed line indicates the average position of the mountain wake observed in the lee of Great Barrier Island, as seen in the top figure.

- When comparing the images of average of radial gradients in radar radial velocities and images showing frequency of enhancement, it can been seen that in Cases 1 Event 2 and Case 3 Event 2 there exists a local maximum 
in the frequency of low-level enhancement. This is consistent with the observed locations of wakes in the lee of Great Barrier and Little Barrier islands, see Figure 3.21 (Case 1, Event 2) and Figure 3.22 (Case 3, Event 2).
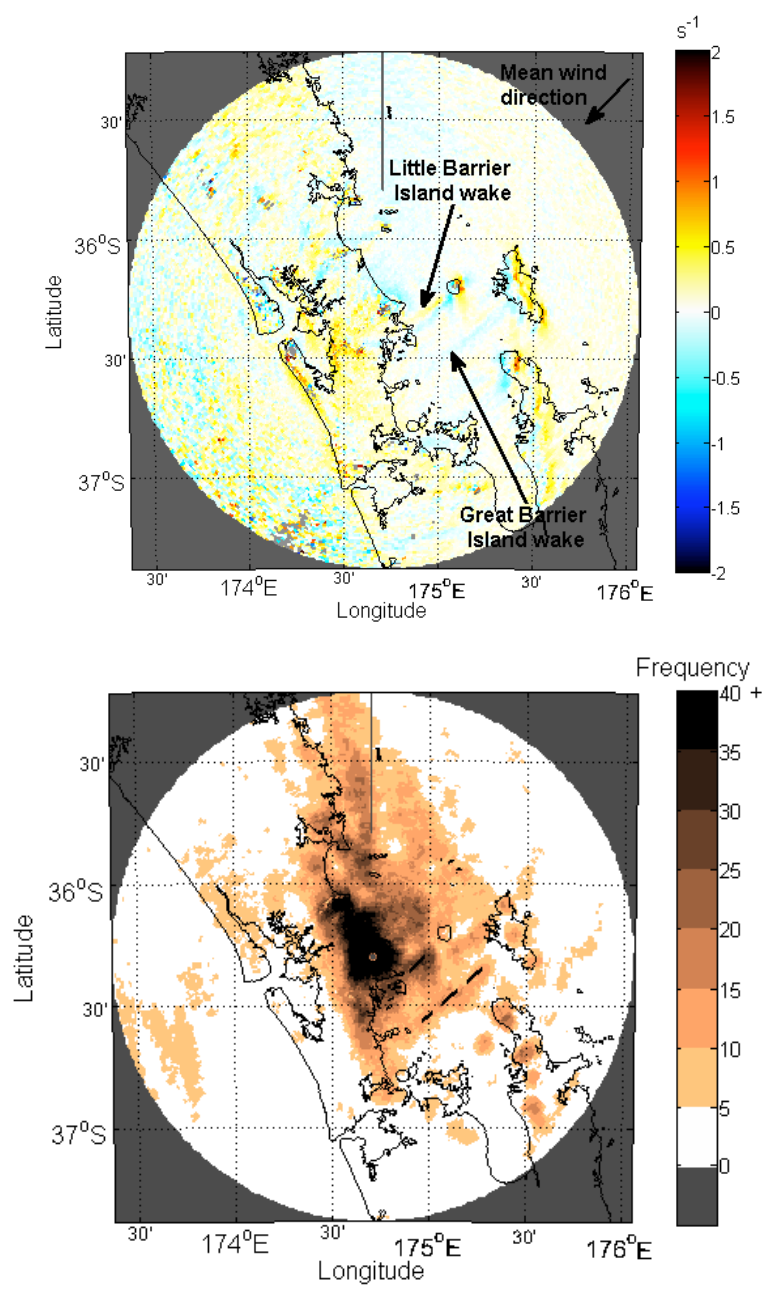

Figure 3.22: Diagrams showing the spatial distribution of low-level enhancement (bottom) and the average location of the mountain wakes in the lee of Great Barrier and Little Barrier islands (top). Case 3, Event 2, $1600 \mathrm{Z} 28$ March 2007 to 1100Z 29 March 2007. The dashed lines indicate the average position of the mountain wakes as observed in the lee of Great Barrier and Little Barrier islands, see in the top image. 
The region of enhancement located at the centre of the radar scan area may be a result of both the location of the radar and mechanical forcing. Mechanical forcing in this region is caused by orographic lifting along the mountains in the vicinity of Mt Tamahunga, see Figure 1.1. The position of this local maximum in the radar scan indicates that some contribution to this maximum may originate from reflections off the ground. This occurs as the radar beam is very close to the ground at these ranges from the radar. Considerable effort was made to minimize this effect in the calibration of the partitioning algorithm. When processing the radar data only reflectivities greater than $0 \mathrm{dBZ}$ were considered, thus reducing the probability of detecting reflections from the sidelobes off the ground. Care was also taken in the calibration of the peakness criterion to make sure any residual reflections from the ground were not classified as convective. However it is possible that there are still some residual echoes from the ground that have been classified as convective precipitation. It is considered that the main effect contributing to this local maximum in the frequency of precipitation enhancement is the low beam height compared to the rest of the radar area, see Figure 2.1. Therefore any low-level precipitation enhancement resulting from orographic lifting, causing up slope convergence or enhancement due to the seeder feeder mechanism, is more likely to be detected by the radar at these short ranges than elsewhere in the radar scan.

Over the Hauraki Gulf and the Coromandel Peninsula the beam height is greater than $500 \mathrm{~m}$ AMSL. Therefore local maxima in these regions may be due to increased vertical motion in regions of low-level convergence within wakes observed in the Hauraki Gulf and orographic lifting on the windward side of the Coromandel ranges respectively. The relationship between precipitation enhancement and mountain wakes observed in the Hauraki Gulf is investigated in Section 3.4. 


\subsection{Mountain wakes and precipitation enhance- ment}

To investigate the role of boundary layer forcing in the initiation and intensification of convection, an in depth case study of Case 3, Event 2 follows. This case study focuses on the development of regions of convection in the vicinity of mountain wakes observed in the lee of Great Barrier, Little Barrier and Taranga Islands.

As seen in Section 3.3.2 local maxima in the frequency of precipitation enhancement were observed in the vicinity of mountain wakes in the lee of Great Barrier and Little Barrier islands, during Case 1, Event 2 (Figure 3.21) and Case 3, Event 2 (Figure 3.22). In Case 1, Event 2 a local maximum in the frequency of low-level precipitation enhancement was observed to coincide with the position of the Great Barrier Island wake. This wake was observed at the edge of an area of precipitation detected by the Mt Tamahunga radar. Precipitation echoes in this area were observed to be patchy and the wake in the lee of Great Barrier Island was not well resolved in RHI images of radial velocity, see Section 3.2.1. As a result this event was not investigated. However Case 3, Event 2 was characterised by broad areas of stratiform precipitation with smaller areas of embedded convection. In this case wakes observed in the Hauraki Gulf were well defined in both $0.5^{\circ}$ PPI images and RHI profiles. The following section presents a detailed investigation of this event, focusing on the relationship between mountain wakes and precipitation enhancement.

\section{Case 3: Event 2, 1600, 28 March 2007 to 1400, 29 March 2007}

As mentioned previously, $0.5^{\circ} \mathrm{PPI}$ images of reflectivity during this event showed broad regions of stratiform precipitation with areas of embedded convection. Precipitation during this event was widespread throughout the study 
area. A maximum hourly rainfall accumulation of $40.6 \mathrm{~mm}$ was measured at Whangarei automatic weather station at 0200Z, 29 March. This event was split into two sub-events at 1100Z, 29 March due to the passage of a cold front moving east across the study area. Precipitation during the latter part of this event was observed in the vicinity of an intense prefrontal convective line. The earlier part of this storm, prior to the passage of the prefrontal convective line is the focus of this investigation. Precipitation echoes observed during this event provide ideal conditions for the observation of wakes in the lee of $\mathrm{Mt}$ Moehau, and Little Barrier, Great Barrier and Taranga islands using radar data. Therefore this period is used to investigate the role that these features play in initiating/intensifying regions of convection in the wider Auckland region.

\section{Synoptic setting}

The synoptic scale environment over the North Island, New Zealand, at mean sea level, was characterised by a low pressure system centred in the northern Tasman Sea. This system moved south to lie to the west of the study area on the 28 March 2007. During this time a high pressure system centred to the east of Banks Peninsula, intensified and moved slowly eastward, strengthening the northeasterly flow over the study area. On 28 March a warm front approached from the west, with a surface trough and stationary front developing behind the warm front at 1200Z 28 March, see Figure 3.23. Upper air soundings from Whenuapai showed mid-level winds $(700-500 \mathrm{hPa}$ ) veering (rotating in a clockwise sense with height) as the trough approached, increasing in strength as the cold front passed over the region at $1100 \mathrm{Z} 29$ March. The $500 \mathrm{hPa}$ geopotiential height field showed a cutoff low, centered over the central Tasman Sea, to the west of the surface low centre, indicating a strongly developing system. 

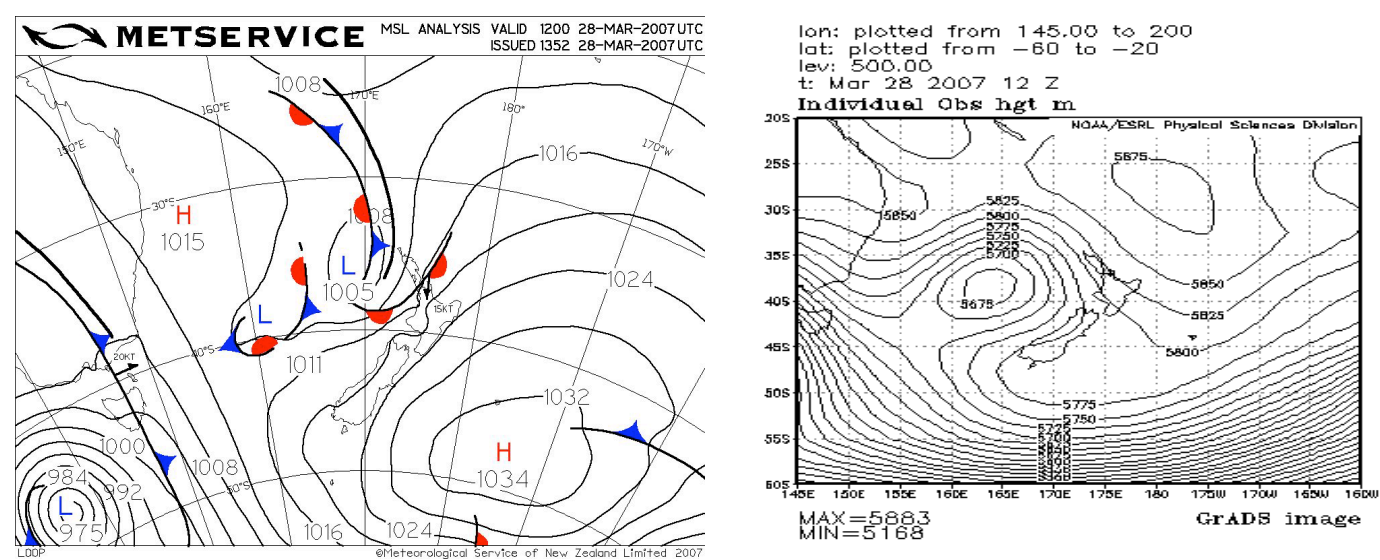

Figure 3.23: 1200Z, 28 March 2007: Mean sea level analysis (left)and 500 $\mathrm{hPa}$ geopotiential height (right). $500 \mathrm{hPa}$ geopotiential height data provided by NCEP-DOE Reanalysis 2 data provided by the NOAA/OAR/ESRL PSD, Boulder, Colorado, USA from their Web site at http://www.cdc.noaa.gov/

Surface stations indicated that the cold front passed over the region between $1100 \mathrm{Z}$ to $1800 \mathrm{Z}$ on the 29 March 2007, with a pressure minimum associated with the surface trough observed to pass through Dargaville AWS four hours prior to the frontal passage, see Figure 3.24. Mean sea level analysis showed the surface trough dissipating as the cold front moved east across the region during the afternoon of 29 March 2007 (UTC).

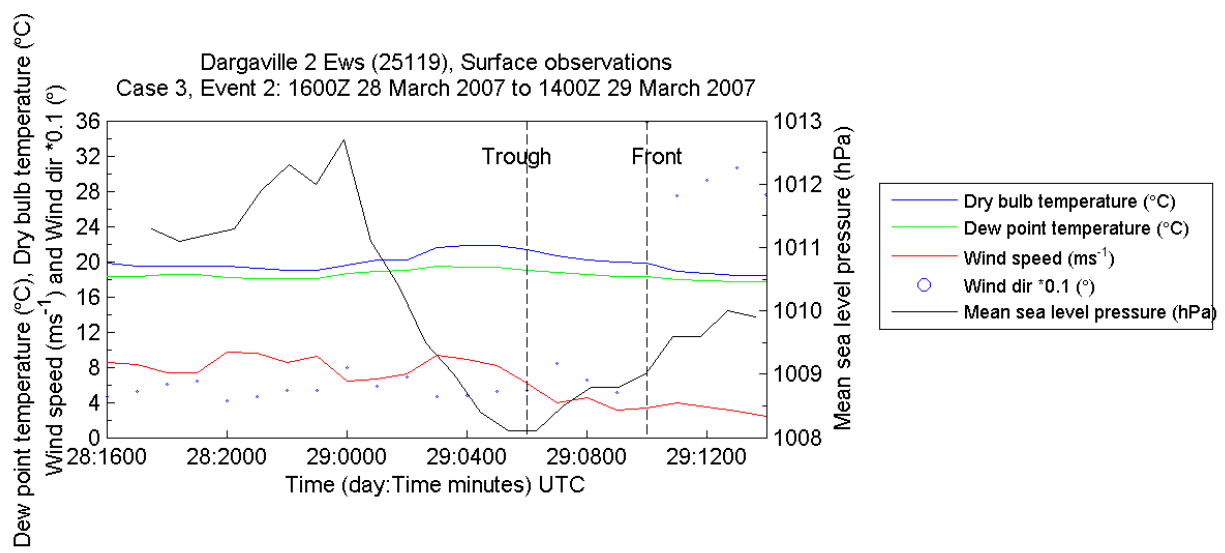

Figure 3.24: Case 3, Event 2: Dargaville AWS record. The positions of the surface trough and cold front are shown. 


\section{Stability and low level wind shear}

Tephigrams constructed from the Whenuapai balloon soundings during this event show moderate to high convective instability, capped between 800 and $700 \mathrm{hPa}$ (see Figure 3.25). This makes the TQ stability index a good indicator of convective instability between 700 and $850 \mathrm{hPa}$, see Section 2.3.2. The values of TQ during this storm were high, between $15.7^{\circ} \mathrm{C}$ and $16^{\circ} \mathrm{C}$, with an anomalously low value of $12.4^{\circ} \mathrm{C}$ recorded at $1200 \mathrm{Z} 28$ March 2007 . At this time Total-Totals and CAPE also indicated very weak convective instability. However, inspection of $0.5^{\circ} \mathrm{PPI}$ images of reflectivity for this period showed broad areas of stratiform precipitation with small regions of embedded convection $(Z>40 \mathrm{dBZ})$. This indicates that the threshold of TQ approximately $>17^{\circ} \mathrm{C}$, suggested by Henry (2000) to indicate the likelihood of embedded convection, needs to be reexamined.

Whenuapai - 1200GMT 28 Mar 07 (0000NZT 29 Mar 07)

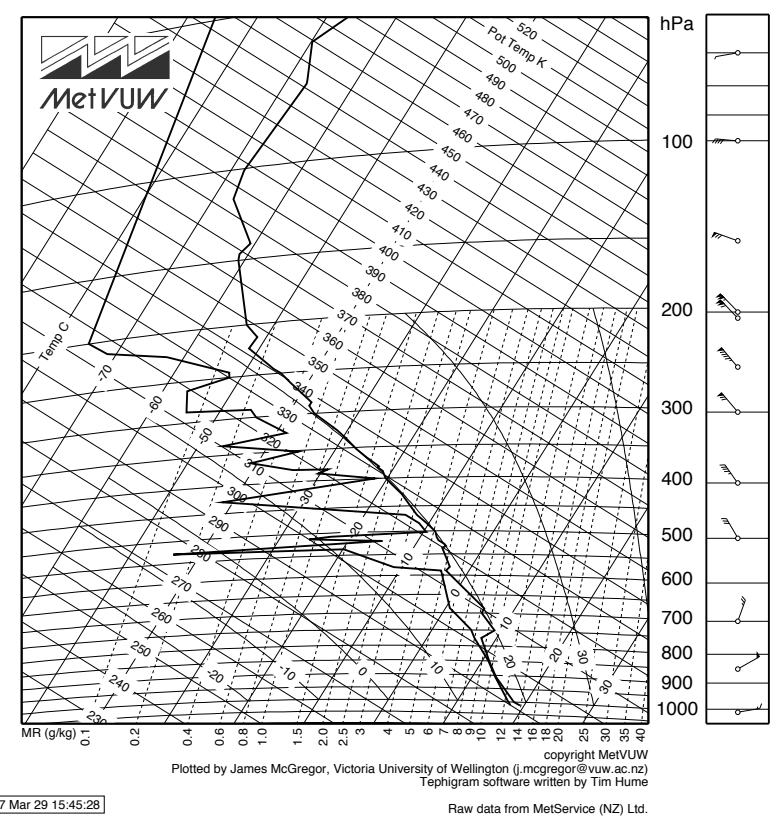

Figure 3.25: Tephigram: 1200Z, 28 March 2007 

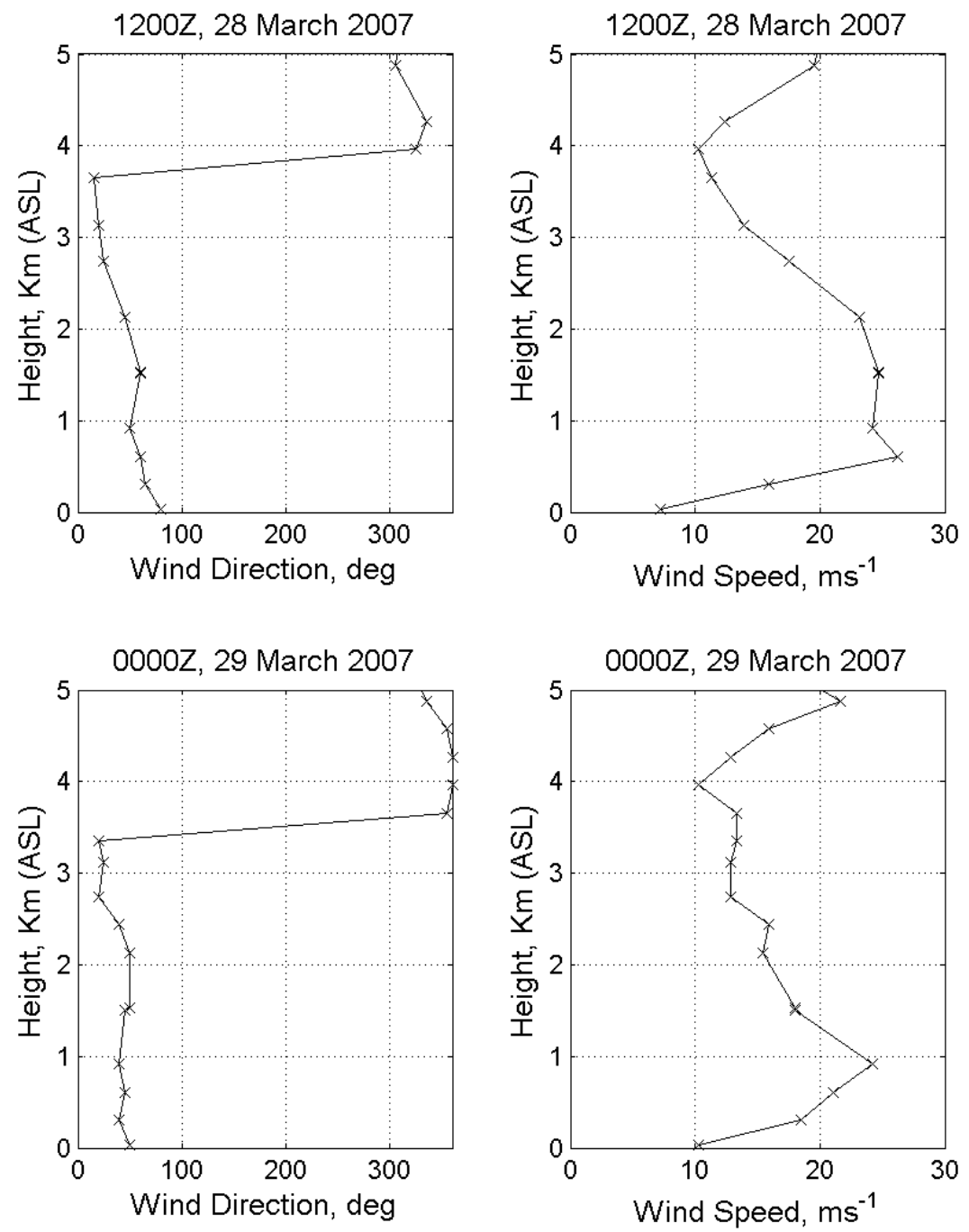

Figure 3.26: Case 3, Event 2. Vertical wind profiles of wind speed $\left(\mathrm{ms}^{-1}\right)$ and direction $\left(^{\circ}\right)$ for 1200Z 28 March and 0000Z 29 March 2007 measured at Whenuapai. 
Winds from the Whenuapai balloon soundings during this event indicated a weakly sheared low-level environment throughout this event. Figure 3.26 shows the surface winds of between 7 and $10 \mathrm{~m} \mathrm{~s}^{-1}$ from the northeast for this event. Winds below $\sim 1 \mathrm{~km}$ show frictional retardation resulting from interaction with the surface. These winds therefore are not considered to be representative of the low-level flow over the Hauraki Gulf, which is likely to show less frictional retardation. The northeasterly winds are persistent to $\sim 2.5 \mathrm{~km}$, with a maximum in wind speed of $\sim 25 \mathrm{~m} \mathrm{~s}^{-1}$ at $\sim 1 \mathrm{~km}$, see Figure 3.26 . Above $2.5 \mathrm{~km}$ winds turn northerly, increase in strength and back (turn anti-clockwise with height) becoming more westerly with height. This creates a weakly sheared low-level environment, which is reflected in the $0-3 \mathrm{~km}$ shearing speeds of between $11 \mathrm{~m} \mathrm{~s}^{-1}$ and $13 \mathrm{~m} \mathrm{~s}^{-1}$ measured between Mokohinau Island at the surface and Whenuapai at $3 \mathrm{~km}$ measured at $1200 \mathrm{Z}$ on the 28 March and 0000Z 29 March 2007 respectively.

\subsubsection{Mountain wakes and low-level precipitation en- hancement}

From Tables A.3 to A.1 we can see that during Case 3 Event 2, mountain wakes were observed in the lee of Great Barrier, Little Barrier and Taranga islands. The Little Barrier Island wake was the strongest and most persistent, appearing as a distinct line of low velocity in $0.5^{\circ} \mathrm{PPI}$ images of radar radial velocity, bounded by strong zones of radar radial shear, as observed in $0.5^{\circ}$ images of gradients in radar radial velocity. Low velocity zones observed in the lee of Great Barrier and Taranga islands were not as well defined and intermittent throughout this event. As noted in Section 3.2.4, deep wakes were observed in the lee of Little Barrier and Great Barrier islands, reaching a maximum altitude of $2.5 \pm 0.4 \mathrm{~km}$ and $2 \pm 0.4 \mathrm{~km}$ respectively. Due to the distance of Taranga Island from the radar and its relatively low elevation (334 m), the 
observation of a low velocity zone in low-level PPI images indicates a deep wake during this event (see Table A.1). During this period the Taranga Island wake was observed in the $0.5^{\circ}$ and $0.9^{\circ} \mathrm{PPI}$ images therefore reaching a maximum height of $1.1 \pm 0.4 \mathrm{~km}$. However this wake was difficult to resolve in RHI profiles, see Section 3.2.4. It is interesting to note that the maximum observed height $(2.5 \pm 0.4 \mathrm{~km}$ observed in the lee of Little Barrier Island) of the wakes in the Hauraki Gulf is equal to the observed depth of the northeasterlies in the Whenuapai sounding for this period, see Figure 3.26.

In Section 3.3.2 it was shown that, during Case 3, Event 2 there was a local maximum in the frequency of low-level enhancement which corresponded with the average position of the wakes observed in the lee of Little Barrier and Great Barrier Islands, see Figure 3.22.

Viewing loops of $0.5^{\circ}$ PPI images of reflectivity identified two types of enhancement $(Z>40 \mathrm{dBZ})$ in the vicinity of the wakes observed in the Hauraki Gulf. These were regions of preexisting convection, that moved into the observed location of wakes and small regions of embedded convection which initiate in the vicinity of observed wakes. A description of the observed periods of enhancement is presented in Appendix B. The role which mountain wakes play in intensifying and initiating regions of convection is investigated below. The term convection is used loosely here to mean cellular areas of reflectivity, $Z>40 \mathrm{dBZ}$ observed in $0.5^{\circ} \mathrm{PPI}$ images of reflectivity, with unknown vertical extent.

\section{Little Barrier Island}

Inspection of images showing convective/stratiform partitioning (see Section 3.3) and $0.5^{\circ} \mathrm{PPI}$ images of radar reflectivity during this event showed that heavy stratiform precipitation in the vicinity of the Little Barrier Island wake was 
common. However, distinct enhancement due to interaction with this wake was relatively rare. Three periods of enhancement were observed in the vicinity of the Little Barrier Island wake, see Table B.2. During two of these periods, intense areas of stratiform precipitation $(Z>30 \mathrm{dBZ})$ were observed in $0.5^{\circ} \mathrm{PPI}$ images of reflectivity. These regions of precipitation were observed to move south, interacting with the Little Barrier wake. Small regions of embedded convection were observed to initiate in the vicinity of the observed wake. RHI profiles of reflectivity during these periods show that, regions of 'embedded convection' were very shallow and short lived, appearing in radar beams 1-3 $(<1.5 \mathrm{~km})$ and observed for $\sim 30$ minutes. Additionally, one period was characterised by a small region of preexisting convection passing over the Little Barrier Island wake. RHI profiles of reflectivity for this period show evidence of intensification of preexisting convection by the Little Barrier Island wake, with the vertical extent of convection increasing from $\sim 1.0 \mathrm{~km}$ to $\sim 2.0 \mathrm{~km}$ as the convective cell passed through the wake(see Figure 3.27). It should be noted that all of these periods coincided with observed periods of deep wakes in the lee of Little Barrier Island (see Section 3.2.4). Despite this, embedded convection was not always observed to initiate/intensify along the Little Barrier Island wake during observed periods of deep wakes. 

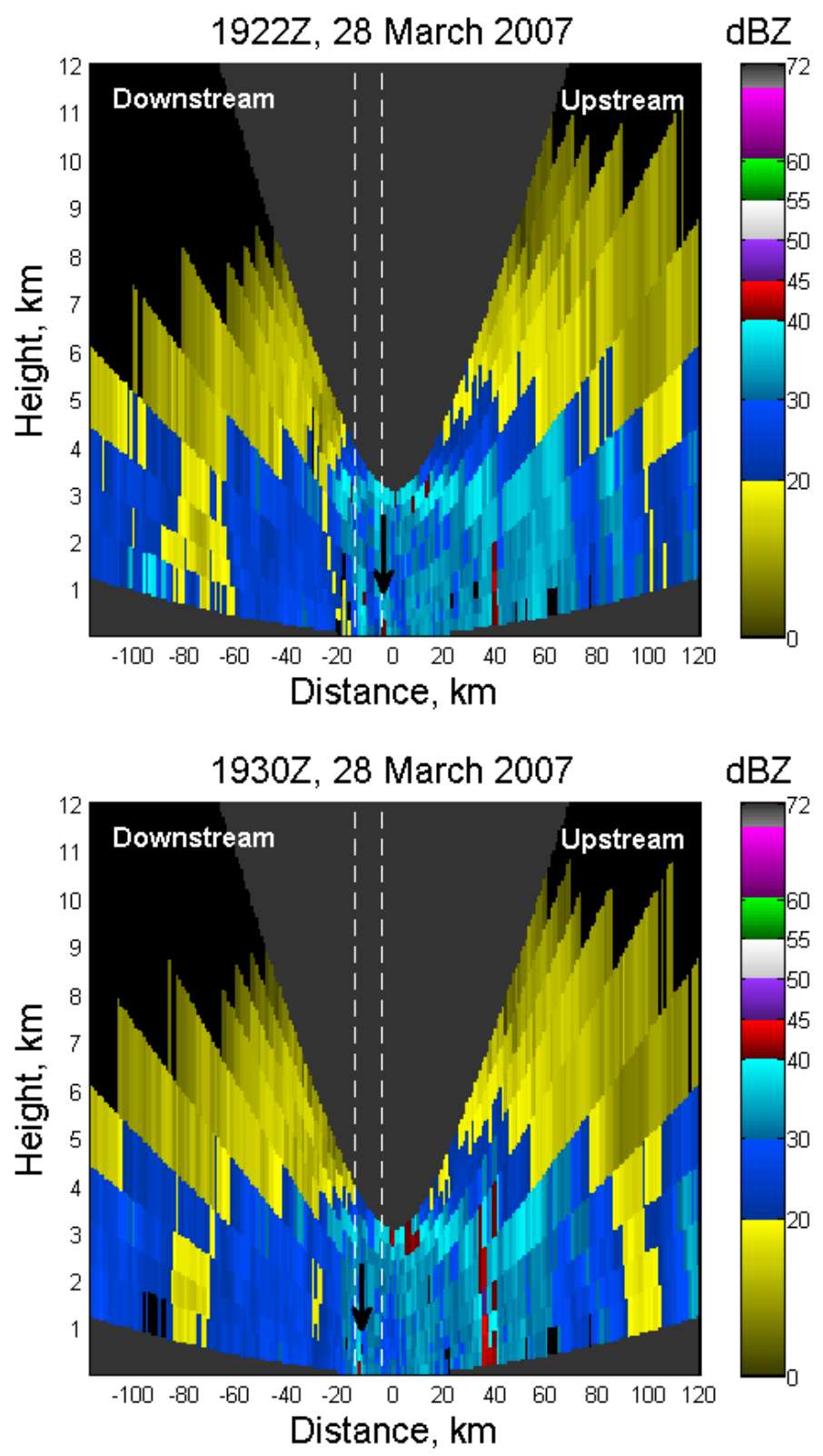

Figure 3.27: Continued on next page 

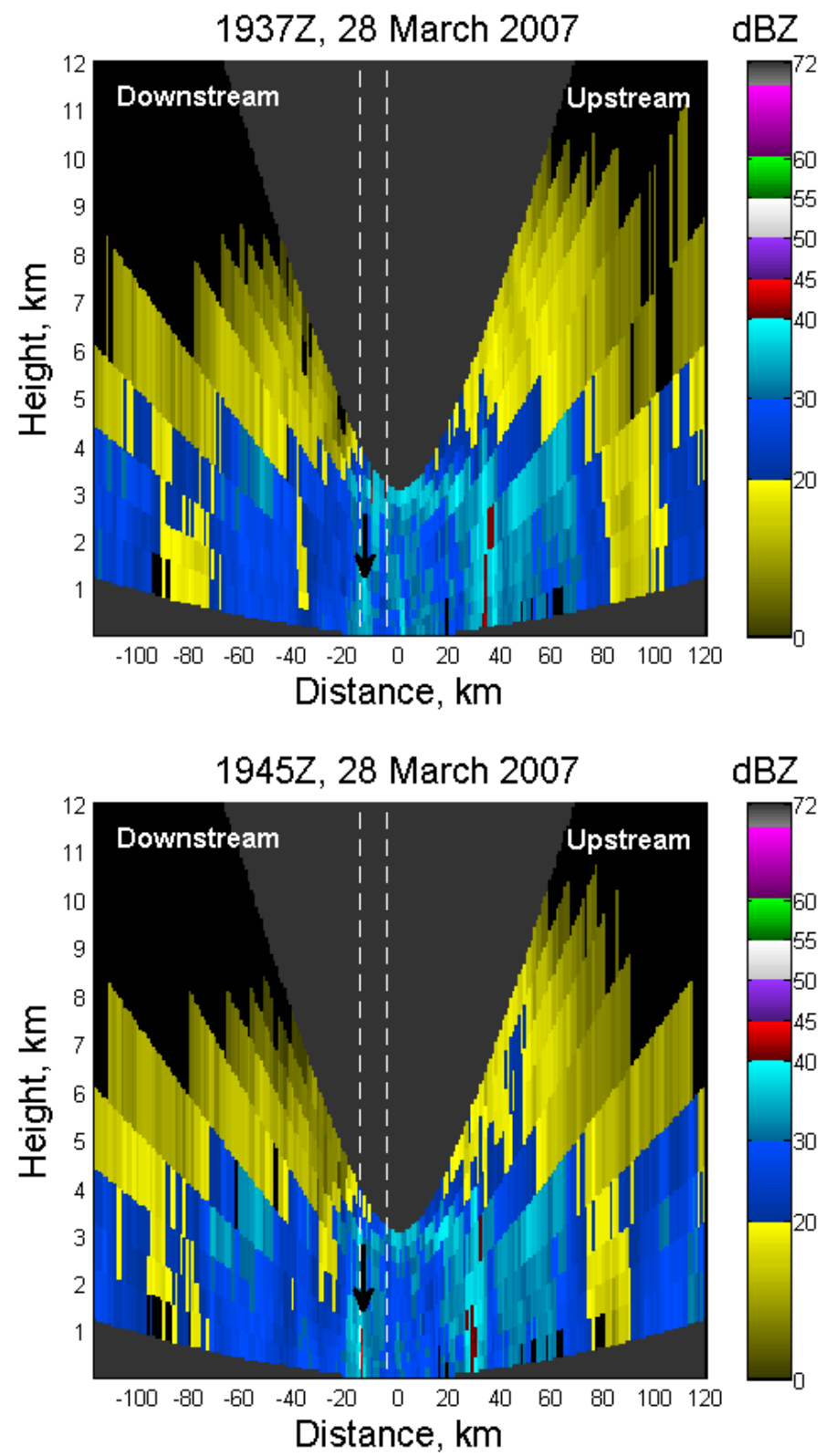

Figure 3.27: Diagram showing RHI profiles of reflectivity indicating the modification of preexisting convection as it passes over the Little Barrier Island wake. Case 3, Event 2, $1922 \mathrm{Z}$ to 1945Z, 28 March 2007. The zone between -5 and $-15 \mathrm{~km}$ indicated by the dashed lines, is the approximate position of the Little Barrier Island wake as seen in RHI profiles of radar radial velocity. In addition, the direction of motion of low-level precipitation as observed in radar imagery is indicated. The black arrows indicate the position of the convective cell as it moves over the observed position of the wake. 


\section{Great Barrier Island}

Inspection of images showing convective/stratiform partitioning (see Section 3.3) and $0.5^{\circ} \mathrm{PPI}$ images of reflectivity show that enhancement in the vicinity of the wakes observed in the lee of Great Barrier Island is rare, see Table B.3. This is supported by the low frequency of enhancement (5-10 measurements of enhancement) observed downstream of Great Barrier Island in the Hauraki Gulf, see Figure 3.22. However there was one period for which distinct lines of enhancement were observed in $0.5^{\circ} \mathrm{PPI}$ images of reflectivity. These lines of enhancement correspond to the observed location of the wakes in the lee of Great Barrier Island. During this period a mobile zone of enhancement, perpendicular to the Great Barrier Island wakes moved southwest along the wakes in the lee of Great Barrier Island. At the intersection between these two zones of enhancement, regions of embedded convection were observed to initiate (see Figure 3.28). It should be noted that the beginning of this period corresponded with a period where a deep wake was observed in the lee of $\mathrm{Mt}$ Hobson (the southern wake), see Section 3.2.4.

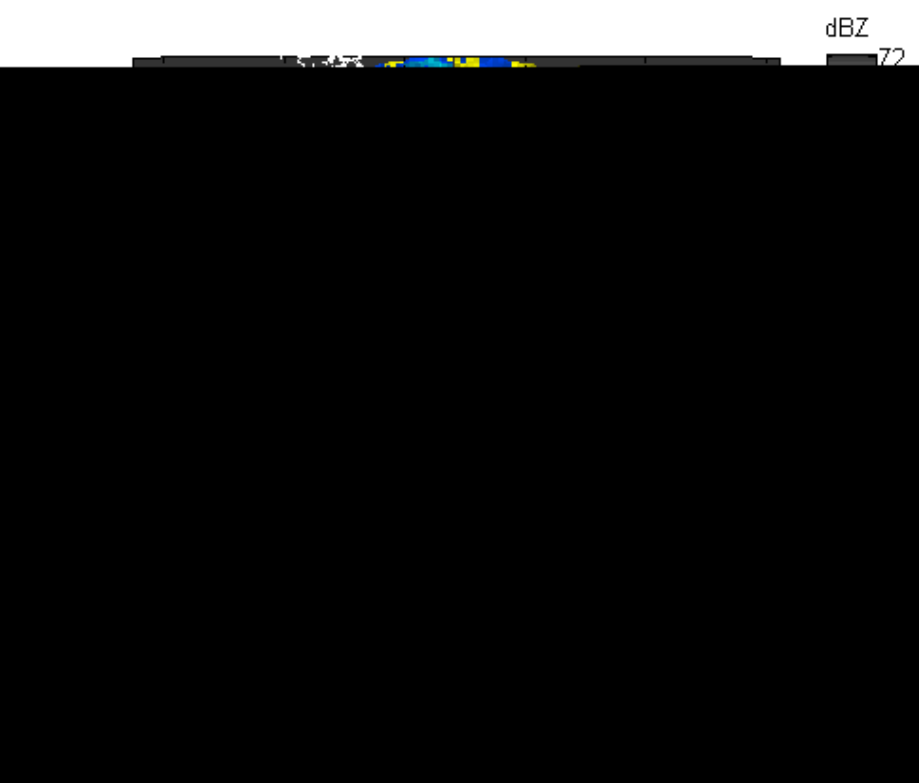

Figure 3.28: Continued on next page 


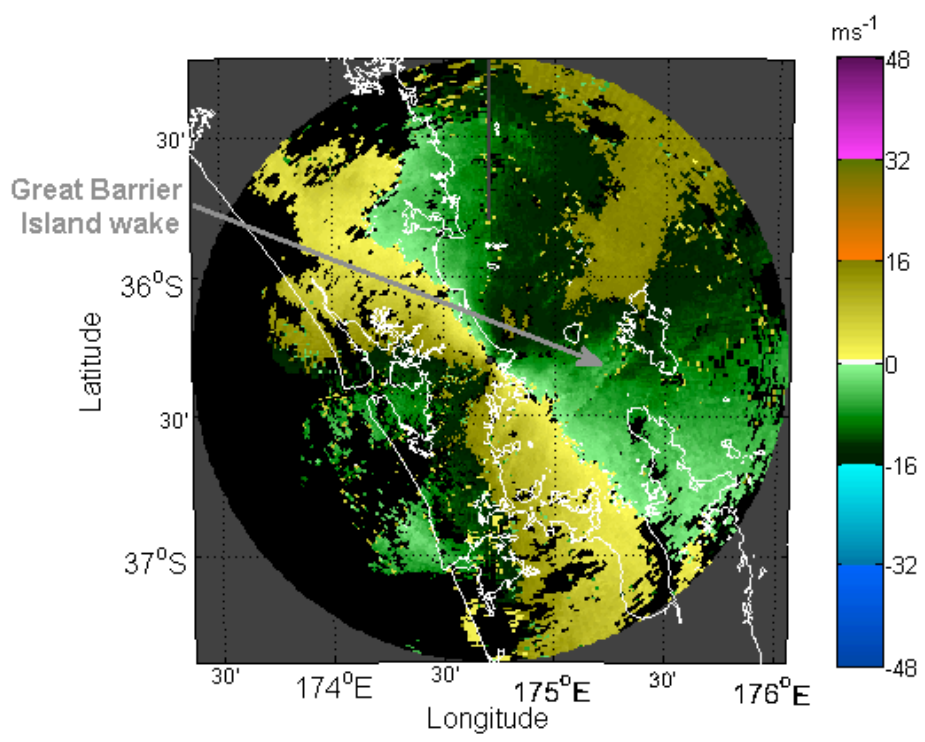

Figure 3.28: Diagram showing the appearance of low-level enhancement due to the Great Barrier Island wake as observed in: $0.5^{\circ} \mathrm{PPI}$ images of reflectivity (previous page) and $0.5^{\circ}$ PPI images of radar radial velocity (above). Case 3 Event 2, 2045Z, 28 March 2007. The position of the wakes are indicated with the dashed lines and the position of the mobile zone of enhancement is indicated by the dashed/dotted line.

RHI profiles of reflectivity during this period show that convective cells initiated along the Great Barrier island wakes have short life cycles observed in two to three images. In addition, convection appears to be shallow in nature (observed below the bright band at $\sim 3.5 \mathrm{~km}$ ), see Figure 3.29 .
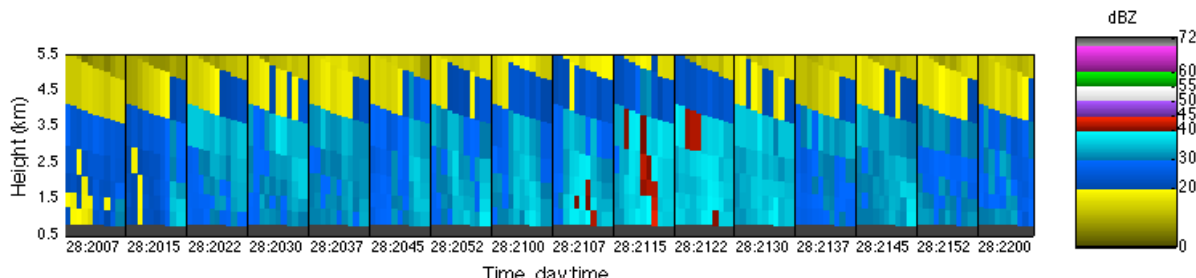

Figure 3.29: Diagram showing a time-series of RHI profiles indicating the vertical extent of enhancement due the Great Barrier wake. The convective cells initiated along these lines can be observed between 2107Z and 2122Z 28 March 2007. Case 3, Event 2, 2007Z to 2200Z, 28 March 2007 


\section{Taranga Island}

The wake in the lee of Taranga Island was observed in $0.5^{\circ} \mathrm{PPI}$ images of reflectivity between $1600 \mathrm{Z}$ and 2000Z 28 March 2007, see Table B.1. Inspection of $0.5^{\circ} \mathrm{PPI}$ images of reflectivity and images of convective/stratiform partitioning for these times showed no evidence of convective initiation in the vicinity of wakes observed in the lee of Taranga Island. In contrast to this, there were two periods where preexisting convection passed between Taranga Island and the east coast of the Northland region. RHI profiles during these periods show evidence that the Taranga Island wake can act to enhance regions of preexisting convection. Figure 3.30 shows the vertical extent of a convective cell as it passes over the observed location of the Taranga Island wake. These images show evidence of increasing reflectivities from 40-45 dBZ to $45-50 \mathrm{dBZ}$ slightly downstream of the observed location of the wake. This was observed at 1637Z 28 March 2007, in addition the area of high reflectivity increased at low levels (below $\sim 1 \mathrm{~km}$ ). 

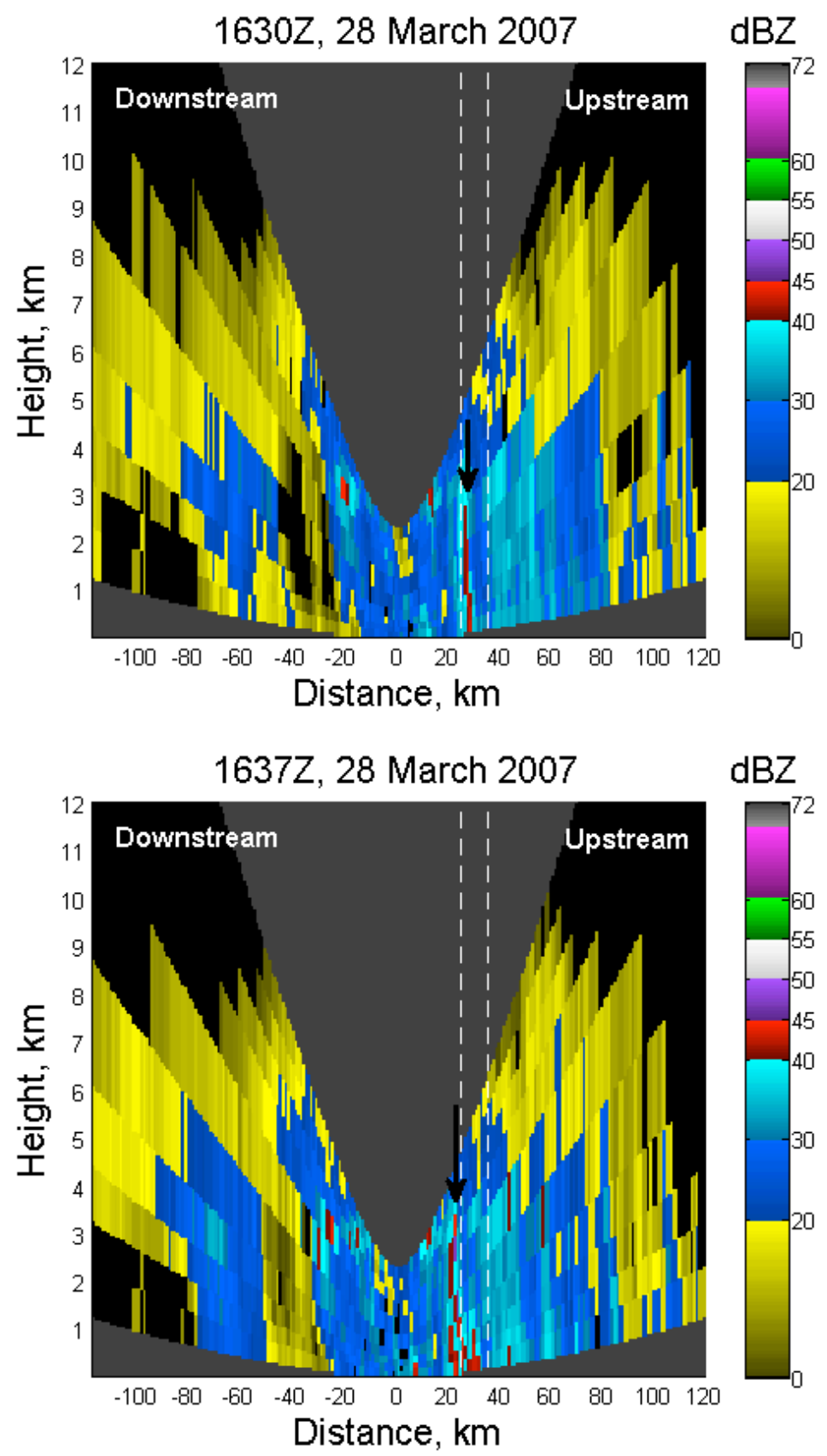

Figure 3.30: Continued on next page 

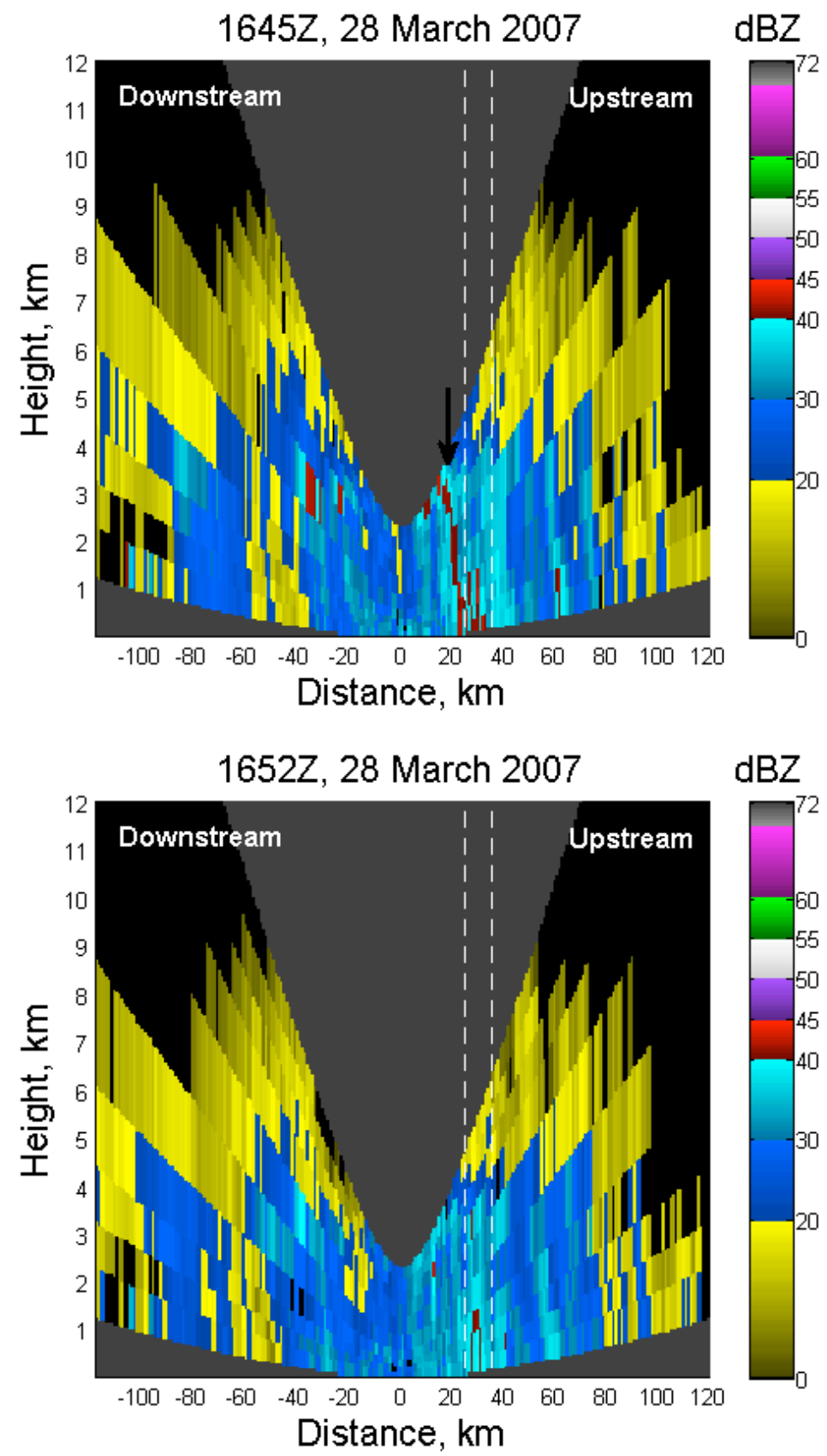

Figure 3.30: Diagram showing RHI profiles of reflectivity indicating the development of preexisting convection as it passes over the Taranga Island wake. Case 3, Event 2: 1630Z to 1652Z, 28 March 2007. The zone between 25 and $35 \mathrm{~km}$ indicated by the dashed lines, is the approximate position of the Taranga Island wake as seen in RHI profiles of radial velocity. In addition, the direction of motion of low-level precipitation as observed in radar imagery is indicated. The black arrows indicate the position of the convection as it passes over the wake. 


\section{Chapter 4}

\section{Summary and Conclusions}

The primary goal of this study was to investigate the role of boundary layer forcing in enhancing low-level precipitation and the initiation/intensification of convection, during cases of high intensity precipitation in the wider Auckland region. This was achieved through the use of high resolution radar data, obtained from the MetService operated, C-band, Doppler radar, located on Mt Tamahunga, north of Auckland city. Seven cases of high intensity precipitation were chosen from the period between 2004 and 2008. For each case a severe weather warning was issued by MetService. In addition, an hourly rainfall accumulation of $20+\mathrm{mm}$ was measured in one or more rain gauges in the study area. A further case was added 28-30 May 2001, during which the New Zealand record for hourly rainfall accumulation of $109 \mathrm{~mm} \mathrm{hr}^{-1}$ ) was measured (as reported by Simes 2003). It was found that precipitation in all eight of the cases investigated was strongly dynamically forced, resulting from the passage of cyclonic systems in the vicinity of the study area, mainly centred to the north and west of the study area. This is consistent with results obtained by Simes (2003), Pascoe (2001) and Chater (1995). Precipitation during these cases was observed in the vicinity of surface fronts and troughs, consistent with results obtained by Simes (2003), Pascoe (2001) and Chater (1995). These cases were further split into eleven heavy precipitation events, 
defined as periods within each case for which $6+\mathrm{mm} \mathrm{hr}^{-1}$ of rain was recorded in at least one rain gauge in the study area. Nine of the eleven events were identified to be steady state, with wind direction in the study area unaltered by the passage of surface fronts and troughs. Heavy precipitation events occurred in surface flows from the northeast quadrant, consistent with results obtained by Hessell (1988), Moir et al. (1986) and Maunder (1974).

Mechanical forcing in the atmospheric boundary layer was investigated throughout the study area. This was analysed by examining the radial gradients in radar radial velocity (radar radial shear) at low levels over the study area. Zones of radar radial shear indicate zones of horizontal wind shear and/or zones of horizontal convergence. During steady state, heavy precipitation events in the wider Auckland region, zones of radar radial shear were observed to be both semi-permanent, resulting from flow modification by topographic features, and mobile, located in the vicinity of preexisting convection. Further, zones of radar radial shear of unknown origin were observed. Semi-permanent zones of radar radial shear were observed in the following areas:- downstream of Mt Moehau and Great Barrier, Little Barrier and Taranga islands, on the windward side of the Coromandel ranges and Great Barrier and Little Barrier islands, and finally along the west coast of the Auckland region. Synoptic conditions during periods of observed zones of radar radial shear in the lee of obstacles in the Hauraki Gulf, during steady state events, were investigated, along with the radar characteristics of these features. Further, the role of these zones of radar radial shear in enhancing low-level precipitation and initiating/intensifying convection in the study area was investigated.

It was found that for seven of the nine steady state, heavy precipitation events, the Mt Tamahunga radar measured sufficient precipitation echoes over the Hauraki Gulf to resolve semi-permanent zones of radar radial shear observed 
in the lee of obstructing obstacles. Lee zones of radar radial shear were observed in five of these events. These features are identified by pairs of shear lines one positive and one negative, extending large distances in the lee of each obstacle, parallel to the surface wind direction. These characteristics suggest a wake structure, as described in Section 1.3.2. Environmental conditions during heavy precipitation events, for which lee zones of radar radial shear were observed, were investigated to examine the relationship between these variables and the existence and nature of these zones of radar radial shear. In addition, the relationship between environmental conditions and low-level precipitation type and large scale motion within the study area were investigated. These conditions include:- surface and mid-level wind speed and direction, low-level vertical wind shear and stability. The average surface wind speed and direction varied between 9 and $19 \mathrm{~m} \mathrm{~s}^{-1}$ from the northeast quadrant. No clear relationship between surface wind speed and the existence of lee zones of radar radial shear or with low-level precipitation in the Hauraki Gulf was found during the events investigated. However, wind direction was seen to play an important role in the radar characteristics of lee zones of radar radial shear observed in the Hauraki Gulf, these features were observed, aligned parallel to the surface flow. In addition, it was noted that in easterly flows the northern-most pair of shear zones in the lee of Great Barrier Island were blocked by Little Barrier Island. Further, in southeast flows, the radar radial shear zones originating from the central peak of Great Barrier Island were also blocked. The Little Barrier and Great Barrier lee zones of radar radial shear were modified accordingly. In all of the heavy precipitation events investigated, winds between the surface and $700 \mathrm{hPa}$ were seen to back by angles between 39 and $69^{\circ}$ creating strong directional shear at low levels. A direct relationship was observed between mid-level winds measured at Whenuapai and the large scale precipitation motion, with low-level precipitation moving approximately in the direction of the mid-level winds. To estimate the wind shear within the lower atmosphere, 0 - 
$3 \mathrm{~km}$ wind shear was calculated between Mokohinau Island at the surface and Whenuapai upper level winds at $3 \mathrm{~km}$. It was noted that the two heavy precipitation events, for which no lee zones of radar radial shear were observed, showed high levels of $0-3 \mathrm{~km}$ shearing speeds, $>22 \mathrm{~m} \mathrm{~s}^{-1}$. All of the steady state, heavy precipitation cases studied displayed some degree of convective instability. This was reflected in the nature of the precipitation field, with all of the events investigated. For all heavy precipitation events areas of both stratiform and convective precipitation were observed in reflectivity data from the Mt Tamahunga radar. However, no direct relationship was found between the existence of semi-permanent zones of radar radial shear measured over the Hauraki Gulf and convective instability.

The radar characteristics of semi-permanent zones of radar radial shear in the lee of Mt Moehau and Great Barrier, Little Barrier and Taranga islands were investigated. These features have a signature in both the PPI images of radar radial velocity and images of radial gradients in radar radial velocities (radar radial shear). These zones of radar radial shear were observed to extend in the lee of each obstacle, parallel to the surface flow measured upstream of each obstacle. In PPI images of radar radial velocity these zones were characterised by a long thin zone of low velocity embedded in the background flow with zones of positive and negative radar radial shear (as observed in images of radar radial shear) defining the edges of these features. These findings are consistent with radar observations of mountain wakes observed in the lee of Lantau Island, Hong Kong (Shun et al. 2003). However no reverse flow was observed within the wakes detected in the Hauraki Gulf. Further, if was seen that the strength of the northern and southern shear lines in the lee of $\mathrm{Mt}$ Moehau and Great Barrier Island were not equal when observed in images of radar radial shear. In the case of Great Barrier Island the southern shear line was much better defined and therefore stronger that the northern shear 
line. In the case of Mt Moehau it was found that the northern shear line was better defined that the southern shear line. This result is consistent with observations by Lane et al. (2006) and is thought to be caused by variations in the topography of the obstacle.

The obstacles for which mountain wakes are detected over the Hauraki Gulf are smaller than the majority of those investigated in previously documented studies of mountain wakes. The observed spatial characteristics of the mountain wakes investigated in this study are summarised in Table 4.1.

Table 4.1: Table summarising the spatial characteristics of mountain wakes, as observed in radar data from the Mt Tamahunga radar.

\begin{tabular}{|c|c|c|c|c|}
\hline & Mountain Height & Width & Length & Max Height \\
\hline Great Barrier Island & $627 \mathrm{~m}$ & $3-7 \mathrm{~km} \mathrm{E} 12 \mathrm{~km} \mathrm{~N}$ & $38-57 \mathrm{~km}$ & $2 \mathrm{~km}$ \\
\hline Little Barrier Island & $722 \mathrm{~m}$ & $4-10 \mathrm{~km}$ & $28-30 \mathrm{~km}$ & $2.5 \mathrm{~km}$ \\
\hline Taranga Island & $417 \mathrm{~m}$ & $4-6 \mathrm{~km}$ & $18-22 \mathrm{~km}$ & $1 \mathrm{~km}$ \\
\hline Mt Moehau & $894 \mathrm{~m}$ & $4 \mathrm{~km}$ & $22-40 \mathrm{~km}$ & N/A \\
\hline
\end{tabular}

In addition, it was observed that the width of each wake is approximately equal to the width of the obstructing obstacle, with the wake often spreading out slightly with distance (Figure 3.13 shows of an example of this for Little Barrier Island). The spatial characteristics of the wakes detected in the Hauraki Gulf suggest wakes similar to those investigated by Yang et al. (2008), Lane et al. (2006), Shun et al. (2003) and Smith et al. (1997). The wakes studied by Yang et al. (2008), Lane et al. (2006) and Shun et al. (2003) are characterised by downstream convergence and reverse flow within the wake structure. However, in contradiction to these studies, no evidence of reverse flow was observed within the wakes investigated in the current study. This suggests a wake structure similar to that investigated by Smith et al. (1997). During the course of this study convergence could not be directly calculated, this was due to the limitations imposed by velocity folding and the spatial resolution of the Mt 
Tamahunga radar data. Further, if reverse flow was present within the wakes investigated in this study it was not resolved in low-level PPI images of radar radial velocity. Therefore there is no way to distinguish between the different wake structures identified in Section 1.3.2.

Low-level wind shear was observed to be related to the radar characteristics and existence of observed wakes in the Hauraki Gulf. Case 3, Event 2 recorded the lowest $0-3 \mathrm{~km}$ shearing speed among the events investigated in this study. During this event deep wakes were seen in the lee of Great Barrier, Little Barrier and Taranga islands. A deep wake was defined to be a wake where the depth of the low velocity zones was observed to exceed twice the height of the obstacle $\pm 0.4 \mathrm{~km}$, as observed in radar RHI profiles of radial velocity. The wake in the lee of Little Barrier Island was found to have the greatest vertical extent, with a depth of $2.5 \pm 0.4 \mathrm{~km}$ observed in RHI profiles of radar radial velocities in Case 3, Event 2. It was also noted in Section 3.4 that this was equal to the depth of the easterly flow as measured in the Whenuapai balloon sounding.

Previous studies suggest that factors affecting the observed characteristics of mountain wakes are:- the mean surface wind speed, mountain height and lowlevel stability (indicated by the Brunt-Väisälä frequency, see Section 1.3.2). Further, low-level wind shear has been shown to provide an important mechanism for the creation of turbulence within the wake structure (Lane et al. 2006, Smith 1989). In this study it was difficult to quantify the contribution of each of these variables to observed wake structure, due to the limitations inherent in the Doppler velocity field, such as resolution and velocity folding. In addition, the position of the Whenuapai balloon sounding located inland, downstream of the observed wakes in the Hauraki Gulf was not ideal. This sounding was considered to be non-representative of the environmental conditions over the 
Hauraki Gulf at low-level due to the effect of frictional retardation (see Section 3.2.2). Cases for which no wakes were observed over the Hauraki Gulf were characterised by high values of $0-3 \mathrm{~km}$ shearing speed, $>22 \mathrm{~m} \mathrm{~s}^{-1}$. This suggests that stagnation and therefore the formation of a wake was unable to be achieved in these events, as noted by (Smith 1989); alternatively the low-level shear was too high to support wakes in the lee of each obstacle in the Hauraki Gulf. A high resolution numerical model such as that used by Lane et al. (2006) would be required to reliably diagnose the mesoscale features of each wake and successfully categorise each wake structure (as defined in Section 1.3.2). These features include the presence of reverse flow, downstream convergence and Kelvin Helmholtz instability.

An algorithm to partition precipitation echoes into their convective and stratiform components, based on the method presented by Steiner et al. (1995), has been calibrated and applied to the study area. The aim was to investigate the spatial distribution of enhanced low-level precipitation, including convection, during heavy precipitation events. Steiner's method was chosen based on its simplicity and therefore computational speed, in addition to its dependance on radar data alone. This method assumes that regions of convective precipitation are cellular in nature and will produce high intensity rainfall rates, which are generally greater than those observed in regions of stratiform precipitation (Steiner et al. 1995).

It was found that 'convective' echoes measured by the Mt Tamahunga radar were most effectively identified when:

- Intensity $=Z \geq 50 \mathrm{dBZ}$ 
- $\Delta Z= \begin{cases}10 & , Z_{b g}<0 \\ 10-\frac{Z_{b g}^{2}}{250} & , 0 \geq Z_{b g}<50 \\ 0 & , Z_{b g} \geq 50\end{cases}$

- Convective radius medium, see Figure 2.4.

- Convective regions $>2 \mathrm{~km}^{2}$

Similar to the original algorithm developed by Steiner et al. (1995), the present algorithm developed for the wider Auckland region has a tendency to underestimate the horizontal extent of areas identified as convective precipitation. Futher, precipitation echoes may be misclassified at the leading edge of convective lines. In these regions precipitation is likely to have formed in the updrafts of the convective line and therefore should be classified as convective (consistent with results by Biggerstaff and Listemaa 2000). Due to the additional criterion used for the Auckland region, which limits the area of convective regions to $>2 \mathrm{~km}$, there is a marked decrease in the tendency of this algorithm to misclassify local peaks in regions of stratiform precipitation. These regions appear to be randomly distributed and therefore unpredictable. This issue could be addressed by introducing a more complex partitioning algorithm, taking into account reflectivity structure in both the horizontal and vertical planes (Biggerstaff and Listemaa 2000, Johnson et al. 1998, Demott et al. 1995, Dixon and Wiener 1993). However, this is beyond the scope of this study. It was concluded that regions identified as convective by this method include individual convective cells, multicellular structures and regions of enhanced low-level precipitation, resulting from the low beam height at close ranges to the radar.

The partitioning algorithm above was applied to the steady state, heavy precipitation events investigated in this study. Local maxima in the frequency 
of low-level enhancement were measured over the Coromandel Peninsula in Event 1, Cases 1 and 8, and Case 3, Event 2. These maxima were thought to result from orographic enhancement over Mt Tamahunga and the Coromandel ranges respectively. Additionally, maxima were observed to correspond with the mean location of wakes in the lee of Great Barrier and Little Barrier Islands (Case 1 Event 2, and Case 3, Event 2). This indicates that there may be a relationship between mountain wakes and low-level enhancement in the Hauraki Gulf.

Case 3, Event 2 was used to investigate the role of mountain wakes in the enhancement of low-level precipitation. Two types of enhancement were detected in the vicinity of wakes in the lee of Great Barrier, Little Barrier and Taranga islands, resulting from the interaction of preexisting convection with the mountain wakes. Further, cellular areas of increased reflectivity were observed to initiate in the vicinity of mountain wakes. All of these periods of enhancement were observed during periods of deep wakes. Areas of enhancement were found to be short lived, that is periods up to 30 minutes. In addition, enhancement was seen to be shallow with all enhancement below the radar 'bright band' at $\sim 3.5 \mathrm{~km}$.

Cellular areas of convective precipitation were observed to initiate from interaction with wakes in the lee of Little Barrier and Great Barrier islands. The resulting convective cells were found to be shallow, reaching heights of $\sim 1.5 \mathrm{~km}$ and $\sim 3.5 \mathrm{~km}$ respectively. Enhancement of preexisting precipitation was detected in the vicinity of Little Barrier and Taranga islands. It appeared that the vertical extent of preexisting convection was increased due to the interaction with mountain wakes. The vertical extent of convective cells in the lee of Little Barrier increased by up to $1 \mathrm{~km}$. Further, in the case of Taranga Island, radar reflectivities were seen to increase from 40-45 dBZ to 45-50 dBZ. 
In addition, a period of enhancement was observed in the lee of Great Barrier Island, which extended the length of the wakes in the lee of Mt Tataweka and Mt Hobson (see Figure 3.28). In this region radar reflectivities were observed to be up to $10 \mathrm{dBZ}$ higher than the background, extending a vertical distance of up to $\sim 2.5 \mathrm{~km}$, see Figure 3.29 .

Very little of the current literature focuses on the interaction between mountain wakes and regions of precipitation. However, it has been found that in regions characterised by stable mountain wakes, observed in the lee of low mountains $(<1500 \mathrm{~m})$, cloud may form within or at the edges of the wake in relatively cloudless skies. Smith et al. (1997) noted that a row of cumulus clouds were observed at the boundaries of the wake in the lee of St Vincent, whilst the interior of the wake remained relatively dry. Further, a study by Yang et al. (2008) observed cloud lines developing in the lee of Kauai and Ohau, Hawaii, during the afternoon, which extended distances of up to $100 \mathrm{~km}$ downstream of each island. This supports the idea that mountain wakes can provide a mechanism to enhance vertical motion and therefore precipitation at low levels in the atmosphere. This is consistent with the results obtained in this study. However, to identify the exact mechanism by which this occurs requires further study.

\subsection{Conclusions and Future work}

This thesis has investigated the role of mechanical forcing within the boundary layer in enhancing low-level precipitation and initiating/intensifying convection in the wider Auckland region. The following conclusions can be drawn based on the results obtained in this study.

- Similar results to Simes (2003), Pascoe (2001) and Chater (1995). Cases of high intensity precipitation in the study area are observed to be 
strongly dynamically forced resulting from the passage of cyclonic systems in the vicinity of the study area. Precipitation measured during these storms was associated with the passage of surface fronts and troughs. These systems are observed to be centered mainly to the north and west of the study area.

- Mechanical forcing within the planetary boundary layer during steady state, heavy precipitation events, resulting from semi-permanent zones of horizontal shear and/or horizontal convergence, are observed on the windward side of the Coromandel ranges, and Great Barrier and Little Barrier islands, in addition to the west coast of the Auckland region. Further, pairs of one positive and one negative zones of radar radial shear were observed over the Hauraki Gulf, in the lee of Mt Moehau and Great Barrier, Little Barrier and Taranga islands. Low-level flow modification and precipitation enhancement, resulting from orographic lifting is well documented in the Auckland region (see Section 1.2). However, zones of radar radial shear observed in the lee of obstacles in the Hauraki Gulf have not been documented previously.

- Lee zones of radar radial shear have a signature in low-level PPI images of radar radial velocity, with a long thin low velocity zone observed in the lee of each obstacle, oriented in the direction of the low-level winds. Further, the zones of radar radial shear correspond with the boundaries of these features. These characteristics along with the spatial dimensions of these features summarised in Table 4.1, suggest a structure similar to that observed in mountain wakes. However, further work is required to diagnose the mesoscale features of these wakes and therefore categorise these structures in relation to previously documented wakes.

- Environmental conditions at mid to low levels in the atmosphere show some relationship with the existence and nature of mountain wakes ob- 
served in the lee of obstacles in the Hauraki Gulf, in addition to low-level precipitation type and large scale motion. Winds between the Mokohinau Island at the surface and Whenuapai at $700 \mathrm{hPa}(\sim 3 \mathrm{~km})$ were observed to back by angles between 39 and $69^{\circ}$ creating a highly directional shear environment between these levels. It was observed that in situations where high shearing speeds $>22 \mathrm{~m} \mathrm{~s}^{-1}$ were recorded wakes were not observed. Moderate to high levels of convective instability were observed among the events studied, depending on the stability indices used. This was reflected in the precipitation observed in the radar reflectivity field over the study area, with areas of both convective and stratiform precipitation observed in all of the cases studied. Regions of precipitation observed in radar data moved approximately in the direction of the $700 \mathrm{hPa}$ winds.

- Local maxima in the frequency of low-level precipitation enhancement, identified in the radar data, are observed to result from orographic lifting in the vicinity of Mt Tamahunga and the Coromandel Peninsula. Local maxima are also observed to correspond with the location of wakes in the lee of Great Barrier and Little Barrier islands, suggesting that mountain wakes may act to enhance low-level precipitation. This is confirmed by detailed investigation of Case 3, Event 2, during which convection was observed to initiate or intensify in the vicinity of wakes observed in lee of Little Barrier and Great Barrier islands.

\section{Future Work}

Work undertaken during the course of this study leaves some questions unanswered, which could be the subject of further studies.

Future studies could include:-

- Work to develop tools to unfold the Doppler velocity field measured 
by the Mt Tamahunga radar, in addition to calculating the true wind direction, would be useful in order to further investigate the mesoscale structure of the wind field over the study area.

- High resolution numerical modeling of the mountain wakes observed in the Hauraki Gulf, similar to those used by Lane et al. (2006) would be useful to diagnose the mesoscale structure of these wakes, further, to determine the contribution of low-level wind speed and stability on the existence and nature of these wakes.

- This study provides a basic method to partition radar reflectivity data into its stratiform and convective components. However it may be interesting to further develop this method using the full three dimensional volume scanned by the radar to better identify convective systems. This may be useful in developing rainfall accumulation and rain rate algorithms specific for the study area. 


\section{References}

Alberoni, P. P., Ducrocq, V., Gregorič, G., Haase, G., Holleman, I., Lindskog, M., Macpherson, B., Nuret, M., and Rossa, A. (2003). Quality and assimilation of radar data for NWP - A review. COST-717 report.

Austin, P. M. (1987). Relation between measured radar reflectivity and surface rainfall. Monthly Weather Review, 115:1053-1070.

Battan, L. J. (1973). Radar Observations of the Atmosphere. University of Chicago Press.

Bennett, L. J., Browning, K. A., Blyth, A. M., Parker, D. J., and Clark, P. A. (2006). A review of the initiation of precipitating convection in the United Kingdom. Quarterly Journal of the Royal Meteorological Society, 132:10011020.

Bergeron, T. (1950). Über der mechanismus der ausgiebigan niederschläge. Ber. Deut. Wetterd., 12:225-232. Cited in Houze (1993).

Biggerstaff, M. I. and Listemaa, S. A. (2000). An improved scheme for convective/stratiform echo classification using radar reflectivity. Journal of Applied Meteorology, 39:2129-2150.

Blanchard, D. O. (1998). Assessing the vertical distribution of convective available potential energy. Weather and Forecasting, 13:870-877.

Bradley, S. G., Gray, W. R., and Stow, C. D. (1992). Rainfall enhancement over the Waitakere ranges of west Auckland, North Island, New Zealand. New Zealand Journal of Geology and Geophysics, 35:301-310.

Browning, K. A., Blyth, A. M., Clark, P. A., Corsmeier, U., Morcrette, C. J., Agnew, J. L., P, B. S., Bamber, D., Barthlott, C., Bennett, L. J., Beswick, 
K. M., Bitter, M., Bozier, K. E., Brooks, B. J., Collier, C. G., Davies, F., Deny, B., Dixon, M. A., Feuerle, T., Forbes, R. M., Gaffard, C., Gray, M. D., Hankers, R., Hewison, T. J., Kalthoff, N., Khodayar, S., Kohler, M., Kottmeier, C., Kraut, S., Kunz, M Ladd, D. N., Lean, H. W., Lenfant, J., Li, Z., Marsham, J., McGregor, J., Mobbs, S. D., Nicol, J., Norton, E., Parker, D. J., Perry, F., Ramatschi, M., Ricketts, H. M. A., Roberts, N. M., Russell, A., Schulz, H., Slack, E. C., Vaughan, G., Waight, J., Wareing, D. P., J, W. R., R, W. A., and Wieser, A. (2007). The convective storm initiation project. Bulletin American Meteorological Society. DOI:10.1175/BAMS-8812-1939.

Chater, B. (1995). Heavy rain events in Auckland. Diploma of Applied Science (Meteorology), Victoria University of Wellington.

Colle, B. A. and Yuter, S. E. (2007). The impact of coastal boundaries and small hills on the precipitation distribution across southern Connecticut and Long Island, New York. Monthly Weather Review, 135:933-954.

Collier, C. G. (1989). Applications of weather radar systems. A guide to uses of radar data in meteorology and hydrology. Ellis Horwood Ltd. Chichester.

Demott, C. A., Cifelli, R., and Rutledge, S. A., editors (1995). An improved method for partitioning radar data into convective and stratiform components., 27th Conference on Radar Meteorology. American Meteorological Society.

Dixon, M. and Wiener, G. (1993). TITAN: Thunderstorm identification, tracking, analysis, and nowcasting - A radar-based methodology. Journal of Atmospheric and Oceanic Technology, 10(6):785-797.

Grubišić, V., Smith, R. B., and Sch ar (1995). The effect of bottom friction on shallow-water flow past an isolated obstacle. Journal of the Atmospheric Sciences, 52:1985-2005.

Henry, N. L. (2000). A static stability index for low-topped convection. Weather and Forecasting, 15:246-254.

Hessell, J. W. D. (1988). The climate and weather of the Auckland region. N.Z. Met. Serv. Misc. Publ. 115(20). 
Holton, J. R. (2004). An introduction to dynamic meteorology. Elsevier Inc., $4^{\text {th }}$ edition.

Hosking, J. G. and Stow, C. D. (1987). Ground-based, high-resolution measurements of the spatial and temporal distribution of rainfall. Journal of Climate and Applied Meteorology, 26:1530-1539.

Houze, Jr., R. A. (1981). Structures of atmospheric precipitation systems: A global survey. Radio Science, 16(5):671-689.

Houze, Jr, R. A. (1993). Cloud Dynamics, volume 53 of International Geophysics Series. Academic Press Ltd.

Johnson, J. T., MacKeen, P. L., Witt, A., Dewayne Mitchell, E., Stumpf, G. J., Eilts, M. D., and W, T. K. (1998). The storm cell identification and tracking algorithm: An enhanced WSR-88D algorithm. Weather and Forecasting, 13:263-276.

Kalnay, E. (2003). Atmopheric modeling, data assimilation and predicitability. Cambridge University Press.

Koch, S. E. and Ray, C. A. (1997). Mesoanalysis of summertime convergence zones in central and eastern north Carolina. Weather and Forecasting, 12:5677.

Lane, T. P., Sharman, R. D., Frehlich, R. G., and Brown, J. M. (2006). Numerical simulations of the wake of Kauai. Journal of Applied Meteorology and Climatology, 45:1313-1331.

Larsen, H. R. and Gray, W. R. (2003). Assessment of radar-based nowcasting model for the Auckland region. Journal of Hydrology (NZ), 42(2):101-112.

Lhermitte, R. M. and Atlas, D. (1961). Precipitation motion by pulse doppler radar. Preprints. ${ }^{t h}$ Weather Radar Conference.

Lin, Y. (2007). Mesoscale Dynamics. Cambrige University Press.

Llasat, M. C. and Rigo, T. (2004). A methodology for the classification of convective structures using meteorological radar: Application to heavy rainfall events on the Mediterranean coast of the Iberian Peninsula. Natural Hazards and Earth System Sciences, 4:59-68. 
Mass, C. (1981). Topographically forced convergence in the western Washington State. Monthly Weather Review, 109:1335-1347.

Matejka, T. and Srivastava, R. C. (1991). An improved version of the extended velocity-azimuth display analysis of single-doppler radar data. Journal of Atmospheric and Oceanic Technology, 8(4):453-466.

Maunder, W. J. (1974). Climate and climatic resources of the Waikato Coromadel King country region. N.Z. Met. Serv. Misc. Publ. 115(7).

McGill, A. J. (1987). Sea breeze circulations about Auckland. Scientific Report 29, Meteorological Service of New Zealand Ltd.

McKendry, I. G. (1992). Numerical simulation of sea breeze interactions over the Auckland region, New Zealand. New Zealand Journal of Geology and Geophysics, 35:9-20.

McKendry, I. G. and Revell, C. G. (1992). Mesoscale eddy development over south Auckland - A case study. Notes and Correspondence, Weather and Forecasting, 7:134-142.

Mohr, C. G. and Vaughan, R. L. (1979). An economical procedure for cartesian interpolation and display of reflectivity factor data in three-dimensional space. Journal of Applied Meteorology, 18(5):661-670.

Moir, R. W., Collen, B., and Thompson, C. S. (1986). The climate and weather of the Northland region. N.Z. Met. Serv. Misc. Publ. 115(2).

Montopoli, M., Marzano, F. S., Vulpiani, G., Fornasiero, A., Alberoni, P. P., Ferraris, L., and Rebora, N. (2006). Spatial charaterization of raincell horizontal profiles from C-band radar measurements at mid-latitudes. Advances in Geosciences, 7:285-292.

Pascoe, M. R. (2001). Forecasting heavy rain in Auckland. Meteorological Service of New Zealand Internal Report no.6,

Rinehart, R. E. (2004). Radar for Meteorologists. Rinehart Publications, 4th edition. 
Roeloffzen, J. C., Van den Berg, W. D., and Oerlemans, J. (1986). Frictional convergence at coastlines. Tellus, 38A:397-411.

Rogers, R. R. and Yau, M. K. (1989). A short course in cloud physics. Pergamon Press, $3^{\text {rd }}$ edition.

Sauvageot, H. and Mesnard, F. (2003). Structural characteristics of rain fields. Journal of Geophysical Research, 108(D13).

Scorer, R. S. (1986). Cloud investigation by satellite. Ellis Horwood Ltd, Chichester.

Shun, C. M., Lau, S. Y., and Lee, O. S. M. (2003). Terminal Doppler weather radar observation of atmospheric flow over complex terrain during tropical cyclone passaes. Journal of Applied Meteorology, 42:1697-1710.

Simes, K. (2003). High intensity rainfall events in Auckland. Diploma of Applied Science (Meteorology), Victoria University of Wellington.

Simpson, J. E. (1994). Sea breeze and local winds. Cambridge University Press.

Sinclair, M. R. (1994). An objective cyclone climatology for the Southern Hemisphere. Monthly Weather Review, 122:2239-2256.

Sinclair, M. R., Wratt, D. S., Henderson, R. D., and Gray, W. R. (1997). Factors affecting the distribution and spillover of precipitation in the Southern Alps of New Zealand. Journal of Applied Meteorology, 36:428-442.

Smith, R. B. (1989). Hydrostatic airflow over mountains. Advances in Geophysics, 31:1-41.

Smith, R. B., Gleason, A. C., Gluhosky, P. A., and Grubišić, V. (1997). The wake of St. Vincent. Journal of the Atmospheric Sciences, 54:606-623.

Smith, R. B. and Grubišić, V. (1993). Aerial observations of Hawaii's wake. Journal of the Atmospheric Sciences, 50(22):3728-3750.

Smolarkiewicz, P. K. and Rotunno, R. (1989). Low Froude number flow past three-dimensional obstacles. Part I: Barocilnically generated lee vorticies. Journal of the Atmospheric Sciences, 46(8):1154-1164. 
Srivastava, R. C., Matejka, T. J., and Lorello, T. J. (1986). Doppler radar study of the trailing anvil region associated with a squall line. Journal of Atmospheric Science, 43:356-377.

Steiner, M., Houze, Jr., R. A., and Yuter, S. E. (1995). Climatological characterization of three-dimensional storm structure from operational radar and rain gauge data. Journal of Applied Meteorology, 34:1978-2007.

Stull, R. B. (1988). An introduction to boundary layer meteorology. Kluwer Academic publishers.

Sturman, A. P. and Tapper, N. (2005). The weather and Climate of Australia and New Zealand. Oxford University Press, $2^{\text {nd }}$ edition.

von Hardenberg, J., Ferraris, L., and Provenzale, A. (2003). The shape of convective rain cells. Geophysical Research Letters, 30(24). doi:10.1029/2003GL018539.

Weckwerth, T. M. and Parsons, D. B. (2006). A review of convective initiation and motivation for IHOP_2002. Monthly Weather Review, 134(1):5-22.

Wilson, J. W., Crook, N. A., Mueller, C. K., Sun, J., and Dixon, M. (1998). Nowcasting thunderstorms: A status report. Bulletin of the American Meteorological Society, 79(10):2079-2099.

Wilson, J. W. and Schreiber, W. E. (1986). Initiation of convective storms at radar-observed boundary-layer convergence lines. Monthly Weather Review, 114:2516-2536.

Wulfmeyer, V., Behrendt, A., Bauer, H., Kottmeier, C., Corsmeier, U., Blyth, A., Graig, G., Schumann, U., Hagen, M., Crewell, S., Di Girolamo, P., Flamant, C., Miller, M., Montani, A., Mobbs, S., Richard, E., Rotach, M. W., Arpagaus, M., Russchenburg, H., Schlüssel, P., König, M., Gärtner, V., Steinacker, R., Dorninger, M., Turner, D. D., Weckwerth, T. M., Hense, A., and Simmer, C. (2008). The convective and orographically induced precipitation study. A research and development project of the world weather research program for improving quantitative precipitation forecasting in low-mountain regions. Bulletin American Meteorological Society. doi:10.1175/2008BAMS2367.1. 
Yanai, M. and Johnson, R. H. (1993). Impacts of cumulus convection on thermodynamic fields. The representation of cumulus convection in numerical models. Meteorological Monographs. Vol. 24, No.46. American Meteorological Society.

Yang, Y., Ma, J., and Xie, S. (2008). Observations of the trade wind wakes of Kauai and Ohau. Geophysical Research Letters, 35. doi:10.1029/2007GL031742.

Yeh, H. and Chen, Y. (2003). The role offshore convergence on coastal rainfall during TAMEX IOP 3. Monthly Weather Review, 130:2709-2730. 


\section{Appendix A}

This appendix presents the periods for which zones of radar radial shear were observed in $0.5^{\circ} \mathrm{PPI}$ images downstream of Mt Moehau and Little Barrier, Great Barrier and Taranga Islands. A description of the appearance of these zones of convergence is also presented, in addition to the radar characteristics of each wake. Note: comments refer to the appearance of each wake in $0.5^{\circ}$ PPI images of radar radial velocity.

Table A.1: Summary of the radar characteristics of the Taranga Island wake

\begin{tabular}{|c|c|c|c|c|c|c|}
\hline \multirow{2}{*}{ Case } & \multirow[t]{2}{*}{ Event } & \multicolumn{3}{|c|}{ Spatial dimensions } & \multirow{2}{*}{$\begin{array}{c}\text { Wind } \\
\text { Direction }\end{array}$} & \multirow[t]{2}{*}{ Comments } \\
\hline & & $\begin{array}{l}\text { Average } \\
\text { length }\end{array}$ & $\begin{array}{c}\text { Average } \\
\text { width }\end{array}$ & $\begin{array}{c}\text { Max } \\
\text { height }\end{array}$ & & \\
\hline 1 & 1 & & & & & Lee wake was not observed. \\
\hline 1 & 2 & $22 \mathrm{~km}$ & 4 to $6 \mathrm{~km}$ & NA & $\bar{N}$ & $\begin{array}{l}\text { Zones of radar radial shear were } \\
\text { observed to spread out with dis- } \\
\text { tance from Taranga Island and } \\
\text { were observed to dissipate at the } \\
\text { coast. Precipitation echoes be- } \\
\text { came patchy in the vicinity of } \\
\text { Taranga Island at the end of the } \\
\text { period. }\end{array}$ \\
\hline 2 & 1 & & & & & Lee wake was not observed. \\
\hline 3 & 1 & & & & & Lee wake was not observed. \\
\hline 3 & 2 & $18 \mathrm{~km}$ & $5 \mathrm{~km}$ & $\mathrm{NA}$ & $\mathrm{E}$ & $\begin{array}{l}\text { A lee wake was observed to be } \\
\text { weak but evident and was ob- } \\
\text { served to dissipate } 1-2 \mathrm{~km} \text { inland. }\end{array}$ \\
\hline
\end{tabular}


Table A.2: Summary of the radar characteristics of the Great Barrier Island wake

\begin{tabular}{|c|c|c|c|c|c|c|}
\hline \multirow[t]{2}{*}{ Case } & \multirow[t]{2}{*}{ Event } & \multicolumn{3}{|c|}{ Spatial dimensions } & \multirow{2}{*}{$\begin{array}{c}\text { Wind } \\
\text { Direction }\end{array}$} & \multirow[t]{2}{*}{ Comments } \\
\hline & & $\begin{array}{l}\text { Average } \\
\text { length }\end{array}$ & $\begin{array}{l}\text { Average } \\
\text { width }\end{array}$ & $\begin{array}{l}\text { Max } \\
\text { height }\end{array}$ & & \\
\hline 1 & 1 & & & & & Lee wake not observed \\
\hline 1 & 2 & $44 \mathrm{~km}$ & $12 \mathrm{~km}$ & & $\mathrm{~N}$ & $\begin{array}{l}\text { During this event only one low } \\
\text { velocity zone in the lee of Great } \\
\text { Barrier Island was observed. } \\
\text { This feature was not well defined } \\
\text { in individual images of radar ra- } \\
\text { dial velocity as observations were } \\
\text { made at the edge of a broad scale } \\
\text { region of precipitation. How- } \\
\text { ever this feature was well de- } \\
\text { fined in averages of radar radial } \\
\text { shear for this period, appearing } \\
\text { to originate from Mt Tataweka, } \\
\text { Great Barrier Island. It was } \\
\text { unclear where this wake dissi- } \\
\text { pated. It was thought dissi- } \\
\text { pation occured over the Coro- } \\
\text { mandel ranges, however zones of } \\
\text { radar radial shear were observed } \\
\text { to extend } 30 \mathrm{~km} \text { over the Coro- } \\
\text { mandel ranges. This was possi- } \\
\text { bly due to a wake in the lee of Mt } \\
\text { Moehau. No rain was detected in } \\
\text { the area except during this pe- } \\
\text { riod. }\end{array}$ \\
\hline 2 & 1 & & & & & Lee wake not observed \\
\hline 3 & 1 & $57 \mathrm{~km}$ & 3 to $7 \mathrm{~km}$ & & $\mathrm{E}$ & $\begin{array}{l}\text { A wake was continuously ob- } \\
\text { served. The southern shear line } \\
\text { was observed to be well defined } \\
\text { and stronger than the northern } \\
\text { shear line for this period. }\end{array}$ \\
\hline 3 & 2 & $38 \mathrm{~km}$ & $7 \mathrm{~km}$ & $2 \mathrm{~km}$ & $\mathrm{E}$ & $\begin{array}{l}\text { Radar radial shear lines were } \\
\text { weak but present in the lee of } \\
\text { Great Barrier Island. The south- } \\
\text { ern shear line was observed to } \\
\text { be stronger than the northern } \\
\text { shear line. Precipitation echoes } \\
\text { became patchy after } 0915 \mathrm{Z} \text {. }\end{array}$ \\
\hline
\end{tabular}


Table A.3: Summary of the radar characteristics of the Little Barrier Island wake

\begin{tabular}{|c|c|c|c|c|c|c|}
\hline \multirow[t]{2}{*}{ Case } & \multirow[t]{2}{*}{ Event } & \multicolumn{3}{|c|}{ Spatial dimensions } & \multirow{2}{*}{$\begin{array}{c}\text { Wind } \\
\text { Direction }\end{array}$} & \multirow[t]{2}{*}{ Comments } \\
\hline & & $\begin{array}{l}\text { Average } \\
\text { length }\end{array}$ & $\begin{array}{l}\text { Average } \\
\text { width }\end{array}$ & $\begin{array}{c}\text { Max } \\
\text { height }\end{array}$ & & \\
\hline 1 & 1 & $28 \mathrm{~km}$ & $10 \mathrm{~km}$ & & $\mathrm{NE}$ & $\begin{array}{l}\text { A weak low velocity zone was } \\
\text { continuously observed, shear } \\
\text { lines were well defined but were } \\
\text { observed to spread out with } \\
\text { distance from Little Barrier } \\
\text { Island. }\end{array}$ \\
\hline 1 & 2 & & & & & Convergence not observed \\
\hline 2 & 1 & & & & $\mathrm{E}$ & $\begin{array}{l}\text { Zones of radar radial shear are } \\
\text { not well defined during this pe- } \\
\text { riod, however there was some ev- } \\
\text { idence that the wake extended to } \\
\text { the coast. After this time rain } \\
\text { was patchy. }\end{array}$ \\
\hline 3 & 1 & $30 \mathrm{~km}$ & 4 to $7 \mathrm{~km}$ & & $\mathrm{E}$ & $\begin{array}{l}\text { A low velocity zone was continu- } \\
\text { ously observed, shear lines dissi- } \\
\text { pated over the land }\end{array}$ \\
\hline 3 & 2 & $30 \mathrm{~km}$ & 4 to $7 \mathrm{~km}$ & $2.5 \mathrm{~km}$ & $\mathrm{E}$ & $\begin{array}{l}\text { Radar radial shear zones defin- } \\
\text { ing the wake boundaries were } \\
\text { observed throughout this period } \\
\text { however the low velocity zone } \\
\text { was difficult to observe at times. } \\
\text { Radar echoes became patchy af- } \\
\text { ter } 0945 \mathrm{Z}\end{array}$ \\
\hline
\end{tabular}


Table A.4: Summary of the radar characteristics of the Mt Moehau wake

\begin{tabular}{|c|c|c|c|c|c|c|}
\hline \multirow[t]{2}{*}{ Case } & \multirow[t]{2}{*}{ Event } & \multicolumn{3}{|c|}{ Spatial dimensions } & \multirow{2}{*}{$\begin{array}{c}\text { Wind } \\
\text { Direction }\end{array}$} & \multirow[t]{2}{*}{ Comments } \\
\hline & & $\begin{array}{l}\text { Average } \\
\text { length }\end{array}$ & $\begin{array}{c}\text { Average } \\
\text { width }\end{array}$ & $\begin{array}{c}\text { Max } \\
\text { height }\end{array}$ & & \\
\hline 1 & 1 & & & & & Lee wake not observed. \\
\hline 1 & 2 & & & & & Lee wake not observed. \\
\hline 2 & 1 & $\begin{array}{l}\text { This } \\
\text { wake } \\
\text { was well } \\
\text { defined } \\
\text { to } 22 \mathrm{~km} \\
\text { and } \\
\text { present } \\
\text { to } 40 \mathrm{~km}\end{array}$ & $4 \mathrm{~km}$ & & $\mathrm{E}$ & $\begin{array}{l}\text { A wake was well defined. The } \\
\text { northern shear line was observed } \\
\text { to be stronger and extended fur- } \\
\text { ther that the southern shear line. }\end{array}$ \\
\hline 3 & 1 & & & & & $\begin{array}{l}\text { Radar echoes were patchy, low } \\
\text { velocity zones were weak and } \\
\text { were not well defined. (Inconclu- } \\
\text { sive) }\end{array}$ \\
\hline 3 & 2 & & & & & Lee wake was not observed. \\
\hline
\end{tabular}




\section{Appendix B}

This appendix presents a description of the types of enhancement observed in the vicinity of mountain wakes observed downstream of Little Barrier, Great Barrier and Taranga Islands for the periods indicated in Tables A.3-A.1. Comments are made on the relationship between regions of enhanced precipitation and each mountain wake.

Table B.1: Table summarizing enhancement observed in the vicinity of the Taranga Island wake.

\begin{tabular}{|l|l|}
\hline $\begin{array}{l}\text { Observation } \\
\text { period }\end{array}$ & Comments \\
\hline $\begin{array}{l}\text { 28 March 2007 } 1700 Z, \\
\text { 0.5 PPI images of radar reflectivity showed a convective cell } \\
\text { initiated at } \sim 1530 \mathrm{Z} 28 \text { March 2007. This cell moved south- } \\
\text { east, reaching the Taranga Island wake at 1630Z, by which } \\
\text { time the cell had begun to dissipate. Between 1630Z and } \\
1700 Z \text { a convective cell moved southeast over the Taranga } \\
\text { Island wake, dissipating just south of it. Inspection of RHI } \\
\text { profiles of radar reflectivity showed that as this cell moved } \\
\text { south across the wake, reflectivities at the leading edge of } \\
\text { the convective cell were seen to increase from between 40- } \\
45 \text { dBZ to 45-50 dBZ, see Figure 3.30. }\end{array}$ \\
\hline $1922 Z$ to 2000Z, \\
28 March 2007 \\
$\begin{array}{l}\text { Inspection of 0.5 PPI images of radar reflectivity showed } \\
\text { a convective cell with reflectivities between 40-45 dBZ ini- } \\
\text { tiated to the north of the Taranga Island wake. This was } \\
\text { observed to move southeast reaching the observed position } \\
\text { of the Taranga Island wake at 1945Z. Between 1945Z and } \\
2000 Z \text { this convective cell moved over the Taranga Island } \\
\text { wake dissipating slightly to the south of the wake. RHI pro- } \\
\text { files of radar reflectivity during this period showed no dis- } \\
\text { tinct enhancement of reflectivity due to the Taranga island } \\
\text { wake. }\end{array}$ \\
\hline
\end{tabular}


Table B.2: Table summarizing enhancement observed in the vicinity of the Little Barrier Island wake.

\begin{tabular}{|c|c|}
\hline $\begin{array}{l}\text { Observation } \\
\text { period }\end{array}$ & Comments \\
\hline $\begin{array}{l}1922 \mathrm{Z} \text { to } 1952 \mathrm{Z} \\
28 \text { March } 2007\end{array}$ & $\begin{array}{l}\text { A distinct line of enhanced reflectivity was observed along } \\
\text { the Little Barrier wake, at } 1922 \mathrm{Z} \text { in } 0.5^{\circ} \mathrm{PPI} \text { images of radar } \\
\text { reflectivity. A region of embedded convection was initiated } \\
\text { along the wake at } 1930 \mathrm{Z} \text {, with a preexisting region of convec- } \\
\text { tion approaching from the north. The convection appeared } \\
\text { to aline with the axis of the wake and dissipated by } 1952 \mathrm{Z} \text {. } \\
\text { RHI profiles of radar reflectivity showed at } 1930 \mathrm{Z} \text { the area } \\
\text { of convection initiated at the Little barrier Island wake was } \\
\text { very shallow with } Z>40 \mathrm{dBZ} \text { and appeared only in the low- } \\
\text { est beam. The region of preexisting convection was difficult } \\
\text { to capture as this feature was weak and not well developed } \\
\text { as it passed over the Little Barrier Island wake. }\end{array}$ \\
\hline $\begin{array}{l}2200 \mathrm{Z} \text { to } 2245 \mathrm{Z}, \\
28 \text { March } 2007\end{array}$ & $\begin{array}{l}\text { A zone of intense stratiform precipitation }(Z=35-40 \mathrm{dBZ}) \\
\text { was observed in } 0.5^{\circ} \mathrm{PPI} \text { images of radar reflectivity. This } \\
\text { zone moved south perpendicular to the wake. Two small } \\
\text { regions of embedded convection }(Z>40 \mathrm{dBZ}) \text { were observed } \\
\text { to initiate along the wake. RHI profiles of radar reflectivity } \\
\text { during this period showed the areas of convection initiated } \\
\text { along the Little Barrier Island wake were shallow and ap- } \\
\text { peared in the beams } 1 \text { and } 1-3(\sim 1.5 \mathrm{~km}) \text { respectively. }\end{array}$ \\
\hline $\begin{array}{l}2315 Z \text { to } 2337 Z \\
28 \text { March } 2007\end{array}$ & $\begin{array}{l}0.5^{\circ} \text { PPI images of radar reflectivity showed a convective } \\
\text { cell which initiated at } 2315 \mathrm{Z} \text { just north of the Little Barrier } \\
\text { Island wake. By } 2322 \mathrm{Z} \text { the cell moved southeast to lie over } \\
\text { the Little Barrier Island wake, and had developed, increasing } \\
\text { in its spatial extent. RHI profiles of radar reflectivity showed } \\
\text { that initially the cell was weak with a vertical extent of } \\
\sim 1 \mathrm{~km} \text { but increased to } \sim 2 \mathrm{~km} \text { near the location of the Little } \\
\text { Barrier Island wake as observed in RHI profiles of radar } \\
\text { radial velocity. }\end{array}$ \\
\hline
\end{tabular}


Table B.3: Table summarizing enhancement observed in the vicinity of the Great Barrier Island wake.

\begin{tabular}{|l|l|}
\hline $\begin{array}{l}\text { Observation } \\
\text { period }\end{array}$ & Comments \\
\hline $2007 \mathrm{Z}$ to 2200Z, & $\begin{array}{l}\text { During this period a mobile secondary line of enhancement } \\
\text { was observed to move southwest, aligned perpendicular to } \\
\text { the wakes downstream of Great Barrier Island. This zone } \\
\text { of enhancement was forced at upper levels. Evidence of the } \\
\text { zones of radar radar shear due to enhanced vertical motion } \\
\text { was only seen above the } 3^{\circ} \text { PPI image. As the secondary } \\
\text { line of enhancement moved southwest along the Great Bar- } \\
\text { rier Island wakes, smaller regions of increased reflectivity } \\
(>40 \text { dBZ) were initiated at the intersection between these } \\
\text { two zones of enhancement, see Figure 3.28. These regions of } \\
\text { embedded convection were short lived appearing in one or } \\
\text { two consecutive } 0.5^{\circ} \text { PPI images of radar reflectivity. }\end{array}$ \\
\hline
\end{tabular}

